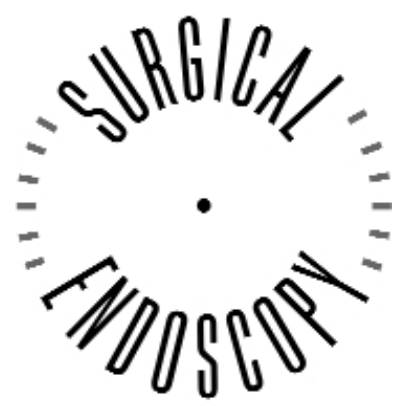

and Other Interventional Techniques

\title{
2006 Scientific Session of the Society of American Gastrointestinal and Endoscopic Surgeons (SAGES) Dallas, Texas, USA, 26-29 April 2006
}

\section{Oral presentations*}

\section{BARIATRIC SURGERY}

ROUTINE UPPER GI SERIES FOLLOWING GASTRIC BYPASS DOES NOT ACCURATELY IDENTIFY LEAKS OR PREDICT STRICTURES.

Jonathan T Carter MD, Sepideh Tafreshian MD, Umesh Tiwari MD, Fernando Herbella MD, John P Cello MD, Marco G Patti MD, Guilherme M Campos MD, Stanley J Rogers MD, Andrew M Posselt MD

Depts. of Surgery and Medicine, Univ. of California, San Francisco, USA.

INTRODUCTION: Most centers performing Roux-en-Y gastric bypass for morbid obesity obtain a routine upper GI series (UGI) in the early postoperative period to evaluate for anastomotic leaks and delayed pouch emptying. We hypothesized that routine UGI does not accurately identify leaks or predict strictures.

METHODS: From December, 1998 to April 2005, 569 gastric bypass procedures were performed at our center (60\% laparoscopically). Routine UGI was obtained in $546(96 \%)$ patients. We compared radiographic findings (leak or delayed emptying) with patient outcome (leak or stricture) to calculate the sensitivity and specificity of the study. Univariate modeling identified risk factors for anastomotic leak or stricture; the low number of events precluded multivariate modeling.

RESULTS: Of 546 routine UGI studies, anastomotic leaks were reported in $5(0.9 \%) ; 2$ of these were later interpreted as artifact. UGI failed to identify 3 leaks, yielding an overall sensitivity of 50\% and PPV of $60 \%$. In univariate analysis, only institutional experience was associated with anastomotic leak (odds-ratio (OR) 6.5 for the first 100 cases, $\mathrm{p}=0.02$ ). Delayed emptying of contrast was observed in 109 (19\%) studies, was more frequent in laparoscopic cases $(26.8 \%$ vs. open $9.0 \%, \mathrm{p}<0.01)$ and when a GIA stapler was used for the gastrojejunostomy $(31.7 \%$ vs. EEA $13.6 \%$, hand-sewn $18.9 \%$; $\mathrm{p}=0.01)$. Only $10(1.7 \%)$ patients developed strictures requiring dilatation. The PPV of delayed contrast emptying for eventual stricture formation was $6 \%$. Risk factors for stricture formation included stapled anastomosis (OR 9.4, p<0.01), long Roux length $(>100 \mathrm{~cm}$ OR 5.4, p=0.03), antecolic Roux (OR 10.2, p=0.03), and delayed contrast emptying (OR 6.3; $<<0.01$ ).

CONCLUSIONS: Due to the overall low incidence of complications and low sensitivity/specificity, routine UGI does not accurately identify leaks or predict strictures after Roux-en-Y gastric bypass. A selective approach, reserved for patients with clinical evidence of leak or stricture, is more appropriate and cost-effective
AN INITIAL EXPERIENCE USING THE LAPAROSCOPIC ADJUSTABLE GASTRIC BAND IN 54 US TEENAGERS

G A Fielding MD, C J Ren MD, E Nadler MD, H A Youn RN Department of Surgery, NYU School of Medicine

This is an analysis of an early US experience using the Laparoscopic Adjustable Gastric Band (LAGB) in US teenagers, assessing safety and efficacy.

Data has been prospectively recorded on all morbidly obese teenagers (13-19 years) treated at our institution by LAGB since 2001. This data has been analyzed for weight and BMI at presentation, age groups, operative morbidity, complications, follow-up and weight loss.

Fifty-four teenagers (12 males, 42 females), mean age 16.2 yrs (13-19), weight 299lbs (221-457), BMI $47.6 \mathrm{~kg} / \mathrm{m} 2$ (35-63), presented for bariatric surgery using LAGB since September 2001. The Age range was 13 yrs (5), 14yrs (3), 15 yrs (7), 16 yrs (10), 17yrs (16), 18 yrs (8), 19 yrs (5). Forty-five were Caucasian, 6 African American, and 3 Hispanic. There were no operative complications. All patients were discharged $<24 \mathrm{hrs}$.

Weight-loss is as listed below:

Time No. BMI \%EWL

6 mths 2540.835

1 Yr 133555

2 yr 43950

4 yr 13082

Two patients had slips repaired (19 $\mathrm{mths}, 7 \mathrm{mths})$, one developed a symptomatic hiatal hernia, and one had a port leak. All were repaired as day cases.

LAGB is a safe, effective treatment for morbidly obese teenagers. 
INSULIN-GLUCOSE METABOLISM IS NOT AFFECTED BY ROUX-LIMB LENGTH

Ih-Ping Huang MD, Nana Gletsu PhD, Scott A Lynch MD, Thomas R Ziegler MD, Leena Khaitan MD, C.Daniel Smith MD, Edward Lin DO, Department of Surgery, Division of GI and General Surgery, Emory University School of Medicine, Atlanta, Georgia

INTRODUCTION: We have previously demonstrated that improvements in insulin-glucose metabolism following roux-en-Y gastric bypass (RYGB) is associated with reduction in C-reactive protein (CRP) levels, an acute phase protein produced primarily by hepatocytes. This study prospectively seeks to determine if such improvements are associated with the length of the roux-limb, which has important implications in determining the optimal procedure for patients with insulin-resistant diabetes undergoing weight-loss surgery.

METHODS: Twenty-eight patients with morbid obesity were enrolled in this General Clinical Research Center study at baseline, 1 month post-op and 6-months post-op. Along with CRP measurements, parameters derived from frequently-sampled IV glucose tolerance test were insulinsecretion, insulin-resistance, and HOMA-index (hepatic insulin sensitivity). These patients either had a $150-\mathrm{cm}$ roux-limb $(\mathrm{n}=8)$ or a $100-\mathrm{cm}$ roux-limb $(n=20)$. Differences were compared with the student t-test and reported as mean \pm SEM.

RESULTS:

\begin{tabular}{|l|l|l|l|}
\hline & 0 month & 1 month & 6 months \\
\hline HOMA $(100 \mathrm{~cm})$ & $3.42 \pm 0.67$ & $1.60 \pm 0.25$ & $0.95 \pm 0.14 *$ \\
\hline HOMA $(150 \mathrm{~cm})$ & $3.11 \pm 0.45$ & $1.38 \pm 0.26$ & $0.82 \pm 0.18 *$ \\
\hline \multicolumn{4}{|r|}{$* \mathrm{p}<0.05$}
\end{tabular}

Although there were overall improvements, HOMA-index, insulin-secretion and insulin-resistance were virtually identical between patients with the $100-\mathrm{cm}$ and $150-\mathrm{cm}$ roux-limbs $(\mathrm{p}=\mathrm{NS})$ at every time point. Contrary to our hypothesis, patients with shorter roux-limbs manifested lower CRP levels than the longer roux-limb group at 6 months $(0.24 \pm 0.03$ vs $0.80 \pm 0.18, \mathrm{p}<0.04)$.

CONCLUSIONS: Insulin-glucose metabolism does not appear to be affected by the length of the roux-limb. Whether the roux-limb affects insulin-resistant diabetes at all remains to be determined. The lower CRP levels associated with shorter roux-limb lengths suggest that a gut-liver interaction exists following intestinal malabsorption procedures.

\section{ESOPHAGEAL DYSMOTILITY IN MORBIDLY OBESE PATIENTS}

John Koppman MD, Andrew Ukleja MD, Samuel Szomstein MD, Raul J Rosenthal MD

Bariatric Institute, Cleveland Clinic Florida

Objective: The majority of esophageal motility studies in the morbidly obese have focused on the relationship between lower esophageal sphincter (LES) pressure and its relation to gastroesophageal reflux disease (GERD) in this population. There are very few studies in the literature that have examined motility disorders in the morbidly obese population in general, outside of the context of GERD. The aim of this study was to determine the prevalence of esophageal motility disorders in obese patients selected for laparoscopic gastric banding. Methods: 112 obese patients (78 women and 34 men) selected for laparoscopic gastric banding underwent manometric evaluation of their esophagus during the period from January 2003 to March 2003. Tracings were retrospectively reviewed for end-points of LES resting pressure, LES relaxation, and esophageal peristalsis. Results: The mean body mass index (BMI) was $42.9 \mathrm{~kg} / \mathrm{m}^{2}$ and the mean age was 40 years. $41 \%$ of patients demonstrated abnormal manometric findings as follows: $22 \%$ had nonspecific esophageal motility disorders (NSMD), $11 \%$ had nutcracker esophagus (peristaltic amplitude $>180 \mathrm{~mm} \mathrm{Hg}$ ), $3 \%$ had isolated hypertensive LES pressure $(>35 \mathrm{~mm} \mathrm{Hg}), 3 \%$ had isolated hypotensive LES pressure $(<12$ $\mathrm{mm} \mathrm{Hg}), 1 \%$ had diffuse esophageal spasm (DES), and $1 \%$ had achalasia. No patients with abnormal esophageal motility related complaints of dysphagia or chest pain. There was no statistically significant relationship between BMI and abnormal esophageal motility. Conclusions: Although several studies have investigated esophageal motility in obese patients with GERD, the selection bias of such studies precludes an accurate conclusion about the prevalence of esophageal dysmotility in the obese population as a whole. This study demonstrates that esophageal motility disorders occur frequently in the obese population and calls for more investigation into the etiology and potential significance of such disorders in the context of obesity.
LAPAROSCOPIC VERTICAL SLEEVE GASTRECTOMY FOR MORBID OBESITY IN 216 PATIENTS: REPORT OF TWO-YEAR RESULTS

Crystine M Lee MD, John J Feng MD, Paul T Cirangle MD, Gregg H Jossart MD

Department of Surgery, California Pacific Medical Center, San Francisco, CA. INTRODUCTION: The vertical gastrectomy (VG) is the restrictive part of the technically difficult biliopancreatic diversion with duodenal switch operation (DS). The VG was originally conceived of as an independent operation - the first stage of a two-stage DS that would reduce mortality and morbidity in the high-risk superobese because of a shorter OR time and no anastomoses. This abstract presents the first two-year data after VG

METHODS: Laparoscopic VG was performed in a non-randomized fashion in obese patients that met the NIH criteria for bariatric surgery. By using 5-7 firings of $45-60 \mathrm{~mm}$ linear $3.5 \mathrm{~mm}$ GI staplers along a $32 \mathrm{Fr}$ bougie, a greater curvature gastrectomy is performed to create a $100-120 \mathrm{ml}$ gastric tube.

RESULTS: Between Nov 2002 and Aug 2005, 216 patients underwent VG. The mean age was 44.7 years (range 16-64) and $173(80 \%)$ were female. The mean preop weight and BMI was $302 \pm 77 \mathrm{lbs}$ and $49 \pm 11 \mathrm{~kg} / \mathrm{m}^{2}$, respectively. Of the 216 patients, $5(2.3 \%)$ had a BMI $>80 \mathrm{~kg} / \mathrm{m}^{2}, 6(2.8 \%)$ had a BMI of $70-80 \mathrm{~kg} / \mathrm{m}^{2}$, and $25(11.6 \%)$ had a BMI of $60-70 \mathrm{~kg} / \mathrm{m}^{2}$. The mean OR time was $66 \pm 11$ mins (range $45-180$ ), the mean EBL was $29 \pm 13 \mathrm{cc}$, and the mean length of stay was $1.9 \pm 1.2$ days. Complications occurred in 20 $(6.3 \%)$ of patients (vs. $7.1 \%$ after lap band). Leaks occurred in $3(1.4 \%)$ of patients, reoperations were performed in $26(7.8 \%)$, and no conversions to open or deaths occurred. Weight loss on par with the DS and RGB was achieved with just the VG alone (see table). A weight loss plateau $(<10 \mathrm{lbs}$ lost $/ 6 \mathrm{mos})$ was found in only $9(4.2 \%)$ of patients.

\begin{tabular}{|l|l|l|l|}
\hline & 0 Mos & 12 Mos & 24 Mos \\
\hline Weight (lbs) & 302 & 242 & 179 \\
\hline BMI (kg/m2) & 49.2 & 36.8 & 27.7 \\
\hline Wt Loss (lbs) & 0 & 60 & 123 \\
\hline EWL (\%) & 0 & 58.5 & 83.1 \\
\hline
\end{tabular}

CONCLUSIONS: The VG operation is able to achieve significant weight loss on with morbidity comparable to that of lap band placement . These two-year data suggest that very few patients require a second-stage operation for weight loss plateau. Further studies are needed to determine if these promising results are borne out with time.

PREVALENCE OF GASTROESOPHAGEAL REFLUX DISEASE (GERD) AND MANOMETRIC OESOPHAGEAL FINDINGS IN PATIENTS WITH MORBID OBESITY SELECTED FOR BARIATRIC SURGERY. A PROSPECTIVE STUDY IN 100 PATIENTS

Simon MSIKA MD, Eric Poupardin MD, Mohamed Merrouche MD, Florence Harnois MD, Jean Marc Sabaté MD, Benoit Coffin MD Department of Digestive Surgery, Department of Gastroenterology, University Hospital Paris VII Louis Mourier Colombes FRANCE Obesity is considered as a predisposing factor of GERD, but the characteristics of GERD and manometric oesophageal findings in patients with morbid obesity remains poorly studied. In patients selected for bariatric surgery, symptomatic GERD or/and abnormal manometric findings could influence the surgical technique (gastric banding or gastric by-pass).

Aims. To determine prospectively in patients with morbid obesity the prevalence of GERD, abnormal manometric findings and to study the relationship between BMI, GERD and manometric findings.

Every obese patients (BMI $>40 \mathrm{~kg} / \mathrm{m}^{2}$ or $>35$ in association with comorbidity) selected for bariatric surgery were prospectively included with an evaluation of GERD symptoms, upper GI endoscopy, 24 hours pH-metry and esophageal manometry.

Results: (mean +/- SD) 100 patients ( $83 \mathrm{~F}$, mean age : 38,4 +/- 10,9 yrs) have been included. BMI was $44,9+/-5,9 \mathrm{~kg} / \mathrm{m}^{2}$ (range 35.4-63.7). Heartburn, regurgitations and epigastric pain were present in 61,44 and 29 patients respectively. 23 had chronic pharyngitis and 20 were asthmatic. Endoscopy evidenced a hiatal hernia in 37 patients, a cardial failure in 14 and oesophagitis (grade 1 to 3 ) in 6. The $\mathrm{pH}$-metry (De Meester score) was pathologic in 46 patients (mean $\%$ of time with $\mathrm{pH}<4: 7.7+/-2.9$ ) ; longer reflux : $27.2+/-14.9$ min). 69 patients had a failure of lower esophageal sphincter (LOS) with a tone $<15 \mathrm{mmHg}$ and 7 had esophageal dyskinesia. There was no hyper pression of LOS. No significant relationship could be evidenced between BMI and De Meester score, LOS tone and esophageal dyskinesia. But BMI was significantly related to the number of reflux $>5 \min (\mathrm{P}=0.008)$ and LOS tone was significantly related to the number of reflux $(\mathrm{P}=0.027)$.

GERD and LOS failure are highly prevalent in patients with morbid obesity, but BMI is not the only explanatory factor. In mordidly obese patients with reflux, the main mechanism could be anormal esophageal clearance. Testing for GERD and oesophageal manometric could be helpful before bariatric surgery in order to select the type of surgery (gastric banding or gastric by-pass). However, because of frequent esophageal symptoms after gastric banding, a preoperative manometry should be useful as a reference before surgery. Analysis of postoperative long-term results are in progress. 


\section{TRENDS AND INSTITUTION-VOLUME BASED ANALYSIS OF GASTROINTESTINAL COMPLICATIONS FOLLOWING BARIATRIC SURGERY IN NEW YORK STATE}

Mark Loewen MD, Thomas Sullivan BS, Thomas Cerabona MD, Edward Yatco MD, John Savino MD, Ashutosh Kaul MD, New York Medical College/Westchester Medical Center

Objective: Aim of this presentation is to analyze recent trends and institutional volume in its effect on gastrointestinal complications of bariatric surgery performed in New York State.

Methods: We retrospectively analyzed data from 1991 to 2003 from the Statewide Planning and Research Cooperative Systems (SPARCS) database. DRG codes pertaining to bariatric surgery were scrutinized, as well as procedure codes relating to gastrointestinal complications.

Results: 24,535 patients underwent bariatric surgery during this period with volume jumping from 536 patients in 1991 to 7982 patients in 2003 . Average length of stay decreased from 7 days in 1991 to 3.4 days in 2003. Incidence of postoperative gastrointestinal complications decreased from $13.1 \%$ in 1991 to $7.3 \%$ in 2003 with a significant trend $(r=0.72, p$ $=0.006$ ). High volume versus low volume in its effect on postoperative complications was analyzed by choosing an arbitrary level of 50 cases per year. High volume institutions had an overall incidence of $8.1 \%$ for postoperative gastrointestinal complications versus $12.4 \%$ for low volume institutions; this was a significant difference ( $\mathrm{p}<0.001$, see table).

\begin{tabular}{|l|c|c|c|}
\hline Volum & Number of inst. & $\mathrm{N}$ & $\mathrm{N}$, complic (\%) \\
\hline High & 38 & 19998 & $1625(8.1 \%)$ \\
\hline Low & 41 & 4536 & $561(12.4 \%)^{*}$ \\
\hline \multicolumn{3}{|c|}{${ }^{*} \mathrm{p}<0.05$} \\
\hline
\end{tabular}

Conclusions: The postoperative complication rate for bariatric surgery in New York State decreased over this 12-year period while overall volume increased. This implies that increased experience and advanced techniques in minimally invasive surgery has had a positive influence on postoperative complication rates. High volume centers had better postoperative complication rates over low volume centers, implying that learning curves and number of cases done are very important to preventing complications.

\section{BARIATRIC SURGERY IN ADOLESCENTS}

Ricardo V Cohen MD, Jose S Pinheiro MD, Jose L Correa MD, Carlos A Schiavon MD

BAROS Surgical Associates and Hospital São Camilo, São Paulo, Brazil

Introduction: If teenage obesity is epidemic and adult bariatric surgery is safe and effective, why not offer gastric bypass to these younger patients who may benefit the most avoiding life-threatening comorbidities?

Methods and procedures: We reviewed the data of 42 adolescent patients who underwent laparoscopic Roux-en-Y gastric bypass in our Institution (2.7\% of our patients). All patients went through psychiatric evaluation, understood the procedure and its life-long life style modifications, and had full parental support.

Results: Most were men (35) with ages from 13 to 18 years. Mean BMI was 45 (41-50). Preoperative comorbidities were as follows: hypertension in 16 patients, depression under treatment in 6 , diabetes in 3 , high serum insulin in 3, cholelithiasis in 3, artropathy in 3, asthma in 2, and GERD in 1. Mean OR time was 55 minutes. There were no intraoperative or postoperative complications. Mean hospital stay was 30 hours. Mean follow-up is 48 months (3-60). 31 patients have a follow-up greater than 12 months. All patients are cured from all comorbidities and mean BMI is 23.5. No postoperative psychiatric problems were detected.

Conclusion: Adolescent patients benefit from laparoscopic gastric bypass with excellent weight loss and cure of comorbidities.

\section{SIZE MATTERS: GASTRIC POUCH SIZE CORRELATES WITH WEIGHT LOSS FOLLOWING LAPAROSCOPIC ROUX-Y GAS- TRIC BYPASS}

Kurt E Roberts MD, Joyce I Kaufman, Andrew J Duffy MD, James D Dziura PhD, Robert L Bell MD

Yale University School of Medicine, Dept of Surgery, Section of Gastrointestinal Surgery

Introduction: The identification of relevant components of successful weight reduction surgery is the most important endeavor in the latest research aiming to increase excess weight loss. Over the past twenty years there has been ongoing discussion about the importance of gastric pouch size as one of the key factors influencing weight loss after restrictive weight reduction surgery. The goal of our analysis is to determine the relationship between gastric pouch size and weight reduction following laparoscopic Roux-Y gastric bypass (LRYGB).

Methods: Between August 2002 and March 2005, 321 LRYGB were performed at the same institution. Patient demographics were entered into a longitudinal, prospective database. Upper gastrointestinal series was performed in all patients on postoperative day one. Assuming that pouch depth remained constant, pouch size was calculated as area $(\mathrm{cm} 2)$ utilizing digital imaging technology and internal standardization for measurement. Linear regression analysis was performed to determine the association between pouch size and weight loss at 6 and 12 months postoperatively. Adjustment was made for age, gender, and preoperative BMI.

Results: Mean age was 41 years (range, 17-64); 262 patients were female $(81.6 \%)$; mean preoperative BMI was $51.1 \mathrm{~kg} / \mathrm{m}^{2}$ (range, $36.1-89.9$ $\mathrm{kg} / \mathrm{m}^{2}$ ). Mean 6 month \%EWL was 50.5 (range, 13.4-85.5\%) and mean 12 month \%EWL was 62.5 (range, 14.6-98.1). Mean pouch size was 63.9 $\mathrm{cm} 2$ (range, $8.6-248.0 \mathrm{~cm}^{2}$ ). A statistically significant inverse correlation between pouch size and \%EWL was found (at 6 month $r=-0.40035$, $\mathrm{p}<0.001$ and at 12 month $\mathrm{r}=-0.43379, \mathrm{p}<0.001)$. No significant correlation was found between pouch size and age or preoperative BMI.

Conclusion: Our analysis demonstrates that gastric pouch size is one important component for successful weight reduction following LRYGB. The creation of a small gastric pouch should be encouraged as the initial step towards ideal weight loss.

\section{A COMPARISON BETWEEN 399 OPEN AND 568 LAPAROSCOP- IC GASTRIC BYPASSES PERFORMED DURING A 4 YEAR PERIOD}

Nikhilesh R Sekhar MD, Alfonso Torquati MD, Yassar K Youssef MD, William O Richards MD

Vanderbilt University Medical Center

Intro: Laparoscopic RYGB was introduced at our institution 4 years ago. We reviewed the short and long term results of the 2 procedures over the same time period.

Methods: Retrospective review of prospectively collected bariatric database.

Results: From 1/01 to 7/05, 568 laparoscopic gastric bypasses and 399 open gastric bypasses were performed. Hospital length of stay in the laparoscopic group was significantly shorter $(2.5 \pm 2.4$ days $)$ than in the open group $(3.7 \pm 3.7$ days $), p=0.001$. Procedure time was significantly shorter in the laparoscopic group (164 $\pm 50 \mathrm{~min}$.) versus the open group $(195 \pm 50 \mathrm{~min}$.), $\mathrm{p}=0.0001$. Follow up at 2 years was $76.6 \%$. Two years excess weight loss (EWL) was significantly greater in the laparoscopic group $(71.3 \pm 18.4 \%)$ versus the open group $(67.3 \pm 15.3 \%), p=0.03$. Wound infection rate was significantly higher in open group $(9.2 \%)$ versus laparoscopic group $(1.7 \%, \mathrm{p}=0.001$. There was no significant difference in 30 -day mortality, open $(0.50 \%)$ versus laparoscopic group $(0.17 \%), p=0.371$. There was no significant difference between 30 -day reoperation rate in the open $(2.4 \%)$ versus laparoscopic group $(2.6 \%)$, $\mathrm{p}=0.705$. Thirty day readmission rate was similar in the open $(5.0 \%)$ versus laparoscopic group $(5.2 \%), \mathrm{p}=.852$. The rate of leakage from the gastrojejunostomy was similar in the open $(0.50 \%)$ versus laparoscopic group $(0.35 \%), \mathrm{p}=0.127$. The conversion rate from laparoscopic procedure to laparotomy was $1.7 \%$.

Conclusion: In our institution, a laparoscopic bariatric surgery program has been introduced with a very low rate of morbidity and mortality. Wound complications, operative time and hospital stay are reduced with the laparoscopic approach. The procedures are equally safe with equivalent 30-day mortality, readmission, reoperation and gastrojejunostomy leakage rates. This large series demonstrates the advantages of the laparoscopic approach for the treatment of morbid obesity. 
RISK OF SECONDARY HYPERPARATHYROIDISM AFTER LAPAROSCOPIC GASTRIC BYPASS SURGERY IN OBESE WOMEN Yassar K Youssef MD, William Richards MD, Nikhilesh O Sekhar MD, Anna Spagnoli MD, Alfonso Torquati

Vanderbilt University, Department of Surgery

Background: Metabolic bone disease is a potential complication of bariatric surgery. It is often undiagnosed, because of lack of physician and patient awareness. Abnormalities in calcium and vitamin D metabolism begin shortly after bariatric surgery; however, clinical evidence of metabolic bone disease may not be detected until years later. The aim of the study is to evaluate, during the first two postoperative years, the effects of laparoscopic gastric bypass on calcium and vitamin D metabolism, and to identify patients at high risk to develop secondary hyperparathyroidism (HPT).

Methods: Serum calcium, alkaline phosphatase, intact PTH, and 25-hydroxy vitamin D were measured at 3, 6, 12 and 24 months after laparoscopic gastric bypass in a cohort of morbidly obese women. Logistic regression was used in both univariate and multivariate model to identify independent preoperative variables associated with secondary HPT.

Results: The study enrolled 193 morbidly obese women. Mean age was $43.7 \pm 9.2$ years. Mean preoperative BMI was 50.8 \pm 9.6 . During the 2 years follow up period, the incidence of secondary HPT (PTH $>65 \mathrm{pg} / \mathrm{ml}$ ) was 53.3\% (103/193). The mean time elapsed between surgery and detection of secondary hyperparathyroidism was 9.1 months (range 3-24 months). Vitamin D deficiency (< $20 \mathrm{ng} / \mathrm{ml}$ ) was observed in 20.2\% (39/193) patients. African Americans (AA) were at higher risk of Vitamin $\mathrm{D}$ deficiency than their Caucasian counterparts $(23.6 \pm 17.6$ vs $35.6 \pm 12.6 \mathrm{ng} / \mathrm{ml}, \mathrm{P}<0.001)$. On univariate analysis, the preoperative factors associated with secondary HPT were race (High PTH: $20.4 \%$ AA vs normal PTH: $11.1 \%$ AA; $\mathrm{P}<0.05$ ), preoperative BMI (High PTH: $52.5 \pm 10.8$ vs normal PTH: $48.9 \pm 7.5$; $\mathrm{P}<0.01$ ) and age (High PTH: $44.9 \pm 9.2$ vs normal PTH: $42.3 \pm 9$ yrs., $\mathrm{P}<0.05$ ). Race and age remained independent risk factors for secondary HPT in the multivariate logistic regression model after adjusting for the covariate roux-limb length. AA were at more than 2.5 times greater risk to develop secondary HPT than Caucasian (OR 2.5; 95\% CI: 1.03-6.17, P<0.05). Patients older than 45 years were at 1.8 times higher risk to develop secondary HPT than their younger counterparts (OR 1.8; 95\% CI: 1.01-3.32, $\mathrm{P}<0.05)$. Conclusions: Women undergoing gastric bypass surgery have high incidence of postoperative secondary HPT. Earlier vitamin D replacement and aggressive calcium citrate supplementation should be at least implemented for African Americans and patients older than 45 years.
FOREIGN MATERIAL EROSION AFTER LAPAROSCOPIC ROUXEN-Y GASTRIC BYPASS: FINDINGS AND TREATMENT

Sherman C Yu MD, Kenny Jastrow MD, Connie Klein, NP, Benjamin Clapp MD, Terry Scarborough MD, Erik Wilson MD

University of Texas Health Science Center Houston

Patients after laparoscopic Roux-en-Y gastric bypass (LRYGB) can have nonspecific, upper gastrointestinal (UGI) complaints. Their work-up often involves an upper endoscopy to evaluate for causes of their symptoms. During endoscopy of these patients, we have noted the erosion of non-dissolvable material, such as Peri-Strips ${ }^{\circledR}$ or silk sutures, into the gastric pouch. This study reports the incidence and presentation of foreign material erosion into the gastric pouch after a LRYGB and the outcome after therapeutic endoscopy. From a prospective LRYGB database, postoperative endoscopies from February 2002 to June 2005 that found foreign material in the gastric pouch were reviewed. All endoscopies were performed by the bariatric surgery team. Presenting symptoms, time until endoscopy, and patient outcomes were evaluated. A therapeutic endoscopy was performed by using endo-shears and biopsy forceps to remove the foreign material. A total of 23 patients (mean BMI 50) underwent 29 therapeutic endoscopies, for a mean of 1.3 endoscopies (range 13) per patient. From February 2002 to November 2004, 208 LRYGB were performed using silk suture for the outer layer of the gastrojejunostomy, and 21 patients $(10 \%)$ had silk suture found on endoscopy. Peri-Strips $®$ were used from February 2002 to December $2003(n=153)$ and endoscopy found 6 patients $(4 \%)$ with erosions. Since converting to vicryl suture and Seamguard $®$, we have had 173 and 228 patients, respectively, without pouch erosion. The most common presenting symptom was abdominal pain $(\mathrm{n}=15$, $65 \%)$. Other symptoms included nausea $(\mathrm{n}=13,57 \%)$, vomiting $(\mathrm{n}=12,52 \%)$, dysphagia $(n=5,22 \%)$ and melena $(n=3,13 \%)$. The initial endoscopy occurred at a mean of 29.6 weeks after surgery, with foreign material found by a mean of 34 weeks. A therapeutic endoscopy occurred at a mean of 37.4 weeks. Food attached to the foreign material was partially obstructing the anastamosis in 5 patients (22\%). Out of 29 therapeutic endoscopies, 20 had symptoms resolved (69\%), 4 had improvements (14\%) and 5 remained unchanged (17\%). There were no endoscopic complications and no anastomotic leaks. Non-absorbable material used during a LRYGB can migrate into the gastric pouch and cause UGI complaints. A therapeutic endoscopy will resolve most UGI symptoms and should be repeated if symptoms represent. Using absorbable material in the creation of the gastric pouch and the gastrojejunostomy will avoid foreign material erosion.

\section{BASIC SCIENCE (CELLULAR BIO, PHYSIOLOGY)}

\section{MAJOR SURGERY INDUCES PROTEOLYSIS OF IGFBP-3 IN TRANSGENIC MICE, AND IS ASSOCIATED WITH A RAPID INCREASE IN SERUM LEVELS OF MATRIX METALOPRO- TEINASE-9 (MMP-9) \\ Avraham Belizon MD, Irena Kirman MD, Emre Balik MD, Moshe Karten,} Suvinit Jain BA, Patrick K Horst BA, Richard L Whelan MD

Columbia University Medical Center, New York NY USA

We have previously demonstrated a significant decrease in the plasma level of intact Insulin-like Growth Factor Binding Protein 3(IGFBP-3) following major open surgery in humans and have postulated that this decrease may have an important effect on postoperative tumor growth. In contrast, the vast majority of patients that undergo laparoscopic surgery do not demonstrate an intact IGFBP-3 decrease after surgery. Our goal was to create an animal model which would allow further study of the effect of surgical trauma on IGFBP-3. In addition, we set out to determine whether MMP-9, a known protease of IGFBP-3, is responsible for the degradation of IGFBP-3 observed after open surgery.

Methods:30 mice were divided into three groups. Sham Laparotomy (SL), $\mathrm{CO} 2$ Pneumoperitoneum(PP), and Anesthesia Control(AC). All mice were hIGFBP- 3 transgenics on a CD-1 background. 48 hours prior and 24 hours following the procedure blood was drawn retroorbitally. Intact IGFBP-3 levels were measured using a combination of western blot analysis and ELISA at each time point. Serum and intracellular levels (mononuclear cell lysates) of MMP-9 were measured at each time point using zymography.

Results:Plasma levels of intact IGFBP-3 were significantly lower post SL when compared to preop levels. A mean decrease of $76.6 \%$ was found after laparotomy $(\mathrm{P}<0.05)$. Zymography analysis demonstrated significantly higher MMP-9-related proteolytic activity post SL when compared to pre-operative levels $(78.5 \mathrm{RU}$ vs. $42.3 \mathrm{RU} \mathrm{P}<0.05)$. In the $\mathrm{PP}$ and $\mathrm{AC}$ groups no significant change was found between the preoperative and postoperative levels of intact plasma IGFBP-3 or MMP-9. Mononuclear intracellular levels of MMP-9 were significantly lower post SL when compared to preop(3RU vs. 37RU). Post procedure intracellular levels of MMP-9 were not significantly decreased in the PP or AC groups.

Conclusion: Plasma levels of intact IGFBP-3 were found to be significantly decreased following SL. This decrease was not seen following PP. Depletion of intact IGFBP-3 following SL correlated with a rapid release of MMP-9 from mononuclear cells and an increase in circulating serum MMP-9 levels. This suggests that MMP-9 may play an important role in IGFBP-3 proteolysis post surgical trauma and that circulating mononuclear cells are an important source. This provides a reliable animal model in which to further study the mechanism of IGFBP3 proteolysis following surgical trauma and its effect on postoperative tumor growth

\section{EXPRESSION OF PPAR-GAMMA AND ENPP1 IN GASTROIN- TESTINAL TISSUE FROM MORBIDLY OBESE PATIENTS}

Scott Celenski MD, Ryan Kar BS, Brian Kluk BS, Sidney Fu PhD, Fred Brody, MBA, MD

The George Washington University Medical Center

Department of Surgery and Department of Biochemistry and Molecular Biology

INTRODUCTION: Peroxisome proliferator-activated receptor-gamma (PPAR-gamma) and ectonucleotide pyrophosphate phosphodiesterase (ENPP1) are two genes linked to obesity and insulin resistance. We sought to characterize the expression of these two genes in gastrointestinal tissue from morbidly obese patients, with and without diabetes, undergoing bariatric surgery.

METHODS AND PROCEDURES: Gastric, small bowel, and omental samples from 15 morbidly patients (6 diabetic) were snap frozen in liquid nitrogen. Total RNA was extracted from the tissue and subsequently reverse transcribed into cDNA for each sample. Specific primers for PPAR-gamma and ENPP1 were designed for real-time quantitative PCR (QPCR) analysis. QPCR was then performed on the cDNA samples to quantitate the expression of PPAR-gamma and ENPP1. The 18S ribosomal gene was used as an internal control to normalize the expression levels for each gene.

RESULTS: Expression of PPAR-gamma and ENPP1 were present in all tissues. There was no significant difference in the level of expression between the different tissue types. The relative level of expression of PPAR-gamma was inversely proportional to BMI using linear regression analysis with a $\mathrm{p}=0.03$ and $\mathrm{r} 2=0.56$. Analysis of ENPP1 expression levels did not reveal a correlation with BMI. There was no difference in gene expression between obese patients with and without diabetes.

CONCLUSION: Expression of PPAR-gamma is inversely proportional to BMI in morbidly obese patients, while ENPP1 expression does not correlate with BMI. These results suggest that increasing BMI is associated with decreased expression of PPAR-gamma. This decreased expression may be related to dysfunctional adipocyte differentiation, maturation, and function. The lack of correlation with ENPP1 suggests that glucose metabolism may be more complex than lipid metabolism. A larger sample size may be needed to reveal a difference in these two cohorts and further characterize the pathways associated with obesity and diabetes. 
REDUCING THE OXIDATIVE STRESS FOLLOWING PNEUMOPERITONEUM (PP), BY USING INTERMITTENT SEQUENTIAL PNEUMATIC COMPRESSION (ISPC) LEG SLEEVES

A Bickel MD, A Drobot MD, M Aviram PhD, A Eitan MD

Department of Surgery and Lipid Research Laboratory, Western Galilee Hospital, Nahariya, The Faculty of Medicine, the Technion, Israel institute of Technology, Haifa, Israel

Background: Increased intra-peritoneal pressure during laparoscopic operations may lead to decreased cardiac output (CO) and visceral perfusion, and possible ischemia-reperfusion effects. Using ISPC device was shown to improve $\mathrm{CO}$ and visceral perfusion during PP.

Aim: To validate ischemia-reperfusion mechanism during laparoscopic cholecystectomy, and to assess the reduction of oxidative stress by ISPC device. Patients and methods: Twenty patients undergoing elective laparoscopic cholecystectomy were enrolled in a randomized prospective controlled study and divided into two groups: 1. Study group (10 patients), activation of ISPC together with creation of PP. 2. Control group, without ISPC. Lipid peroxidation and glutathion levels (as indicators of oxidative stress) as well as liver and renal function tests, were measured before and at the end of PP, and at 30 minutes, 4 and 24 hours afterwards, together with hemodynamic and respiratory parameters.

Results: There was no significant difference between both groups concerning liver enzymes and billirubin, as well as hemodynamic parameters. In the control group, increased lipid peroxides levels were noted 4 hourd after $\mathrm{PP}$ termination, in comparison to pre-PP levels $(560.4$ to $649.2 \mathrm{mmol} / \mathrm{liter}$, $\mathrm{p}=0.002$ ). In the study group (ISPC) such changes were not inspected. Reciprocal decreased glutathion levels were noted in the control group.

Conclusions: Our study validates the ischemia-reperfusion mechanism following laparoscopic surgery. The use of ISPC device decreases the oxidative stress (secondary to relative ischemia-reperfusion insult) following PP, due to improved $\mathrm{CO}$ and visceral perfusion.

PROSPECTIVE HISTOLOGICAL EVALUATION OF INTRAABDOMINAL PROSTHETICS FOUR MONTHS AFTER IMPLANTATION IN A RABBIT MODEL

Andrew G Harrell MD, Yuri W Novitsky MD, Joey A Cristiano BS, Abby Connoy-Beltz PhD, H. James Norton PhD, Kent W Kercher MD, B. Todd Heniford MD

Carolinas Medical Center

Background: Intraperitoneal prosthetics are required for laparoscopic ventral hernia repair. The biocompatibility of these materials may affect the inflammatory response, scar plate formation, or tissue ingrowth. We evaluated the host response to intraperitoneal placement of several prosthetics used in clinical practice.

Materials and methods: A 4 x $4 \mathrm{~cm}$ piece of mesh was implanted on intact peritoneum in New Zealand white rabbits. The mesh types included: ePTFE (DualMesh $\left.{ }^{\circledR}\right)$, ePTFE and polypropylene (Composix ${ }^{\circledR}$, heavy weight polypropylene), polypropylene and oxidized regenerated cellulose (Proceed ${ }^{\circledR}$, mid-weight polypropylene), and polypropylene (Marlex ${ }^{\circledR}$, heavy weight polypropylene). At 4 months, standard H\&E and Masson's trichrome stains of the mesh-tissue interaction were analyzed by three observers blinded to the mesh types. Each specimen was evaluated for scar plate formation, inflammatory response, and tissue ingrowth. Each category was graded on a standard scale of 1 to $4(1=$ severe inflammatory response and $4=$ normal tissue). The scores were analyzed with Wilcoxon Rank Sum test with $\mathrm{p}<0.05$ significant.

Results: Ten samples of each mesh type were evaluated. There was no difference in tissue incorporation between the groups. The mean scar plate formation was greater in the heavy weight polypropylene meshes than for DualMesh, $p=0.04$. Proceed had less scarring compared to Composix or Marlex that approached significance. The mean number of macrophages was greatest around the ePTFE when compared to mid-weight polypropylene, $\mathrm{p}=0.02$. The heavy weight polypropylene meshes were intermediate.

Conclusions: These prosthetic materials demonstrate comparable host biocompatibility as evidenced by the tissue ingrowth. Statistically less scarring formed around DualMesh than the heavy weight polypropylene meshes. Interestingly, a larger number of macrophages were also seen around the DualMesh. Proceed, a reduced polypropylene content mesh, may have benefits over the heavy weight polypropylene Composix or Marlex. These favorable histologic properties have the potential for improved patient tolerance.
VALIDATION OF ESOPHAGEAL DOPPLER FOR NON-INVASIVE HEMODYNAMIC MONITORING DURING PNEUMOPERITONEUM

Allan Okrainec MD, Simon Bergman MD, Liane S Feldman MD, Sebastian Demyttenaere MD, Franco Carli MD, Gerald M Fried MD, Steinberg-Bernstein Centre for Minimally Invasive Surgery, McGill University, Montreal

Introduction: Commonly used perioperative measurements of hemodynamics, like Swan-Ganz catheters, are invasive and may not be reliable under pneumoperitoneum. The purpose of this study was to validate the use of esophageal doppler (ED) for noninvasive hemodynamic monitoring under pneumoperitoneum in an experimental pig model.

Methods: Eleven female pigs were submitted to two 30 min study periods: 1) Baseline: no interventions, 2) Pneumoperitoneum: $12 \mathrm{mmHg} \mathrm{CO}_{2}$ pneumoperitoneum. One pig was excluded due to tachycardia $>140$ at baseline. A Swan-Ganz pulmonary artery catheter was used to measure cardiac output (CO-SG), CVP (CVP-SG), and pulmonary capillary wedge pressure (PCWP). An ED was inserted and stroke volume (SV-ED), cardiac output (CO-ED), and corrected flow time (FTc), an index of preload, were recorded. Transthoracic echocardiography was used to measure left ventricular end-diastolic diameter (LVEDD) and cardiac output (COTTE). Pearson correlation was used to assess individual associations between measured hemodynamic parameters.

Results: There was good correlation between CO-ED and CO-SG $(\mathrm{R}=.529, \mathrm{p}=.000)$. There was excellent correlation between CO-ED and CO-TTE $(\mathrm{R}=.815, \mathrm{p}=.000)$. SV-ED correlated well with SV-SG $(\mathrm{R}=.508$, $\mathrm{p}=.002)$ and SV-TTE $(\mathrm{R}=.732, \mathrm{p}=.000)$. These relationships were consistent when analyzed separately at baseline and under pneumoperitoneum (data not shown). There was no correlation between FTc and LVEDD or PCWP.

Conclusion: Esophageal doppler monitoring is a valid non-invasive method to measure cardiac output and stroke volume at baseline and during pneumoperitoneum in a porcine model. Corrected flow time did not correlate with other estimates of preload at baseline or during pneumoperitoneum.

EFFECT OF LAPAROSCOPIC NISSEN FUNDOPLICATION ON RUNX3 GENE EXPRESSION IN BARRETT'S METAPLASIA

Alfonso Torquati MD, Anna Spagnoli MD, William O Richards MD Vanderbilt University, Departments of Surgery and Pediatrics

RUNX3, a tumor-suppressor gene, is highly expressed in normal esophagus. We have previously demonstrated that SEG-1, a Barrett's adenocarcinoma cell line, lacks RUNX3. These findings suggest that RUNX3 plays a pivotal role in the progression from Barrett's esophagus to esophageal adenocarcinoma. The study tested the hypothesis that the inactivation of RUNX3 gene expression can be halted by antireflux surgery. Material and methods: Specimens of Barrett's metaplasia were obtained from 8 patients 2 years or more status post laparoscopic Nissen fundoplication and 10 patients (Control Group) on treatment with proton pump inhibitors (PPI). Quantitative reverse transcription-polymerase chain reaction (RT-PCR) was employed to measure RUNX3 mRNA expression in the Barrett's specimens. To minimize the errors arising from the variation in the amount of starting RNA among samples, amplification of beta-actin mRNA was performed as an internal reference against which RUNX3 mRNA was normalized. Results: RUNX3 mRNA was detected in all eighteen specimens of Barrett's metaplasia. However, significant quantitative differences were observed among the two groups as shown in Figure 1. Patients who underwent laparoscopic Nissen fundoplication had greater RUNX3 mRNA expression than patients treated with PPI. $(4.1 \pm 2.2$ vs. $2.2 \pm 1.2 ; \mathrm{P}=0.04)$. Conclusions: Barrett's metaplasia specimens from patients status post antireflux surgery have higher level of RUNX3 gene than specimens from patient on PPI treatment. This finding suggests that antireflux surgery has the potential to halt RUNX3 inactivation and ultimately to alter the malignant progression of Barrett's esophagus.

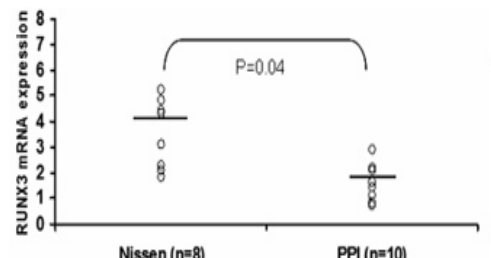

gure 1. Ouantitative RT.PCR analysis of RUNX3 mRNA expression level in specimens of RUNX3 mRNA expression level in specimens of Barrett's Esophagus. Each point represents the level of RUNX3 mRNA expression of an individual case. The horizontal bar represents the mean RUNX3 mRNA expression level. 
LAPAROSCOPIC LYMPHATIC MAPPING AND SENTINEL LYMPHNODE DETECTION IN COLON CANCER. TECHNICAL ASPECTS AND PRELIMINARY RESULTS

Paolo P Bianchi MD, Chiara Ceriani MD, Valerio Panizzo MD, Matteo Rottoli MD, Marco Montorsi MD

Cattedra e Unità Operativa Chirurgia Generale. Universita di Milano. Istituto Clinico Humanitas IRCCS. Milano

Introduction: The application of sentinel lymphnode (SL) technique to colon cancer is a method to improve staging still under evaluation. Aim of this study is to evaluate the feasibilty and accuracy of lymphnode mapping in laparoscopic resections of the colon. Matherial and Methods. Twenty patients were enrolled from March 2004 to July 2005 in the study. The first five cases were excluded because the learning curve. Polyps endoscopically removed were tattooed or clipped before surgery to permit laparoscopical localization of the tumor site. Before surgical dissection $2 \mathrm{ml}$ of Patent Blu $\mathrm{V}$ dye were injected subserosally in four sites around the tumor with a 22 gauge spinal needle percutaneously. The needle was extracted with mild aspiration and the site of injection was carefully protected to avoid dye diffusion. The lymphnodes coloured in 2 to 5 minutes were tagged as sentinel with metallic clips and the operation was completed with standardized resection. All sentinel lymphnodes were examined by hematoxylin and eosin (H\&E) staining with multiple sectioning of 3-5 micron slices and 200 microns interval. Immunonhistochemical (IHC) evaluation with CK-antibodies was applied only to doubtful cases. Results. Of the fifteen patients studied ten neoplasms were located in the left and five in the right colon. Lymphatic mapping caused no complications and added 10 to 15 minutes to the overall operative time. Detection rate of SL was $100 \%$, in an obese patient was performed an 'ex vivo' technique, with subserosal injection of dye on the specimen after removal. The total number of lymphnode examined was 322 (range: 8-36, average 21). SL were 34 (average 2.3). Of the 15 patients four $(26.6 \%)$ had lymphnode metastasis. In 3 of these 4 patients both SL and non-SL detected metastasis, the one false negative case $(25 \%)$ was registered in a large cecal tumor staged as IIIc (T3N2). In one patient SL was the only positive lymphnode. One doubtful case, evaluated with IHC, revealed isolated tumor cells (ITC) and was classified pT3NO(i+). Accuracy, Sensitivity and Negative Predictive Value (NPV) were respectively $93.3 \%, 75 \%$ and $91.6 \%$ Conclusions. Laparoscopic lymphatic mapping in colon surgery with blue dye is a feasible and relative simple technique. The detection rate of SL reaches $100 \%$, performing a salvage ?ex vivo? technique. The high false negative rate $(25 \%)$, in this preliminary cases, may be reduced with selection of patients and exclusion of III stages.

LAPAROSCOPIC (MEDIAL TO LATERAL) COLON RESECTION: A VIEW BEYOND THE LEARNING CURVE

Eric D Edwards MD, Wilbur B Bowne MD, Jiyoun E Kim MD, Palak Shah MD, Kell Juliard MS, Armando E Castro MD, Pratap K Gadangi MD, George S Ferzli MD

Lutheran Medical Center/SUNY Health Science Center, Brooklyn, N.Y.

INTRODUCTION: Since our report on the lateral approach to laparoscopic colon resection (LCR) (JACS. 2001; 193:105-108), medial to lateral (M-L) segmental resection continues to evolve. We analyze our learning curve experience with a standardized M-L technique to demonstrate influence of operative volume on proficiency and outcome.

METHODS: 100 consecutive patients underwent a standardized 3 -trocar M-L segmental LCR from January 1999 to December 2004. Yearly patient demographics, indications for surgery, operative proficiency (time), and outcome (ie. blood loss, conversion to open, resumption of bowel function and diet, length of hospital stay, morbidity and mortality) were recorded. Learning curve analysis was performed using a t-test and ANOVA method.

RESULTS: M-L/ LCRs included sigmoid (55\%), right (34\%), left (6\%), and transverse $(5 \%)$ approaches. Yearly recorded patient age, gender, indications for surgery, and perioperative parameters were similar. Overall learning curve proficiency was influenced by increasing operative experience $(\mathrm{p}=0.02)$. However, significant and consistent improvement in the learning curve occurred only after $>38($ SEM $+/-3)$ LCRs $(p<0.006)$.

Notably, all open conversions (3\%) occurred during the early ( $<38$ cases) learning curve. Similarly, early LCR patients experienced a greater morbidity (mean: $21 \%$ vs. $11 \%$ ) and mortality (5\% vs. $1 \%$ ) compared to their later ( $>38$ cases) learning curve counterparts.

CONCLUSIONS: M-L/ LCR requires a minimum of 35 - 40 procedures to obtain optimum proficiency. Operative and patient outcomes improve beyond the early learning curve.
OPERATIVE TIME IS A POOR SURROGATE FOR THE LEARNING CURVE IN LAPAROSCOPIC COLORECTAL SURGERY

Wenliang Chen MD, Elizabeth Sailhammer MD, David Berger MD, David Rattner MD

Massachusetts General Hospital, Boston, MA

Background: Previous studies have relied on operative time and conversion rate to construct learning curves in laparoscopic colorectal surgery. We hypothesized that operative time and conversion rate were less important than complication rate and re-admission rate in defining good outcomes and hence the learning curve.

Methods: A database of 287 consecutive laparoscopic colorectal resections from a single tertiary referral center was analyzed. Outcome measures included operative time, conversion rate, major and minor complications, length of stay, as well as 15 and 30-day hospital readmission rate. Data were analyzed both by surgeon and by quartile case numbers.

Results: There were 151 right colectomies and 136 left colectomies. For both right and left colectomies, the conversion rate decreased in each of the first three quartiles reaching a nadir of $0 \%$ for right colectomies and $3 \%$ for left colectomies in the third quartiles. The conversion rates increased slightly in the 4th quartile. Operative time remained stable for three quartiles and increased slightly in the 4th quartile. Two surgeons performed 199/287 cases. Analysis of the two high volume surgeons demonstrated that the surgeon with the shorter operative times had the higher major complication rate ( $8 \%$ vs $2 \%$ ), overall complication rate $(18 \%$ vs $6 \%)$ and 30 day readmission rate $10 \%$ vs $3 \%)$ and length of stay (4.0 vs 3.3 days) (all comparisons $\mathrm{p}<0.05$ ).

Conclusions: In this series, operative time failed to decrease with experience and shorter operative times did not correlate with better clinical outcomes. The failure of operative time to decline with experience often reflects surgeons' willingness to attempt more difficult cases rather than accurately representing a "learning curve". Therefore complication and readmission rates are more important than operative time and conversion rates in evaluating the learning curve and quality of laparoscopic colorectal surgery.

\section{LAPAROSCOPIC TOTAL MESORECTAL EXCISION FOR MID- DLE AND LOW RECTAL ADENOCARCINOMA WITH OR WITH- OUT SPHINCTER PRESERVATION: A PROSPECTIVE STUDY}

Elie Chouillard MD, Abe Fingerhut MD, Roberto Bergamaschi MPH

Centre Hospitalier Intercommunal Poissy France, Department of Surgery, Lehigh Hospital, Allentown, PA, USA

Goal: To assess the feasibility, safety, and effectiveness (perioperative and oncological outcomes) of laparoscopic total mesorectal excision (LTME) for rectum adenocarcinoma, with or without anal sphincter preservation Material and methods: Between November 1998 and July 2004, 84 unselected patients had laparoscopic TME for rectal adenocarcinoma and were followed up prospectively. Survival probability analysis was performed using the Kaplan-Meier method.

Results : 41 women and 43 men (mean age 58 (range, 21-86)) underwent LTME. Four patients $(5 \%)$ required conversion. Mean operative time was $210 \mathrm{~min}$ (range, 120-500). No patient required blood transfusion. Intra-operative complications included ( 3 patients $(4 \%)$ ) 2 left ureteral injuries and 1 deferent duct section. There was no postoperative mortality. Postoperative complications included 5 deep abscess $(6 \%)$ associated with anastomotic leakage in $3(4 \%)$ and wound infection in $4(5 \%)$, pneumonia $(n=3)$, urinary infection $(n=3)$, sexual dysfunction $(n=1)$, and hematoma $(n=1)$.

66 sphincter-preserving procedures and 18 abdominoperineal resections were performed. Among the former, 22 were performed for very low tumors, located within $4 \mathrm{~cm}$ of the dentate line. The average length of distal margins was $5.5 \mathrm{~cm}$ (range, 0-11). The mean number of harvested lymph nodes removed was 15 (range, 0-45) and mean length of the resected specimen was $28 \mathrm{~cm}$ (range, 20-101). The distal margin (dentate line) was positive in one patient $(1 \%)$, who had reoperative abdominoperineal resection. Average followup was 49 months (12-81). The most common late complications included incisional hernia $(\mathrm{n}=3(4 \%))$ and intestinal obstruction $(\mathrm{n}=4(5 \%)$. No port-site metastases occurred. Recurrence developed in 22 patients $(26 \%)$ : distant or peritoneal metastases (22 patients) with locoregional recurrence (3 patients). Overall local recurrence was $4 \%$.

Three year survival was $76 \%$.

Conclusions: Laparoscopic total mesorectal excision for rectal cancer is feasible and safe. Oncological appropriateness can be respected. However, large scale randomized studies are still needed in order to evaluate its efficacy and efficiency more accurately. 


\section{LAPAROSCOPIC LAVAGE AND DRAINAGE OF COMPLICATED} DIVERTICULITIS LONG TERM RESULTS

Jorge M Trevino MD, Morris E Franklin MD, John J Gonzalez MD, Eduardo Jaramillo MD

Texas Endosurgery Institue

BACKGROUND: The accepted standard of treatment for non-elective management of perforated diverticulitis has been an open laparotomy with staged resection of the colon advocated to avoid resection and primary anastomosis in the setting of a contaminated field. For a select group of patients that warrant operation for diffuse peritoneal signs but those who are not found to have gross fecal contamination, it has been proposed that they undergo peritoneal lavage, inspection of their colon, and intraoperative drain placement of the peritoneal cavity. When the patient recovers from their acute disease they may then undergo definitive colonic resection with primary anastomosis, thus avoiding a colostomy. We report our experience using this laparoscopic peritoneal lavage technique with delayed definitive resection.

METHODS: Patient records were retrospectively reviewed who underwent intraoperative peritoneal lavage and drainage placement for complicated diverticulitis at the Texas Endosurgery Institute from August 1993 to August 2005. The technique include insufflation of the abdominal cavity, thoroughly examination and adhesiolysis when needed, localization of the inflamed or perforated place, drainage of the purulent material and irrigation of the cavity with copious amounts of sterile normal saline and after this a combination of betadine, heparin and saline solution, suction of all the remain solution and placement of two $10 \mathrm{~mm}$ flat Jackson Pratts drains in the pelvis.

RESULTS: We enroll a total of 29 patients, 9 female and 20 male, the mean age was 60 years $(28-99 y)$, None of our patients was converted to open surgery, EBL $30.3 \mathrm{cc}(10-55 \mathrm{cc})$, Mean operative time $62 \mathrm{~min}(40-150 \mathrm{~min})$, Mean beginning of PO was 2 days (1-3 d). Eight complications were reported: 6 patients with paralytic ileus and 2 atelectasis. No mortality was reported. The mean follow up was 96 months (1-168 months). To date 16 patients were operated for definitive sigmoidectomy with no complications during the laparoscopic resection.

CONCLUSIONS: Intraoperative peritoneal lavage for purulent diverticulitis, has proven to be a safe alternative to the current standard of treatment for the management of perforated diverticulitis. We found that a single stage laparoscopic approach decreases length of hospital stay, immediately improves patient symptomatology, and avoiding colostomy placement decreases the cost for overall treatment of the disease and maintains the quality of life of the patients

\section{A PROVINCE-WIDE POPULATION SURVEY OF APPENDICITIS} IN CANADA. NEW TWISTS TO AN OLD DISEASE

Jean-Pierre Gagné MD, Marc Billard MD, Robert Gagnon MSc, Marcel Laurion MD, André Jacques MD

Le Collège des Médecins du Québec, Montréal, Québec, Canada

Objectives: This study, sponsored and conducted by Le Collège des Médecins du Québec, audited the management of acute appendicitis in the Province of Québec (7,25 million population), Canada, during one year (April 2002-March 2003).

Methods: A questionnaire was sent to the Health Records Department of all hospitals treating appendicitis in the province. Data from $85(100 \%)$ hospitals was received and reviewed.

Results: During the study period, 7599 appendectomies were performed and $5707(75 \%)$ were selected for study $(55 \%$ men). The rate of normal and perforated appendix was $6.0 \%$ and $17.1 \%$ respectively. Median hospital stay for simple and perforated appendicitis was 2.5 and 5.7 days respectively. At least one imaging procedure was done in $86 \%$ of cases (23\% CT scans, $55 \%$ ultrasounds).

Antibiotics were not given at all in $7 \%$ of cases and inadequately given in $8 \%$ of patients with a perforation. Sixteen percent of patients did not receive preoperative or intraoperative doses and $69 \%$ of patients received unnecessary doses.

Laparoscopy was used in $35 \%$ of cases and was associated with a reduction in postoperative stay for simple $(2.2$ vs 2.6 days, $\mathrm{p}<0.001)$ and perforated appendicitis (4.6 vs 5.8 days, $\mathrm{p}<0.001$ ). A low rate of laparoscopy $(<25 \%)$ was found in $53 \%$ of teaching and $45 \%$ of non-teaching institutions. Conversion rates were $10.3 \%$ for simple appendicitis and $28.5 \%$ for perforated ones $(\mathrm{p}<0.001)$

Conclusion: Although results of this survey compare to similar published series, a few concerns emerge. Many have to do with non compliance with recommended antibiotic usage for acute appendicitis. Although laparoscopy seems to be slowly making its way into the surgical armamentarium, the low rate of laparoscopic appendectomies in teaching hospitals raises the issue of appropriate resident training.
A PROSPECTIVE RANDOMIZED STUDY WITH A 5 YEARS MINIMUM FOLLOW-UP OF TEM VS LAPAROSCOPIC TOTAL MESORECTAL EXCISION AFTER NEOADJUVANT THERAPY

Emanuele Lezoche MD, Mario Guerrieri MD, Angelo De Sanctis MD, Roberto Campagnacci MD, Maddalena Baldarelli MD, Giovanni Lezoche MD

${ }^{1}$ Department of Surgery "Paride Stefanini", II Clinica Chirurgica, University "La Sapienza"1, Rome, Italy

${ }^{2}$ Department of General Surgery, University of Ancona, Ancona, Italy

Background: debate is still ongoing regarding the role of laparoscopy and Transanal Endoscopic Microsurgery (TEM): in rectal cancer surgery. Neoadjuvant therapy (NT) represent an integral part of the multidisciplinary approach to low rectal cancer treatment. Aim of this study was to compare the oncological results with a 5 years minimum follow-up of TEM and Laparoscopic Low Anterior Resection (LLAR) with total mesorectal excision in the treatment of T2 N0 rectal cancer following NT.

Methods: Seventy patients (pts) staged at the admission as T2 N0, G1-2 rectal cancer with a tumour diameter lower than $3 \mathrm{~cm}$ and located within $6 \mathrm{~cm}$ from the anal verge were enrolled: 35 were randomized to TEM and 35 to LLAR. The pts of both groups were previously underwent high dose radiotherapy (overall administration of 5,040 cGy in 28 fractions over 5 weeks) combined with continuous infusion of 5-Flurouracil (200 $\mathrm{mg} / \mathrm{m}^{2} /$ day)

Results: At median follow-up of 68.3 months (60-108) in both arms 2 local recurrence $(5.7 \%)$ were observed after TEM and $1(2.9 \%)$ after LLAR ( $\mathrm{p}=0.981)$. One distant metastasis $(2.9 \%)$ occurred after TEM and $1(2.9 \%)$ after LLAR. The cumulative survival probability was 0.971 for TEM and 0.943 for LLAR.

Conclusion: The study shows similar results between the two arms in terms of local recurrences, distant metastasis and cumulative survival probability. TEM should be a possible alternative to the rectal resection in the treatment of selected $\mathrm{T} 2$ rectal cancer.

\section{COMPARISON OF CONVENTIONAL LAPARASCOPIC VERSES HAND ASSISTED ONCOLOGIC SEGMENTAL COLONIC RESECTION}

Chad D Ringley MD, Victor P Bochkarev MD, Corrigan L McBride MD, Jon Thompson MD, Dmitry Oleynikov MD

University of Nebraska Medical Center

Laparoscopic assisted segmental colon resection has evolved to be a viable option in the treatment of colorectal cancer. This study evaluates the efficacy of the hand assisted technique (HALS) as compared to the totally laparoscopic technique (LAP) of segmental oncologic colon resection in regards to lymph node harvest, operative times, intra operative blood loss, incisional length and length of hospital stay in an attempt to help delineate the role of each in the treatment of colorectal cancer.

The prospective databases of three advanced laparoscopic surgeons were analyzed to acquire data for this evaluation. Forty patients underwent elective oncologic segmental colon resection between June 2001 and July 2005 (22 HALS, 18 LAP). Main outcome measures included lymph node harvest, operative times, intra operative blood loss, incisional length and length of hospital stay. Statistical analysis was performed via the SPSS statistical program to ascertain any differences between the two groups. A total of forty patients were evaluated in the study, 22 in the HALS group and 18 in the LAP group. The two groups were comparable with regards to patient demographics. The tumor margins were clear in all patients. HALS resection resulted in a statistically significant higher lymph node yield than the LAP group $(\mathrm{HALS}=16+/-6.5$; $\mathrm{LAP}=9.4+/$ $5.3 ; \mathrm{p}=0.009)$ and significantly shorter operative times (HALS $=125.5$ $\min +/-33.5 ;$ LAP $=169.1 \mathrm{~min}+/-59.1 ; \mathrm{p}=0.009)$. Both groups were comparable in regards to length of hospital stay and intra operative blood loss. However, the LAP group yielded a statistically significant smaller incision for specimen extraction (LAP $=5.9 \mathrm{~cm}+/-0.8$; HALS $=6.8 \mathrm{~cm}$ $+/-0.7 ; \mathrm{p}=0.007$ ).

This evaluation suggest that hand assisted laparoscopic oncologic segmental colonic resection is associated with shorter operative times, higher lymph node harvest and equivalent hospital stays and intra operative blood loss as compared to the totally laparoscopic approach. The totally laparoscopic technique was completed with a smaller incision; however, this less than a centimeter reduction in incisional length has doubtful clinical significance. 
UPRIGHT, SUPINE, OR BIPOSITIONAL REFLUX: PATTERNS OF REFLUX DO NOT IMPACT OUTCOME AFTER LAPAROSCOPIC NISSEN FUNDOPLICATION

Alexander S Rosemurgy MD, Sam Al-Saadi MD, Desiree V Villadolid BS, Demitri Arnaoutakis, Sarah M Cowgill MD

University of South Florida, College of Medicine, Department of Surgery INTRODUCTION: This study was undertaken to determine if body position in which reflux occurs before fundoplication, i.e., pattern of reflux, impacts symptoms before or after laparoscopic Nissen fundoplication. METHODS: 401 patients underwent $\mathrm{pH}$ studies and the severity of reflux in the upright and supine positions was determined. The percent time with $\mathrm{pH}<4$ was used to assign patients to one of four groups: upright reflux $(\mathrm{pH}$ $<4$ more than $8.3 \%$ of time in upright position, $\mathrm{N}=78)$, supine reflux $(\mathrm{pH}<$ 4 more than $3.5 \%$ of time in supine position, $\mathrm{N}=75$ ), bipositional reflux (both supine and upright reflux, $\mathrm{N}=155$ ) or neither $(\mathrm{N}=93)$. Before and after laparoscopic Nissen fundoplication, the frequency and severity of symptoms of reflux (e.g., dysphagia, regurgitation, choking, heartburn, chest pain) were scored by a Likert scale $(0=$ never/not bothersome to $10=$ always/very bothersome). For each patient, symptom scores before vs. after fundoplication were compared using Wilcoxon matched pairs test; comparisons of symptom scores among patients grouped by reflux patterns were made using Kruskal-Wallis test. RESULTS: Before fundoplication, the patterns of reflux did not impact the frequency and severity of reflux symptoms. After laparoscopic fundoplication, symptoms of bipositional reflux improved, while nearly all symptoms of isolated supine or upright reflux or neither improved, except for frequency of dysphagia (Table).
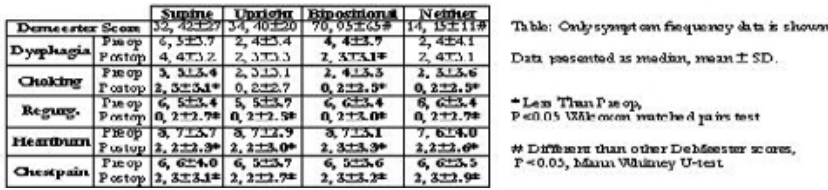

CONCLUSIONS: Preoperatively, regardless of the pattern of reflux, symptoms among patients were similar. After fundoplication, symptoms improved uniformly for bipositional reflux. After fundoplication, symptoms of isolated upright or supine reflux or neither nearly uniformly improved, without discriminating differences. For patients with all patterns of reflux, laparoscopic fundoplication imparts dramatic and broad relief of symptoms and application of laparoscopic Nissen fundoplication is encouraged.

\section{ORAL-CS: A PROSPECTIVE RANDOMIZED TRIAL TO DETER- MINE IF NSAIDS REDUCE HOSPITAL STAY AFTER LAPARO- SCOPIC COLON SURGERY}

C M Schlachta MD, S E Burpee MD, C Fernandez MSc, B Chan MD, J Mamazza MD, E C Poulin MD

Department of Surgery, St. Michael's Hospital, Toronto, Canada

Introduction: The objective of this study was to determine if NSAIDS reduce ileus following laparoscopic colorectal surgery thus shortening hospital stay.

Methods: This was a single centre, prospective, randomized, double blind, placebo controlled, clinical trial of patients undergoing laparoscopic colorectal resection. Patients who met the inclusion criteria received either intravenous ketorolac (group A) or placebo (group B) for 48 hours after surgery in addition to PCA morphine. Patients were assessed daily by a blinded assistant for level of pain control. Diet advancement and discharge were according to strictly defined criteria. Statistical analysis was performed with a 0.05 level of significance.

Results: From October 2002 to March 2005, 190 patients underwent laparoscopic colorectal surgery, of which 84 were eligible for this study and 70 consented. According to protocol, another 20 patients were excluded prior to and 6 after randomization leaving 22 patients in each group. Two patients who suffered anastomotic leaks in the early postoperative period were excluded from further analysis. Median length of stay for the entire study was 4.0 days with significant correlation between $\mathrm{mg}$ of morphine consumed and time to first flatus $(\mathrm{r}=0.422, \mathrm{p}=0.005)$, full $\operatorname{diet}(\mathrm{r}=0.522, \mathrm{p}<0.001)$, and discharge $(\mathrm{r}=0.437, \mathrm{p}=0.004)$. There were no differences between groups in age, body mass index or operating time. Patients in group A consumed less morphine $(33 \pm 31 \mathrm{mg}$ vs. $63 \pm 41 \mathrm{mg}$, $\mathrm{p}=0.011$ ), and had less time to first flatus (median $2.0 \mathrm{~d}$ vs. $3.0 \mathrm{~d}, \mathrm{p}<0.001$ ) and full diet (median $2.0 \mathrm{~d}$ vs. $3.0 \mathrm{~d}, \mathrm{p}=0.031$ ). The reduction in length of stay was not significant (mean $3.6 \mathrm{~d}$ vs. $4.5 \mathrm{~d}$, median $4.0 \mathrm{~d}$ vs. $4.0 \mathrm{~d}$, $\mathrm{p}=0.142$ ). Pain control was superior in group A. Three patients required readmission giving five anastomotic leaks (4 in group A vs. 1 in group B, $\mathrm{p}=0.15)$ of which two were re-operated.

Conclusion: Intravenous ketorolac was efficacious in improving pain control and reducing postoperative ileus when anastomotic leaks were excluded. This simple intervention shows promise in reducing hospital stay although the outcome was not statistically significant. The high number of leaks is inconsistent with this group's experience and is of concern.
LAPAROSCOPIC SURGERY FOR COLORECTAL CANCER: EXPERIENCE IN 500 SUCCESSFUL CASES

Hwei-Ming Wang MD, Joe-Bin Chen MD, Feng-Fan Chiang MD, ChouChen Chen MD

Taichung Veterans General Hospital

AIM: Controversial issues surrounding the use of laparoscopic surgery (LAP) for colorectal cancer include high conversion - high complication rate-port site recurrence and poor outcome than open surgery (OPEN) previously reported. The purpose of this single center, prospective study was to assess the oncological outcomes achieved after curative LAP for cancer.

MATERIALS \& METHODS: We enrolled 514 consecutive patients with colorectal cancer undergoing LAP between July 1998 and May 2004. The data were including patient profile-operative complication-pathology and oncological outcome. We compared the oncologic outcomes achieved using LAP and OPEN during period from July 1998 to June 2001. Patient follow-up ranged from 36 to 72 months. The follow-up rate was $95 \%$. We recorded the final status of all cancer patients as of June 30, 2004

RESULTS: We attempted to perform LAP in 514 patients and 14 patients $(2.7 \%)$ needed conversion to open surgery. The LAP was successfully in 500 patients with 308 males and 192 females, age from 26 to 96 years, av. 64.2 years. Of the 500 LAP patients, $85(17.0 \%)$ experienced complications \& $42(8.4 \%)$ patients had major complications that required further surgery. Major complication of LAP for rectal cancer was higher than colon cancer: $11.4 \%(34 / 298)$ vs. $4.0 \%(8 / 202)$. There were three $(0.6 \%)$ operative mortality due to sepsis, CVA and hepatic failure. We examined the oncologic results achieved in 185 patients who had curative LAP between July 1998 and June 2001. The 3Y-DFS between LAP and OPEN were no difference in stage I $(94.2 \%$ vs. $93.9 \%)$, stage II $(79.7 \%$ vs. $73.4 \%)$, stage III (57.2\% vs. $56.7 \%)$ and over-all (75.8\% vs. $70.3 \%)$. There were two $(0.4 \%)$ port site recurrence found in LAP patients.

CONCLUSION: The LAP for cancer was feasible for the acceptable morbidity rate $\&$ operation time. The oncological results are encouraging and equal to OPEN. 
A MULTI-INSTITUTIONAL STUDY OF THE IMPACT OF A VIRTUAL REALITY SIMULATOR TRAINING CURRICULUM ON MASTERY OF COLONOSCOPY DURING FELLOWSHIP

Brian J Dunkin MD, Jeffrey Marks MD, Timothy McCashland MD, Sumeet Bushan MD, Darius Sorbi MD, Jeffrey Raskin MD, Ramon Mourelo MD, Jeffrey Ponsky MD

University of Miami, Miami, FL, Cleveland Clinic Foundation, Cleveland, $\mathrm{OH}$, University of Nebraska, Omaha, NE, Wake Forest University, Salem, NC, Mayo Clinic, Scottsdale, AZ

Objective: To determine the impact of virtual reality simulation training on the performance of colonoscopy by first-year endoscopy fellows.

Methods: From 7/1/2002 to 6/30/2003 26 first year endoscopy fellows from 9 institutions were randomized into two groups (14 fellows from 5 institutions completed study). Group A (8) received a 16-week training curriculum on a virtual reality colonoscopy simulator (Simbionix GI Mentor, Simbionix USA, $\mathrm{OH})$. Group B (6) had no simulator training. The clinical performance of all fellows during colonoscopy cases was recorded throughout the first year of fellowship. Study endpoints included: 1) procedure time 2) ability to reach cecum 3) time to cecum 4) necessity for attending to take over exam 5) medications used 6) recovery time, and 7) complications. Results expressed in mean values.

Results: 1091 colonoscopy cases were analyzed (570 Group A, 521 Group B). Each fellow averaged 78 cases (4-330). There were no significant differences in patient demographics, indication, number of therapies, or urgency of procedure between the groups. Procedure time (A $29 \mathrm{~min}$, B $24 \mathrm{~min} \mathrm{p}<0.001$ ) and time to cecum (A 16 min, B 12 min $\mathrm{p}<0.001$ ) was somewhat longer in Group A. Recovery time (A $64 \mathrm{~min}$, B 64 min NS), and complications (A 15, B 18 NS), were not statistically different between groups. Group A reached the cecum slightly less often (A 85.3\%, B 94.2\%) with more attending take-over A $33.7 \%$, B 19.8\%). Medication use was equivalent. No significant differences were found comparing the groups earlier in the training year versus later.

Conclusions: This study failed to show an overall benefit to virtual reality simulator training on teaching first year endoscopy fellows colonoscopy. The total procedure time and time to intubate the cecum was somewhat shorter in the non-simulator training group, although not by a clinically significant amount. This lack of demonstrated benefit may be from an inappropriate curriculum. Repetition was the only requirement for advancing through the simulator training. Achieving benchmarks on the simulator established by experts may be more appropriate. Studies are underway to establish these benchmarks and repeat this type of investigation with a revised training curriculum.

\section{DO POSTGRADUATE COURSES REALLY ALTER PHYSICIAN} DECISION MAKING?

Brian J Dunkin MD, Jeffrey Hazey MD

University of Miami, Miami, FL, University of Ohio, Columbus, Ohio Objective: Postgraduate courses are frequently offered at national meetings to teach participants about the latest developments in medicine. The common format is a number of brief lectures by experts in the field. This study was conducted to determine if this format is effective in altering audience opinion about the clinical management of hypothetical surgical problems.

Methods: In April of 2005156 physicians registered to attend a postgraduate course on endoluminal therapy conducted at a national surgery meeting (Society of American Gastrointestinal and Endoscopic Surgeons, SAGES). Ten experts gave 15 to 30 minute lectures on different methods of endoluminal therapies. Eight of these talks addressed the management of a clinically relevant medical problem. Prior to each lecture, a moderator presented a hypothetical patient problem to the audience. Each problem had two options for management, one of which was an endoluminal therapy. An audience response system was used to have the audience vote on a preferred option. The expert then gave the lecture followed by a revote from the audience. Results were immediately displayed.

Results: Eight hypothetical patient management questions were posed to the audience. An average of 67 (47-77) participants responded to each question. $84 \%$ of the audience stated they performed flexible endoscopy as part of their surgical practice. In 7 of 8 cases a larger number of audience members chose endoluminal therapies post-lecture than pre. Following three presentations, the majority of the audience reversed their opinion and chose an endoluminal therapy to manage the hypothetical patient problem after initially choosing a non-endoscopic option. In 4 of 8 cases, a larger percentage of the audience chose an endoluminal therapy after the lecture. After only one presentation did more of the audience choose a non-endoluminal therapy. The largest percent change in opinion pre and post lecture was from $42 \%$ choosing endoluminal therapy pre lecture to $93 \%$ post.

Conclusions: This study shows that a brief presentation given by an expert in a post-graduate course setting is effective in significantly changing the opinion of the audience (either reversing their pre-lecture decision or increasing the post-lecture decision). This finding supports the postgraduate course lecture format and demonstrates how audience participation can be used to judge the effectiveness of individual speakers as well as the program as a whole.

\section{REVERSE-ALIGNMENT SURGICAL SKILLS ASSESSMENT}

James Frydman MD, Jon C Gould MD, University of Wisconsin Medical School

Introduction: At times during certain laparoscopic procedures, a surgeon must operate while the camera is oriented at an angle approximating 180degrees to the axis of his/her instruments. The aim of this study is to measure the degree to which task performance is impaired under reverse-alignment (mirror image) conditions in operators with varying levels of skill.

Methods: Nineteen general surgery residents (PGY\# 2-5, laparoscopic case experience 1-144 cases) and 3 attending surgeons (>1,000 laparoscopic cases) were tested in a video trainer. A task designed to simulate tack placement during laparoscopic ventral hernia repair was created. Our template consists of a 3.75? diameter circle with 8 smaller 0.38 ? diameter circles spaced evenly within the perimeter of the larger circle. Time required to accurately target (not drag) the tip of a laparoscopic dissector in each hand to the 8 small circles was measured in both forward and reverse-alignment conditions. Data regarding prior laparoscopic case volume and MISTELS scores were available for each resident. Spearman correlation coefficient calculation was used to determine if any measure of laparoscopic skill correlated with reverse-image skills.

\begin{tabular}{|l|c|c|}
\hline RESULTS & $\mathrm{r} 2$ & p-value \\
\hline Forward:reverse & 0.31 & 0.02 \\
\hline Rev:PGY\# & 0.08 & 0.24 \\
\hline Rev:L/S\# & 0.06 & 0.29 \\
\hline Rev:MISTELS & 0.13 & 0.12 \\
\hline MISTELS:L/S\# & 0.45 & 0.004 \\
\hline
\end{tabular}

r2 of $1.0=$ perfect correlation between variables. Rev=reverse-alignment time (seconds). L/S\#=laparoscopic case volume experience.

Mean resident reverse-alignment times were significantly greater than attending times (149 +/- 99 seconds resident vs. 32 +/-8 attending; $\mathrm{p}=0.006$ ).

Conclusion: This data suggests that reverse-alignment surgical skills can be acquired with experience, but may require a volume of cases exceeding that encountered in residency training. Reverse image skills are not derivative from surgical skills developed in a video trainer with forward orientation.

\section{CONCURRENT VALIDITY OF AUGMENTED REALITY MET- RICS APPLIED TO THE FUNDAMENTALS OF LAPAROSCOPIC SURGERY (FLS)}

E. Matt Ritter MD, Tamara W Kindelan MD, Curtis Michael, Elisabeth A Pimentel BA, Mark W Bowyer MD

INCA Medical Simulation Center, Department of Surgery, Uniformed Services University, 2Division of General Surgery, National Naval Medical Center, Bethesda Maryland

Objective: Current skills assessment in the Fundamentals of Laparoscopic Surgery (FLS) program is labor intensive requiring one proctor for every 1-2 subjects. The ProMIS Augmented Reality (AR) simulator (Haptica, Dublin IRE) allows for objective assessment of physical tasks through instrument tracking technology. We hypothesized that the ProMIS metrics could differentiate between ability groups as well as standard FLS scoring with fewer personnel requirements

Methods: We recruited 60 volunteer subjects. Subjects were stratified based on their laparoscopic surgical experience. Those who had performed more than 100 laparoscopic procedures were considered experienced $(n=8)$. Those with less than 10 laparoscopic procedure were considered novices $(n=44)$. The rest were intermediates $(n=8)$. All subjects performed up to 5 trials of the peg transfer task from FLS in the ProMIS simulator. FLS score, instrument path length, and instrument smoothness assessment were generated for each trial.

Results: For each of the 5 trials, experienced surgeons outperformed intermediates who in turn out performed novices. Statistically significant differences were seen between the groups across all trials for FLS score $(\mathrm{p}<$ $0.001)$, ProMIS path length $(\mathrm{p}<0.001)$ and ProMIS smoothness $(\mathrm{p}<$ 0.001). When the FLS score was compared to the path length and smoothness metrics, a strong relationship between the scores was apparent for novices $(\mathrm{r}=0.78, \mathrm{r}=0.94, \mathrm{p}<0.001)$ respectively), intermediates $(\mathrm{r}=$ $0.5, \mathrm{p}=0.2, \mathrm{r}=0.98, \mathrm{p}<0.001)$, and experienced surgeons $(\mathrm{r}=0.86, \mathrm{p}=$ $0.006, \mathrm{r}=0.99, \mathrm{p}<0.001)$

Conclusions: The construct that the standard scoring of the FLS peg transfer task can discriminate between experienced, intermediate, and novice surgeons is validated. The same construct is valid when the task is assessed using the metrics of the ProMIS. The high correlation between these scores establishes the concurrent validity of the ProMIS metrics. The use of AR for objective assessment of FLS tasks could reduce the personnel requirements of assessing these skills while maintaining the objectivity. 
WHAT CAN MOTION DERIVATIVES TELL US ABOUT SKILL PERFORMANCE?

Laurel N Vuong BS, Steven D Schwaitzberg MD, Caroline G Cao PhD

Tufts University School of Medicine, Cambrige Health Alliance, Tufts University School of Engineering

Surgical simulators is a popular topic of discussion on training in laparoscopic surgery. They reduce the need to use human cadavers or animal models for skills development. A subset of the MISTELS methodology has been employed in the manual skills assessment for the Fundamentals Laparoscopic Skills (FLS) program because it was shown to be a valid discriminator of surgical experience. Pure performance outcome, such as time to task completion and number of errors, is used for scoring, which is dependent on the consistency of the scorer. A new simulator environment has been created which uses motion tracking for measurement of performance outcome measures and motion derivatives such as smoothness and efficiency. The purpose of the study was to determining if the motion derivatives can be used to automatically and objectively discriminate experience levels. Twenty-one subjects ( 6 medical students, 14 surgical residents, and 1 expert surgeon) were recruited to perform the following tasks: peg transfer, pattern cutting, pre-tied loop placement, extracorporeal and intracorporeal knot-tying in the new simulator environment. Subjects were evaluated on time to completion, errors, smoothness and total path length (used to calculate efficiency). Results show that experience level is still distinguishable when using task-dependent parameters to evaluate performances during peg transfer $(\mathrm{p}=0.035)$, pre-tied loop placement $(\mathrm{p}=0.022)$, extracorporeal $(\mathrm{p}=0.0006)$ and intracorporeal $(\mathrm{p}=$ 0.025 ) knot tying in this new simulator environment. Evaluation of performance using task-independent parameters significantly distinguished training level in three tasks: (1) smoothness of the left instrument was significant as a function of experience level in extracorporeal knot-tying $(\mathrm{p}=$ 0.016 ), (2) efficiency (total path length divided by time to completion) was also significant in the movement of the right tool as a function of experience level in peg transfer $(\mathrm{p}=0.0011)$ and $(3)$ pre-tied loop placement $(\mathrm{p}=0.013979)$. This preliminary analysis shows that automatic and objectively measured motion derivatives can be associated with the level of experience .

These results indicate a potential for the application of an automatic and objective means of skills evaluation.

\section{ERGONOMICS/INSTRUMENTATION}

ENERGY SOURCES FOR LAPAROSCOPIC COLECTOMY: A PROSPECTIVE RANDOMICED COMPARISON BETWEEN CONVENTIONAL ELECTRO SURGERY, BIPOLAR COMPUTER-CONTROLLED ELECTROSURGERY AND ULTRASONIC DISSECTION

EM Targarona MD, C Balague MD, J Marin MD, R Beringoade MD, C Martinez MD, J Garriga MD, M Trias MD

Serv. Surgery. Hospital Sant Pau. UAB, Barcelona, Spain.

Success of lap surgery is linked to technical advances in instrumentation. Evolution of energy sources permits design of more efective hemostatic devices, as alternative to electrosurgery. Ultrasonic energy avoid the use of electricty, with efective control of medium size vesels and cutting ability. Bipolar computer-controlled technology avoid disadvantages of electricity and is able to control large vessels. The supossed advantages is to facilitate surgical perfomance with reduction of blood loss and op. time. However, they increase the cost of lap procedures, and evidence-based data is scarce. Aim: to compare the efficacy of 3 different energy sources on left colectomy.

M \& M: 38 patients requiring left colon resection were randomiced. Inclusion criteria: lesion above $15 \mathrm{~cm}$ of the anus and below the splenic flexure. Colon resection was done with an standard 4 trocars technique. GI, n:11, Electro surgery: all dissection performed with electrosurgery and vessels controlled with clips. GII, $\mathrm{n}: 12$, Ultrasonic:.5 mm ultrasonic shears used for dissection and vascular section. Large vessels controlled with endostapler. GIII, n:15, Bipolar electrosurgery computer-controlled: All vascular and mesocolon section done with a $10 \mathrm{~mm}$ device. Age, sex, BMI, Op.t, conversion, blood loss, morbidity, hosp. stay and cost were recorded. An intention to treat principle was followed. Results

\begin{tabular}{|lc|c|c|}
\hline & I. Electrosurg. & II. Ultrasonic & III. Bipolar \\
\hline Op. time & $180(90-210)$ & $120(65-220)^{*}$ & $110(70-210)^{*}$ \\
\hline Blood loss & $180(90-210)$ & $100(0-150)^{*}$ & $100(0-450)$ \\
\hline Conversion & $3 / 11$ & $0 / 12$ & $1 / 15$ \\
\hline Stay & $7(6-32)$ & $8(4-18)$ & $6(6-16)$ \\
\hline Cost (?) & 2995 & 2928 & 2664 \\
\hline
\end{tabular}

*: $\mathrm{p}<0.01$. Conclusion: High energy power sources reduce op. time and blood loss, antd it may be considered cost-efective when using left colectomy as a model. 
DOES COLLIS GASTROPLASTY REDUCE RECURRENCE RATE AFTER LAPAROSCOPIC TYPE III PARAESOPHAGEAL HERNIA REPAIR?

L Biertho MD, S Faidi MD, CJ Allen MD, M A PhD

Centre for Minimal Access Surgery, McMaster University, and Department of Medicine, St. Joseph's Healthcare, Hamilton Ontario Canada

BACKGROUND: Surgical repair of Type III paraesophageal hernias $(\mathrm{PEH})$ is associated with high recurrence rate. One factor implicated is reluctancy of surgeons to do a Collis gastroplasty when needed. The aim of this study was to evaluate the outcomes of laparoscopic repair of Type III PEH with or without Collis gastroplasty.

METHODS: 77 patients (25M:52F, mean age $62.4 \pm 12.0$ yrs) with Type III PEH undergoing laparoscopic repair with Nissen fundoplication between 2000 and 2005 were prospectively followed. Patients who required a Collis gastroplasty (Group I, n=11) are compared to those who did not (Group 2, $\mathrm{n}=66$ ).

RESULTS: All procedures were completed laparoscopically. Mean operative time was $168.4 \pm 41.5 \mathrm{~min}$ in Group 1 and $102.5 \pm 30.2 \mathrm{~min}$ in Group 2 $(\mathrm{p}=0.0002) .35$ patients $(45 \%)$ had half the stomach or more in the chest. There was no major peri-operative complication or 30-days mortality. 3 patients in Group 2 had a post-operative intrathoracic stomach migration that required emergency redo surgery ( 0 versus $4.5 \%, \mathrm{p}=0.4698)$. There was no significant difference in hospital stay between the two groups (3.2 \pm 1.4 in Group 1 versus 3.6 \pm 2.2 days in Group 2, $\mathrm{p}=0.4258$ ) Patients were followed for a range of 0.5 to 51 months. There was a trend towards a higher post-operative complication rate in Group 2 (9.1 vs $18.2 \%$, $\mathrm{p}=0.4549$ ). There was no significant difference in rate of redo surgery (9.1 vs $6.1 \%, \mathrm{p}=0.7008)$.

\begin{tabular}{|l|c|c|}
\hline \multicolumn{1}{|l|}{$\begin{array}{l}\text { Long Term Postoperative } \\
\text { Complications }\end{array}$} & Group 1 & Group 2 \\
\hline & 1 (1 redo surg) & 9 (2 redo surg) \\
\hline Hernia Recurred & 0 & 2 (1 redo surg) \\
\hline Slipped Nissen & 0 & 1 (1 redo surg) \\
\hline Wrap Migration & 0
\end{tabular}

CONCLUSION: These data confirm that laparoscopic repair of type III $\mathrm{PEH}$ is feasible and safe. Collis gastroplasty increases operative time with no significant increase in hospital stay and peri-operative morbidity. Collis gastroplasty may also be associated with a decrease in recurrence rate.

\section{LAPAROSCOPIC TRANSHIATAL AND THORACOSCOPIC ESOPHAGECTOMY FOR THE TREATMENT OF ESOPHAGEAL BENIGN DISEASES. LONG-TERM FOLLOW-UP}

Aureo L De Paula PhD, Antonio L Macedo MD, Vkadimir Schraibman MD Hospital de Especialidades de Goiania e Hospital ALbert Einstein Indications for esophagectomy are limited in patients presenting benign diseases. These procedures are related to high morbidity and mortality, and also to adverse effects in short and long term follow-up. The objective of this paper is to present the results in long term follow-up in patients submitted to thoracoscopic esophagectomy (TE) and trans-hiatal laparoscopic esophagectomy (THLE).

Between July 1992 and July 2004, 62 patients were submitted to TE and/or THLE. Median age was 55,1 years (19-78). 23 were female and 39 male. Median weight was $67 \mathrm{~kg}(38-113)$. Main indications included: idiophatic advanced achalasia (12), Chagas disease (22), stenosing nondilatable esophagitis (3), antireflux surgery failure (5), Heller surgery failure (17), sclerodermia (2) and caustic stenosis (1). All patients presented disphagia, regurgitation and median weight loss of $18 \%$. Median duration of symptoms was 11,8 years (3-35). All patients did upper endoscopy, upper GI series, esophageal manometry and 24 hour pH-metry.

First surgical option was THLE, done in 57 patients. TE was done in 5 patients. Conversion to open surgery in one patient. One patient was converted from THLE to TE. Median operative time was $216 \mathrm{~min}$ (185-392). Intra-operatory complications included: unilateral pneumothorax (14) and bilateral (6), duodenal perforation during piloromiotomy (2), traqueal lesion (1). Median in hospital stay was 7,2 days (4-21). Immediate postoperative complications included: bleeding without blood transfusion (2), pleural effusion (13), transitory disphonia (4), slow gastric emptying (2) and esophagogastric anastomosis fistula (7). Mortality was $1,6 \%$ (pulmonary embolism). Mean post-operative follow-up was 88 months (7151). After 6 months of surgery all patients were cured from disphagia. Main post-operative complaint was regurgitation. Patients with TE showed intra-thoracic stomach with slower emptying time. Endocopic pyloric dilation was done in 14 patients.

Esophagectomies done by THLE and TE showed to be technically viable with low morbidity and mortality. There was a significant improvement in short and long term follow-up after the institution of a gastric tube as a routine.
THE RISE AND FALL OF ANTIREFLUX SURGERY IN THE UNITED STATES

Jonathan F Finks MD, Yongliang Wei MS, John D Birkmeyer MD UNIVERSITY OF MICHIGAN

BACKGROUND: National rates of laparoscopic anti-reflux surgery grew steadily in the 1990s. Since then, a highly visible randomized trial has questioned the long-term effectiveness of anti-reflux surgery, several new endoscopic therapies have been developed, and proton pump inhibitors have become over-the-counter and less expensive. We examined the potential impact of these factors on surgical utilization rates.

METHODS: Using data from the Nationwide Inpatient Sample (NIS), we identified all patients over 18 years undergoing anti-reflux surgery between 1994 and 2003. The NIS is the largest all-payer inpatient care database in the United States, representing $20 \%$ of non-federal US hospitals. Sampling weights were used to estimate the total number of procedures performed in the US each year. Population-based rates were then determined using denominators from US census data.

RESULTS: Confirming the results of earlier studies, the annual number of anti-reflux procedures performed in the US grew rapidly during the 1990 s, peaking at $32,907(15.6 / 100,000)$ in 2000 . After 2000 , surgical rates declined steadily, falling approximately $27 \%$ by 2003 to 23,998 cases $(11.2 / 100,000),[p<.0001]$. Utility rates fell faster for people in the 30 to 50 age range than for those over 50 . The large majority of antireflux surgery continues to be performed transabdominally, using laparoscopic techniques. Rates of mortality and splenectomy have remained stable and relatively low (0.5\% and $0.9 \%$, respectively, in 2003).

CONCLUSIONS: The use of anti-reflux surgery in the United States has declined substantially in the last several years. This shift in practice patterns may reflect new questions about the long-term effectiveness of surgery. These results suggest the need for prospective randomized clinical trials assessing current therapies.

\section{ESOPHAGEAL BODY MOTILITY AFTER PARTIAL AND} TOTAL LAPAROSCOPIC FUNDOPLICATION

Fernando A Herbella MD, Pietro Tedesco MD, Ian Nipomnick MD, Marco G Patti MD

Center for Study of Gastrointestinal Motility and Secretion, University of California, San Francisco, USA

INTRODUCTION: Gastroesophageal reflux disease can be associated to abnormal esophageal body motility. Laparoscopic fundoplication is an efficient method to control reflux. The effect of a successful fundoplication on esophageal motility is still controversial.

PATIENTS AND METHODS: Esophageal manometries of seventy-one patients who underwent laparoscopic fundoplication with reflux control (post-operative DeMeester score $<14.7$ ) were reviewed. Patients were grouped according to the type of fundoplication and pre-operative esophageal peristalsis: Group A, partial fundoplication and abnormal esophageal peristalsis $(n=16)$; group $B$, total fundoplication and normal peristalsis $(n=41)$; group $C$ total fundoplication and abnormal peristalsis $(\mathrm{n}=14)$.

\begin{tabular}{|l|l|l|l|l|l|l|}
\hline Group & \multicolumn{2}{|c|}{ A } & \multicolumn{2}{c|}{ B } & \multicolumn{2}{c|}{ C } \\
\hline & pre & post & pre & post & pre & post \\
\hline LES & $8 \pm 3^{*}$ & $13 \pm 4^{*}$ & $12 \pm 12^{*}$ & $19 \pm 8^{*}$ & $9 \pm 3^{*}$ & $14 \pm 7^{*}$ \\
DA & $33 \pm 13^{*}$ & $50 \pm 23^{*}$ & $104 \pm 35$ & $98 \pm 42$ & $41 \pm 13^{*}$ & $86 \pm 36^{*}$ \\
\hline
\end{tabular}

LES - lower esophageal sphincter pressure DA - distal amplitude * statistical significant values given as mean \pm standard deviation (mmHạ)

RESULTS: Pre- and post-operative results are outlined in the table below: Normalization of peristalsis was achieved in $31 \%$ of group A patients and $86 \%$ of group C patients.

CONCLUSIONS: Laparoscopic fundoplication increases lower esophageal sphincter pressure and distal esophageal amplitude in patients with abnormal pre-operative esophageal motility. A total fundoplication determines normalization of peristalsis in the majority of patients. 
NISSEN FUNDOPLICATION (NF) AS A SALVAGE PROCEDURE AFTER FAILURE OF MEDICAL MANAGEMENT FOR GASTROESOPHAGEAL REFLUX DISEASE (GERD): DETAILED ANALYSIS OF CLINICAL OUTCOMES OVER SEVEN YEARS

Mohammad K Jamal MD, Eric J DeMaria MD, Igor Belyanski BS, Alfredo M Carbonell DO, Jason M Johnson DO, Brennan J Carmody MD, Luke G Wolfe MS

Virginia Commonwealth University Health System, Richmond, Virginia Surgical literature suggests that NF has inferior outcomes in patients with severe GERD who fail medical management. We report a single surgeon experience in a group of 123 patients who underwent NF as a salvage procedure after failed symptom control with medical management. Patients undergoing NF between 1998 and 2004 were included in this retrospective analysis. Pre- and post-operative symptom scoring (SS) in 7 categories was carried out using a standard questionnaire. Patients were asked to quantitate their symptoms on a scale of 0 to 3 based on severity $(0=$ none, $1=$ mild, $2=$ moderate, $3=$ severe). A total SS was calculated as the sum of scores in all symptom categories.

Demographic characteristics included a male:female ratio of 2:3, mean age of 49 years and a lengthy mean duration of symptoms of 80 months before NF The group included patients with prior failed NF (16\%), those on combined PPI and H2 blocker therapy (14\%) and patients with Barretts esophagus $(8.7 \%)$, peptic stricture $(6.5 \%)$ and hiatal hernia $(56 \%)$. The most severe symptoms were in a sub-group of 72 patients (59\%) with positive SS in 3 or more categories despite medical management. Forty-one patients underwent $24-\mathrm{hr} \mathrm{pH}$ testing with a mean DeMeester score of $56(33 \%), 95 \mathrm{had}$ an upper endoscopy $(77 \%)$ and 88 had manometry $(72 \%)$ prior to NF.

$\mathrm{NF}$ was completed laparoscopically in $102 / 103$ patients while 20 patients were treated open. The average hospital stay was 3.3 days in the laparoscopic group and 8.7 days in the open group. Forty one patients $(33 \%)$ were discharged within 24 hours of the procedure. The mean duration of follow-up was 1 year. There were 12 minor complications and 1 death in the group $(0.8 \%)$.

Whereas only $15 \%$ of patients were free of all symptoms after NF, there was a significant postoperative improvement in SS for heartburn (1.84 $\pm 1.08 \mathrm{vs}$. $0.63 \pm 0.91, \mathrm{p}<0.0001)$, regurgitation $(0.89 \pm 1.09$ vs. $0.45 \pm 0.88, \mathrm{p}<0.0003)$ vomiting $(0.77 \pm 1.09$ vs. $0.07 \pm 0.28, \mathrm{p}<0.0001)$, nocturnal cough $(0.74 \pm$ 1.08 vs. $0.45 \pm 0.80, \mathrm{p}<0.005)$ and chest pain $(1.01 \pm 1.22$ vs. $0.59 \pm 0.89$ $\mathrm{p}<0.0012$ ). Of the 72 patients with more than 3 positive symptoms before NF, the majority $(60 \%)$ showed elimination or improvement of all preoperative symptoms and reduction in total SS $(8.6 \pm 2.5$ vs. $3.8 \pm 4.0, p<0.0001)$. Our results show that NF is an effective "salvage procedure" in patients with severe GERD who fail medical management. It can be safely performed laparoscopically with minimal morbidity.

EVALUATION OF PATIENTS POST FUNDOPLICATION WITH AND WITHOUT DYSPHAGIA WITH COMBINED MANOMETRY AND IMPEDANCE

Leena Khaitan BA, Andrea Adams BA, C D Smith BA

Emory Endosurgery Unit, Emory University School of Medicine

Background: Following esophagogastric fundoplication (EGF), the incidence of dysphagia has been reported to be between 3-9\%. Multichannel intraluminal impedance is a new technology that when combined with manometry (EFT study), allows assessment of bolus transit simultaneous with contraction pressures within the esophagus. This allows better characterization of esophageal disorders. The purpose of this study is to further understand differences in manometry and bolus transport in patients with and without dysphagia following EGF

Methods: Standard EFT studies with 10 liquid and 10 viscous swallows were performed in 287 patients between 12/01 and 8/05. (Sandhill Scientific, Highland Ranch, CO) Data regarding patient demographics, symptoms, manometric and impedance findings were maintained in a prospectively collected database. Results are reported as proportions and mean \pm SD and data analyzed using t-test and chi square where appropriate. Results: Eighty three patients(pts) had previous EGF of whom 48 had dysphagia (Group 1) and 35 did not (Group 2). Other symptoms included heartburn (42 pts), chest pain (17 pts), regurgitation (23 pts), and extraesophageal symptoms (17 pts). Seven patients had more than one prior EGF. Overall, patients had fewer completely transmitted swallows than peristaltic swallows (72\% transmitted swallows vs $86 \%$ peristaltic swallows with liquid material; $62 \%$ transmitted swallows vs $84 \%$ peristaltic swallows with viscous material). Lower esophageal sphincter (LES) pressure, LES relaxation, and esophageal peristalsis were not different between groups. By impedance, however, more patients with dysphagia had impaired bolus transit $(43 \%$ vs $31 \%, \mathrm{p}=0.14$ with liquid swallows, $63 \%$ vs $51 \%, \mathrm{p}=0.16$ with viscous swallows, respectively). Furthermore, contraction amplitudes were significantly lower in the patients with dysphagia $(82 \mathrm{mmHg}$, group1 vs $102 \mathrm{mmHg}$, group $2, \mathrm{p}<0.02$ )

Conclusions: Despite normal manometry, more patients with dysphagia have impaired bolus transit compared to those without dysphagia. The combination of impaired esophageal clearance identified by impedance and lower distal contraction amplitudes may account for dysphagia symptoms in patients with prior EGF. EFT studies are more helpful in characterizing dysphagia following EGF than standard manometry alone and may aid in future care of these patients. EVALUATION OF ACELLULAR HUMAN DERMIS
REINFORCEMENT OF THE CRURAL CLOSURE IN PATIENTS WITH DIFFICULT HIATAL HERNIAS

E W Lee BS, P M Frisella RN, B D Matthews MD, L M Brunt MD

Department of Surgery and Institute for Minimally Invasive Surgery, Washington University School of Medicine, St. Louis, MO

INTRODUCTION: Prosthetic repair of large hiatal hernias has not been widely accepted despite high reported recurrence rates with primary repair. AlloDerm (Lifecell Corp.) is an acellular human dermis preparation that may circumvent mesh-related complications at the hiatus by becoming remodeled by native cells.

METHODS: Records of 17 patients (pts) who underwent laparoscopic repair of difficult hiatal hernias $(\mathrm{HH})$ using AlloDerm to buttress the crural closure from June 2004 to July 2005 were retrospectively analyzed. Hernias were paraesophageal (PEH) in 11 pts, large type 1 in 2 pts, and recurrent after prior $\mathrm{HH}$ repair in 4 pts. Follow-up $(\mathrm{F} / \mathrm{U})$ was by office visit and by phone. Barium swallow (BAS) was obtained 6-12 months postop. Data are mean $\pm \mathrm{SD}$

RESULTS: Mean age of the 17 pts was $65 \pm 12$ years, BMI $31 \pm 4$, and ASA class $2.4 \pm 0.5$. Mean GE junction distance above the diaphragm in the PEH and type I HH?s was $4.9 \pm 1.5 \mathrm{~cm} ; 9$ of 12 patients had $>50 \%$ of the stomach in the chest. Mean operating time was $273 \pm 48$ minutes. Average hiatal defect size was $5 \times 3 \mathrm{~cm} ; 4 \pm 1$ sutures were used to close the crura primarily followed by Alloderm onlay repair. Nissen fundoplication was performed in all patients, esophageal lengthening in $4 \mathrm{pts}$, and gastropexy in 3 pts. Complications were one intraoperative gastric perforation repaired laparoscopically, and one possible esophageal leak that resolved with conservative treatment. Mean follow-up was $8 \pm 6$ months (range 0.5 ? 22 months). Postoperatively, only 1 (6\%) patient had heartburn/regurgitation, 1 (6\%) had dysphagia (from esophageal dysmotility), and only $2(12 \%)$ take proton pump inhibitors. Follow-up BAS at an interval of $8 \pm 5$ months in 7 pts showed $1(6 \%)$ possible anatomic failure of a redo Nissen in an obese patient. Reoperative conversion to a gastric bypass 15 months later showed an intact crural closure with a remodeled Alloderm buttress site.

CONCLUSIONS: AlloDerm may be an effective material to use to buttress the crural closure in pts with large or difficult hiatal hernias. Longer follow-up in larger numbers of patients is needed to assess the validity of this approach

\section{LONG TERM RISK OF MORTALITY AFTER ANTIREFLUX SURGERY}

Steven R Lopushinsky MD, David R Urbach MD

Departments of Surgery and Health Policy, Management and Evaluation, University of Toronto, Toronto, Ontario, Canada

Introduction: The objective of this study was to examine long-term mortality of patients with complicated gastroesophageal reflux disease (GERD) undergoing anti-reflux surgery. A randomized controlled trial conducted in Veterans Affairs hospitals suggested that patients having antireflux surgery are at greater risk of death as compared with patients treated medically.

Methods: We developed a population-based inception cohort of 43,992 adult patients newly diagnosed with complicated GERD between the years 1991 and 1994, using administrative data. In Ontario, Canada, administrative health databases contain information on all residents receiving health services. Cox-proportional hazard models were created to compare mortality rates between patients undergoing surgery and those that did not. Antireflux surgery was modeled as a time-dependent variable. Patients were followed until death or December 31, 2002. Hazard ratios (HR) and 95\% confidence intervals (CI) are reported.

Results: Of the 43,992 patients with complicated GERD newly diagnosed between 1991 and 1994, 1,827 patients went on to have an anti-reflux procedure. At the time of index GERD diagnosis, patients who eventually had surgery tended to be younger $(46.6$ vs. 55.1 years; $p<0.0001)$, female $(53.48 \%$ vs. $50.83 \% ; \mathrm{p}=0.0267)$, and had fewer comorbid conditions (Charlson comorbidity score, 0.086 vs. $0.21 ; p<0.0001$ ). Overall, 11,377 patients died during the study period. The unadjusted HR of death associated with surgery was 0.42 (95\% CI, 0.36 to 0.49$)$. After adjustment for confounding variables, the HR was 0.83 (95\% CI, 0.71 to 0.97). Age, gender, Charlson score, and GERD severity were independent predictors of mortality.

Conclusion: In a population-based cohort study, we found no evidence that anti-reflux surgery is associated with higher rates of mortality as compared with medical therapy. 
SEVERELY DISORDERED ESOPHAGEAL PERISTALSIS IS NOT A CONTRAINDICATION TO LAPAROSCOPIC NISSEN FUNDOPLICATIO

Yuri W Novitsky MD, Jason Wong MD, Kent W Kercher MD, Donald R Czerniach MD, Demetrius E Litwin MD, Lee . L Swanstrom MD, B. Todd Heniford MD

Carolinas Medical Center; University of Massachussetts Medical Cente, Legacy Health System

Background: In patients with esophageal dysmotility a full fundoplication is controversial. Although Laparoscopic Nissen fundoplication (LNF) is known to be superior to partial wrap in patients with weak peristalsis, its efficacy in patients with severe dysmotility is unknown. We hypothesized that LNF is preferable in patients with severe esophageal dysmotility.

Methods: Multicenter retrospective review of consecutive patients with severe esophageal dysmotility (distal esophageal amplitude [DEA] of $<=30 \mathrm{mmHg}$ and/or $>=60 \%$ of non-peristaltic esophageal body contractions [EBC]) who underwent a LNF. Variables measured included demographics, symptoms, esophageal manometry and 24-hr $\mathrm{pH}$ studies, postoperative dysphagia and reflux recurrence.

Results: Forty-eight patients with severe esophageal dysmotility underwent LNF. All patients presented with symptoms of GERD. Nineteen (39\%) patients had dysphagia. Ten had impaired EBC, 32 patients had an abnormal DEA, and 6 patients had both. Average abnormal DEA was 24.9 $\pm 5.2 \mathrm{mmHg}$ (range, $6.0-30.0 \mathrm{mmHg}$ ). The mean number of non-peristaltic EBC was $69.4 \pm 10.3 \%$ (range, $60-100 \%$ ). There were no intraoperative complications and no conversions. Postoperatively, early dysphagia occurred in $35(73 \%)$ patients. Significant dysphagia remained unresolved after 8 weeks postoperatively in $8(16 \%)$ patients. Four patients were successfully treated with esophageal dilatations, one patient required a re-fundoplication and persistent dysphagia was found in $3(6 \%)$ patients. Abnormal DEA was improved postoperatively in $11(73 \%)$ of tested patients. At an average follow up of 25.4 months (range, 1-46 months) 8 patients $(16 \%)$ were receiving anti-reflux medications, including 6 with documented normal esophageal $\mathrm{pH}$ studies.

Conclusion: LNF provides low rates of reflux recurrence with little longterm postoperative dysphagia in patients with severely disordered esophageal peristalsis. A $360^{\circ}$ fundoplication is thus the preferred antireflux procedure in all patients, even in those with severe esophageal dysmotility.

\section{MINIMALLY INVASIVE ESOPHAGECTOMY FOR CARCINO-} MA ESOPHAGUSAN INDIAN EXPERIENCE

Chinnuswamy Palanivelu MD, Parthsarathy R, AnanadPrakash, MadhanKumar

Dept of Minimal Access Surgery and Surgical Gastroenterology, Gem Hospital, India

Objective: The experience of minimally invasive esophagectomy (MIE) for malignant esophageal lesion is limited in world literature. The aim of this study was to evaluate the outcome of minimally invasive esophagectomy procedures viz., thoracolaparoscopic esophagectomy, laparoscopic transhiatal esophagectomy and laparoscopic esophagogastrectomy for the treatment of esophageal cancer.

Method: From 1995 to 2004, we performed MIE in 130 patients of esophageal cancer . Indications for surgery was squamous cell carcinoma $(n=110)$ and adenocarcinoma $(n=20)$. Squamous cell carcinoma was found in middle third $(n=72)$ and lower third $(n=38)$ of esophagus while adenocarcinoma was found at lower end of esophagus and cardia only.Only one patient $(0.77 \%)$ received neoadjuvant therapy. Thoracolaparoscopic esophagectomy was performed for middle third lesions. Laparoscopic transhiatal esophagectomy was performed for lower third SCC ( $n=38)$ while all patients harboring adenocarcinoma at cardia underwent laparoscopic esophagogastrectomy $(n=20)$ with intrathocacic anastomosis.

Result: Of 130 patients, $102(78.46 \%)$ were males and $28(21.54 \%)$ females. Median age was 61.3 years (range, 30 - 79). Approach to esophagectomy combined with 2 field lymphadenectomy was thoracolaparoscopic $(n=72,55.38 \%)$, laparoscopic transhiatal $(n=38,29.24 \%)$ and laparoscopic esophagogastrectomy $(n=20,15.30 \%)$. Minimally invasive esophagectomy was successfully completed in all patients. Mean number of lymphnodes harvested were 16 (range, 11-34). Median operative time was $210+/-80$ minutes and mean blood loss $150+/-90 \mathrm{~mL}$. Median intensive care unit stay was 2 days (range, 1-35), time to start oral intake was 4 days (range, 2-45) and hospital stay was 8 days (range, 6-55). 30 days postoperative mortality was $0.77 \%(\mathrm{n}=1)$. Major morbidity occurred in $16.75 \%$ with anastomotic leak rate of $4.62 \%(n=6)$. In a mean followup of 16 months there were no neck or port-site reccurence.

Conclusion: MIE is feasible, safe and oncologically acceptable procedure for malignant esophageal lesions with lower mortality rate $(0.77 \%)$ and shorter hospital stay ( 8 days). It has potential to revolutionise the management of esophageal cancer.
LONG TERM OBJECTIVE FOLLOW-UP AFTER LAPAROSCOPIC REPAIR OF LARGE TYPE II-III HIATAL HERNIAS: THE USE OF MESH ALLOWS LOWER RECURRENCE RATE

Giuseppe Portale MD, Giovanni Zaninotto MD, Mario Costantini MD, Emanuela Guirroli MD, Loredana Nicoletti RN, Ermanno Ancona MD Department of Medical and Surgical Sciences, Clinica Chirurgica III, Padova, Italy

Introduction: Laparoscopic repair of large paraesophageal or mixed (type IIIII) hiatal hernias $(\mathrm{HH})$ with prosthetic hiatal closure is now considered feasible and effective with similar results to open surgery. However, in most studies, the outcome analyses are based on symptomatic assessment and relatively short-term follow-up (F-up); concerns remain on possible high recurrence rates in the long-term F-up with objective tests. We retrospectively evaluated the outcomes of laparoscopic repair of large type II-III HH, with or without prosthetic hiatal closure, in the long-term F-up, by means of both symptomatic and radiologic or endoscopic evaluation.

Methods and procedures: From January 1995 to August 2005, 56 pts (10M:46F, mean age 63 yrs) with a diagnosis of large type II-III HH ( $>1 / 3$ radiographic/intraoperative stomach in the chest) underwent laparoscopic repair at our Department. Principles of surgical technique included reduction of the hernia, complete excision of the sac, primary closure of the crura (with/without mesh reinforcement) and antireflux procedure. Laparoscopic fundoplication (Nissen or Toupet) with simple sutured crural closure was performed in 19 pts (group A); a double mesh was added in 37 pts (group B)

Results: There were 5 conversions to open surgery. The mean lenght of radiographic/endoscopic F-up was similar in the two groups [31 mos $( \pm 32)$ group $\mathrm{A}, 23$ months $( \pm 26)$ group $\mathrm{B}, \mathrm{p}=\mathrm{n} . \mathrm{s}$.]. Recurrences occurred in $7 / 19$ $(37 \%)$ group A pts and in $3 / 37(8 \%)$ group $B(p=0.02)$. They were classified as ?early? (total disruption of the hiatal closure on POD 5, 1 pt), "mid-term" (1-12 mos post-op, 3 pts) and "late" (12-72 mos post-op, 6 pts). 4 of these pts underwent reoperation and 1 is scheduled for surgery. Additional 3 $(5.4 \%)$ pts presented a small sliding hernia ( $<3 \mathrm{~cm}$ "telescoping") on post-op barium swallow and did not require reoperation (asymptomatic at 73 mos Fup). 1 group B pt had severe dysphagia on POD 2, due to both obstruction from the mesh and tight fundoplication: she underwent reoperation.

Conclusions: Laparoscopic repair of large type II-III hiatal hernia is a safe and effective treatment. Short-term symptomatic results are excellent, but long-term objective radiologic and/or endoscopic evaluation reveals a significant percentage of recurrence: the main reason for failure of hiatal repair is tension. The use of prosthetic mesh effectively reduce the incidence of postoperative hernia recurrence or wrap migration in the chest.

\section{IMPAIRED ESOPHAGEAL CLEARANCE AFTER NISSEN FUN- DOPLICATION CAN BE OBJECTIVELY MEASURED WITH ESOPHAGEAL IMPEDANCE}

Elina Quiroga MD, Muna Dahir, Brant K Oelschlager MD

The Swallowing Center University of Washington

Nissen fundoplication is assumed to impair esophageal clearance, though the extent to which this happens is difficult to measure with traditional methods. To determine the true physiologic impact of a Nissen fundoplication we used multichannel intraluminal impedance (MII), a new method that allows precise measurement of esophageal clearance.

Methods: We performed simultaneous manometry/MII and $24 \mathrm{hr} \mathrm{pH}$ monitoring in 28 consecutive patients before and at least 6 months after (range 6-13 mo) laparoscopic Nissen fundoplication. We did not include any patient with potential obstruction of the cardia (i.e. stricture, paraesophageal hernia, or prior antireflux procedure)

Results: Transit time increased significantly after Nissen fundoplication and the number of swallows that achieved complete bolus clearance was significantly reduced. Peristaltic activity, as measured by manometry was unaffected.

\begin{tabular}{|l|c|c|c|c|}
\hline & $\begin{array}{c}\text { Peristalsis } \\
\text { Manometw) }\end{array}$ & $\begin{array}{c}\text { Complete Bolus } \\
\text { Clearance (MII) }\end{array}$ & $\begin{array}{c}\text { Bolus transit } \\
\text { Time (MII) }\end{array}$ & $\begin{array}{c}\text { Esophageal Acid } \\
\text { Exposure }\end{array}$ \\
\hline Preoperative & $93 \%$ & $78 \%$ & $7.8 \mathrm{sec}$ & $14.1 \%$ \\
\hline Postoperative & $90 \%$ & $63 \%$ & $8.5 \mathrm{sec}$ & $3.4 \%$ \\
\hline p-Value & 0.51 & 0.01 & 0.02 & 0.001 \\
\hline
\end{tabular}

$* \%$ of swallows that achieved complete bolus clearance

The operation was effective in the control of reflux. No patient developed new dysphagia after fundoplication. Three of Twelve patients who had dysphagia preoperatively, had persistent dysphagia post-operatively. All three had normal peristaltic activity by manometry, but 2 had abnormal esophageal clearance.Conclusion: Nissen fundoplication causes impairment of esophageal clearance. This impairment is usually subclinical, but can be measured objectively with MII. This information may prove important in developing strategies to minimize dysphagia. 
POSTMYOTOMY RECOLLECTION OF PREMYOTOMY SYMP. TOMS OF ACHALASIA IS VERY ACCURATE, SUPPORTING LONGITUDINAL STUDIES OF SYMPTOM IMPROVEMENT

Alexander S Rosemurgy BA, Desiree V Villadolid BA, Sam Al-Saadi BA, Justin Hedgecock, Sarah M Cowgill MD

University of South Florida, College of Medicine, Department of Surgery

Introduction: Recollection of preoperative symptom frequency and severity may change postoperatively, thus invalidating longitudinal studies. This study was undertaken to compare symptoms of achalasia before myotomy to postoperative recollection of premyotomy symptoms.

Methods: 288 patients, 55\% male, of median age 46 years, have undergone laparoscopic Heller myotomy and have been followed through a prospectively maintained registry. Preoperatively, patients scored the frequency and severity of their symptoms utilizing a Likert scale: 0 (never/not severe) to 10 (always/severe). After laparoscopic Heller myotomy, patients scored the frequency and severity of their symptoms, and rescored their preoperative symptoms. Data are presented as median, mean $\pm \mathrm{SD}$

Results: Before myotomy, dysphagia, regurgitation, choking, chest pain, vomiting, and heartburn were particularly notable; symptom scores nearly globally improved after myotomy $(\mathrm{p}<0.05$ for all, Wilcoxon matched pairs test), especially obstructive symptoms. Postmyotomy recollection of premyotomy symptom frequency and severity was not substantively different from before myotomy, with few exceptions (Table).

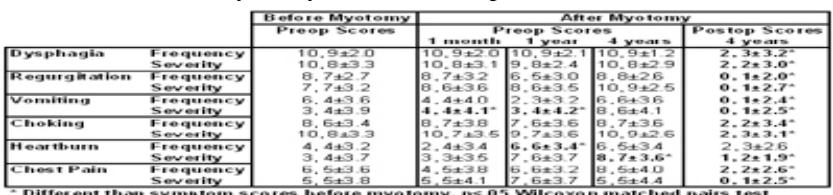

Conclusions: Before myotomy, patient symptom scores reflected the deleterious impact of achalasia. After myotomy, patient symptom scores dramatically improved, reflecting the favorable impact of laparoscopic Heller myotomy. Even years after myotomy, patient recollection of premyotomy symptom severity and frequency are very accurate and support longitudinal studies of symptom improvement after myotomy.

\section{LAPAROSCOPIC VERSUS OPEN TRANSHIATAL RESECTION FOR MALIGNANCIES OF THE DISTAL ESOPHAGUS: A COM- PARISON OF TWO COHORTS}

J.J.G Scheepers MD, D vd Peet PhD, C Sietses PhD, M.A. Cuesta PhD

Department of Surgery Vrije Universiteit Medical Center (VUMC)

Introduction: Resection of the esophagus remains the only curative therapy for esophageal cancer. Conventional resections are right sided thoracotomy in combination with laparotomy, and the transhiatal approach according to Orringer. An alternative approach is laparoscopic transhiatal resection, which combines perfect visualization of the esophagus during mediastinal dissection with the known advantages of laparoscopy.

This study evaluates the outcome of two groups of patients treated for distal esophageal cancer by means of a laparoscopic or open transhiatal esophagus resection.

Patients and methods: 50 laparoscopic transhiatal esophageal resections (between 2001-2004) were compared with a historical control group of 50 open transhiatal resections (between 1997-2001)

Results: Operating time was not significantly longer in the laparoscopic group (300 vs 280 minutes), but laparoscopic esophageal resection was associated with less blood loss $680 \mathrm{vs} 1125 \mathrm{ml}(\mathrm{p}<0.05)$, shorter ICU stay 1,4 vs 4,3 days $(\mathrm{p}<0.05)$, and shorter hospital stay 14 vs 18 days $(\mathrm{p}<0.05)$ There were no differences in pathological staging, morbidity and mortality. The Kaplan Meier analysis of laparoscopic vs open resection at 5 years shows an overall survival of $24 \%$ vs $26 \%$ ( $\mathrm{p}=\mathrm{NS}$ ) with the same disease free survival at 5 years $(\mathrm{p}=\mathrm{NS})$. In the laparoscopic group, conversion to an open procedure was necessary in 10 patients $(20 \%)$.

Conclusion: Laparoscopic transhiatal esophagus resection is a safe procedure with important advantages to the open procedure such as less blood loss and shorter ICU stay. Moreover there are no differences in overall and disease free survival between both groups.

\section{SELF EXPANDING ENDOLUMINAL STENTS ARE EFFECTIVE IN THE TREATMENT OF COMPLICATIONS AFTER UPPER GI SURGERY}

Michael R St Jean MD, Stephanie Dunkle-Blatter MD, Fahad Ali Syed MD, Anthony T Petrick MD

Section of Minimally Invasive and Bariatric Surgery, Geisinger Medical Center, Danville, PA

Background: Self expanding endoluminal stents (SEES) have expanded options for management of surgical complications after upper gastrointestinal (UGI) surgery. The objective of this study was to review our initial experience with SEES \& to define the risks \& benefits associated with SEES placement after UGI surgery. Methods: All patients undergoing SEES after esophageal or gastric surgery from Sept. 2001 to Sept. 2005 were retrospectively reviewed. Data was stored in a password protected database for patient information was collected by review of an electronic medical record (EPIC Systems). Statistical method: Fisher's Exact Test. Results: 20 pts $(15 \mathrm{M} \& 5 \mathrm{~F})$ with a mean age of $62 \mathrm{yrs}$ [range, 43-85] underwent a total of 40 procedures [range, 1-6/pt]. A total of 37 stents were deployed (ave1.85/pt, range $0-10$ ) with a stent migration rate of $50 \%$ including two complete migration of a stent through the GI tract $\mathrm{s} / \mathrm{p}$ RYGBP. Stent migration led to restenting in 4 pts $(20 \%)$ while the total \# of restenting procedures required was $12(30 \%)$ in 9 pts(45\%). Reasons for initial stenting procedures included benign stricture $\mathrm{n}-4(20 \%)$, malignant strictures n-8(40\%), anastomotic leak n-7(35\%) \& fistula n-1(5\%). UGI tract procedures prior to stenting:Esophageal resection n-7(35\%); Esophageal Ca nonoperative $\mathrm{n}-3(15 \%)$; PEH repair $\mathrm{n}=2(10 \%)$; Lap Nissen $\mathrm{n}=1(5 \%)$; RYGBP n-3(15\%); MI esophagectomy n-4(20\%). 7 pts with leaks \& 1 fistula were treated w/stenting $(40 \%)$. Median durations to radiographic or endoscopic evidence of resolution of leak or fistula was 9.5 days (range233) with return to po diet median 8.5 days(range 1-40).Patients managed conventionally had median resolution in 12.5 days(range3-60) and resumed po intake in median 11days(range3-60). SEPS were more prone to migration than SEMS $62.5 \%$ vs $17.2 \%(\mathrm{p}=.02)$. No pts experienced procedure related morbidity or mortality. Conclusions: SEES seem to be an effective means of treating postoperative complications in the upper GI tract \& may avert reoperation in selected pts. Pts with stents resolved leaks \& fistulas more quickly than similar pts managed with observation \& drainage. The time to oral feeding was also improved in the stented pts. There was no mortality \& morbidity related to repeat procedures due to stent migration. The rate of migration of the SEPS in our series was much higher than previously reported in the literature.

\section{DEFINING FAILURE AND ITS OUTCOMES AFTER HELLER MYOTOMY FOR THE MANAGEMENT OF ACHALASIA}

Alessandro Stival MD, D. Lee Howell MD, Vickie Swafford RN, John G Hunter MD, C. Daniel Smith MD

Emory Endosurgery Unit, Emory University School of Medicine, Atlanta, GA 30322

OBJECTIVES: Heller myotomy for the management of Achalasia has realized considerable success in $90-95 \%$ of patients. However, little is written about the failures, including long-term outcomes. Herein we report our experience with 209 patients undergoing laparoscopic Heller myotomy specifically focusing on failures.

METHODS: Data on all patients undergoing foregut surgery are collected prospectively. Between 1994 and 2004, 209 patients underwent Heller myotomy for Achalasia, with nearly all also receiving a fundoplication $(99.5 \%)$. A management algorithm and standardized operative technique was followed by the two surgeons caring for the majority of these patients. Average follow-up was 21 months (1 to 91). Symptom questionnaires were used at different intervals during follow-up. Failure was defined as persistence or recurrence of severe symptoms, need for endoscopic intervention(s), repeat Heller myotomy or esophagectomy. In these 209 patients there were 26 failures $(12 \%)$.

RESULTS: Among the 26 failures, all had a concurrent fundoplication: $76 \%$ Toupet, $20 \%$ Dor, and $4 \%$ a modified Dor. None experienced an intraoperative complication during initial procedure (i.e., perforation). Nineteen patients $(73 \%)$ had undergone a preoperative endoscopic intervention (pneumatic dilation and/or botox injection) compared to only 7 $(27 \%)$ of those without failure $(\mathrm{p}<0.05)$. Six patients $(23 \%)$ had undergone a prior foregut operation compared with only $2.7 \%$ among the nonfailure patients $(\mathrm{p}<0.05)$. Moderate to severe dysphagia was the main complaint for $92.3 \%$ of these patients, followed for regurgitation $(50 \%)$, and heartburn (38.5\%). Their control included expectant management and reassurance in $12(46 \%)$, endoscopic dilation in $7(27 \%)$, redo Heller myotomy in $3(12 \%)$ and esophagectomy in $4(15 \%)$.

CONCLUSION: Treatment of Achalasia with Heller myotomy is successful in the vast majority of patients. Among those who fail, prior endoscopic treatment and mismanagement with prior fundoplication is more common. Over of those who fail will require some intervention for management. Prior to Heller myotomy patients should be specifically counseled about the consequences of failure, including the possibility of esophagectomy. 


\section{LAPAROSCOPIC GASTRIC ELECTRICAL STIMULATION FOR} GASTROPARESIS

F J Brody, MBA MD, E Nsien MD, A Ali MD, Eliz Drenon, BS MPH,

Khashayar Vaziri MD

The George Washington University Medical Center

Introduction: Currently, the pathophysiologic mechanisms of gastroparesis are poorly understood. This study characterizes a cohort of diabetic and idiopathic gastroparetic patients before and after implantation of a gastric electrical stimulation (GES) for gastroparesis.

Methods: Twenty-three gastroparetic patients (10 diabetic and 13 idiopathic) were implanted with the GES device. Gastroparesis was assessed using pre- and post-operative esophageal manometry, 48 hour Bravo, and 4 hour gastric emptying test (GET) studies. Frequency and severity of gastrointestinal (GI) symptoms were evaluated using the GI Symptoms Score and were measured pre- and post-operatively at 6 months.

Following laparoscopic implantation, mean severity scores were reduced significantly at 6 -months-post op (t-value $2.365 ; 95 \%$ confidence; alpha< $0.05 ; 7 \mathrm{df} ; 0.02<\mathrm{P}<0.05)$ ). A similar decrease in mean frequency scores was found also (t-value $2.365 ; 95 \%$ confidence; alpha $<0.05 ; 7 \mathrm{df}$; $0.02<\mathrm{P}<0.05$ ). Pre-operatively all patients showed an abnormal GET. Mean pre-operative GET at 2 and 4 hrs were $65 \%$ ( $\pm 4 \%$ SEM) and $34 \%$ $( \pm 5 \%$ SEM), respectively. Post-operative GET at 2 and $4 \mathrm{hrs}$ were $45 \%$ $( \pm 3 \%$ SEM) and $13 \%$ ( $\pm 3 \%$ SEM $)$, respectively. Although decreased, the post-operative values were not significant. Pre-operatively, abnorma esophageal manometric findings were present in $50 \%$ of patients. Postoperatively, esophageal function improved in the majority of patients. Pre-operative Bravo studies documented GERD in 57\% of the patients based on DeMeester scores and \% time $<\mathrm{pH} 4$. Pre-operatively, the mean DeMeester score measured $25.64 \pm 6.45$. Post-operatively, DeMeester scores and \% time $<\mathrm{pH} 4$ were improved in $50 \%$ of the cohort. However, this decrease was not significant.

Conclusions: This limited, but unique, set of clinically relevant data describes the high degree of physiologic abnormalities apparent in idiopathic and diabetic gastroparetic patients. These findings may help unravel the complexities of this disease and further delineate the mechanisms of electrical stimulation for not only gastroparesis but obesity as well.
LONG-TERM OUTCOMES CONFIRM THE SUPERIOR EFFICACY OF EXTENDED HELLER MYOTOMY FOR ACHALASIA

Andrew S Wright MD, Chase W Williams BS, Carlos A Pellegrini MD, Brant K Oelschlager MD

University of Washington Department of Surgery

Standard Heller myotomy (SM) for achalasia extends $1-2 \mathrm{~cm}$ onto the stomach. We proposed the use of an extended $(>3 \mathrm{~cm})$ myotomy $(\mathrm{EM})$ and in 2003 reported better relief of dysphagia than with SM at 16 months. This study is designed to examine the long-term efficacy and durability of EM

Methods: Patients with achalasia who had a laparoscopic Heller myotomy between 1994 and 2003 were identified from a prospective database that includes symptom questionnaires and esophageal physiology studies. From 9/94 to $8 / 98$ we performed a SM with Dor fundoplication $(n=55)$, and from 9/98 through 2003 we performed an EM with Toupet $(n=102)$. In 2001 we performed a telephone survey of all available patients. This was repeated in 2005 for those with EM. The survey included scales of symptom frequency $(0=$ never, $1=1 \mathrm{x} /$ month, $2=1 \mathrm{x} /$ week, $3=1 \mathrm{x} /$ day, $4=>1 \mathrm{x} /$ day $)$ and severity $(0-$ $10,0=$ no symptoms, $10=$ symptoms equivalent to before surgery) as well as need for post-operative intervention for dysphagia

Results: We were able to contact 35 patients following SM (46mo median $\mathrm{F} / \mathrm{U}$ ) and 67 patients following EM (46mo median F/U). Patient demographics were similar between groups. Post-op results are shown in the Table.

\begin{tabular}{|c|c|c|c|c|c|}
\hline & $\begin{array}{c}\text { Dysphagiala } \\
\text { Severity }\end{array}$ & LESP & $\begin{array}{c}\# \\
\text { Interventions } \\
\end{array}$ & $\begin{array}{l}\text { Heartburm } \\
\text { Frequency }\end{array}$ & YpH $\mathrm{F}<4$ \\
\hline SM & $4.6 \pm 2.3$ & $17 \pm 8.6$ & 18 & $1.5 \pm 1.6$ & $4.9 \pm 7.5$ \\
\hline EM & $3.1 \pm 2.6^{\star}$ & $10.9 \pm 5.7 \dagger$ & $4 \uparrow$ & $1.2 \pm 0.9$ & $7.2 \pm 6.3$ \\
\hline
\end{tabular}

Of the SM group 9 patients (26\%) required a total of 14 endoscopic interventions and 4 re-operations while 4 EM patients $(6 \%)$ required one endoscopic intervention each. Of the EM group, 31 were contacted in both 2001 (16mo median $\mathrm{F} / \mathrm{U}$ ) and 2005 (64mo median $\mathrm{F} / \mathrm{U})$. There was no significant change over time in dysphagia severity $(2.5 \& \# \mathrm{xB} 1 ; 1.8$ vs. $2.9 \& \# \mathrm{xB} 1 ; 2.3$, $\mathrm{p}=0.4$ ). Conclusions: Extended gastric myotomy provides excellent durable relief of dysphagia, and is superior to a standard myotomy for the treatment of achalasia.

\section{FLEXIBLE DIAGNOSTIC \& THERAPEUTIC ENDOSCOPY}

\section{TRANSNASAL SMALL-CALIBER ESOPHAGOGASTRODUO- DENOSCOPY FOR PREOPERATIVE EVALUATION IN THE HIGH-RISK MORBIDLY OBESE PATIENT}

Ramzi S Alami MD, Rob Schuster MD, S Friedland MD, Myriam J Curet MD, Sherry M Wren MD, R Soetikno MD, John M Morton MD, Bassem Y Safadi MD

Departments of Surgery/Gastroenterology, Palo Alto Veterans Health Care System and Stanford University School of Medicine

Introduction: Esophagogastroduodenoscopy (EGD) is an important facet of the preoperative evaluation for bariatric surgery. Morbidly obese patients are at high-risk for airway complications during this procedure and an attractive alternative is transnasal EGD. We report a successful series of patients evaluated using this technique.

Methods: All patients undergoing preoperative transnasal small-caliber (5mm and 5.9mm) EGD for morbid obesity surgery between Sept. 2004 and June 2005 at a Tertiary Veterans Affairs Hospital were included in the analysis. The variables assessed were the adequacy of the exam, patient tolerance, need for sedation and the ability to perform interventions.

Results: There were 25 patients included in the study. All patients met the 1991 NIH Consensus Conference Criteria for bariatric surgery and were undergoing pre-operative evaluation. There were 25 patients (17male/8female) with an average age of 55years, (range 44-63), and average BMI of 47, (range 38-69). The most common co-morbidities included hypertension $(82 \%)$, diabetes mellitus $(80 \%)$ and obstructive sleep apnea $(68 \%)$. All 25 patients had successful cannulation of the second portion of the duodenum with excellent patient tolerance. There were no sedation requirements in $23 / 25$ patients $(92 \%)$. Significant pathology was found in 14/25 patients (56\%) and consisted of hiatal hernia (28\%), gastritis (16\%), esophageal intestinal metaplasia (16\%), esophagitis $(12 \%)$, gastric polyps $(8 \%)$, gastric ulcer $(4 \%)$ and esophageal varices $(4 \%)$. Biopsies were indicated in 12 patients and successful in all $12(100 \%)$.

Conclusion: Transnasal small-caliber EGD is a feasible and safe alternative to conventional EGD in the preoperative evaluation of patients undergoing bariatric surgery. It requires minimal to no sedation in a population at high-risk of complications in this setting. In addition, this technique is effective in identifying pathology that requires pre-operative treatment and offers a complete exam with biopsy capabilities. This technique should be considered in all morbidly obese patients at high risk for airway compromise during EGD.

\section{THE UTILITY OF THE MAGNETIC ENDOSCOPE POSITION DETECTING UNIT AS A VISUAL AID AND MEANS OF POLYP LOCALIZATION}

T V Azarani BS, T D Arnell MD, D L Feingold MD, K A Forde MD, E Balik MD, N Sakellarios, C Bailey, D D Markowitz, R Rosenberg, O Lebwohl, R J Garcia-Carrasquillo, H Frucht, R L Whelan MD, New York Presbyterian Hospital-Columbia Campus, New York, NY, USA Introduction: The endoscope position detecting unit (EPDU) utilizes magnetic imaging and a specialized colonoscope to give a 3 dimensional view of the position of the colonoscope during colonoscopy. The objective of this study was to determine if the EPDU provides an accurate visual portrayal of the position of the colonoscope within the colon, thereby acting as a visual aid for the endoscopist in determining polyp location. Materials and Methods: The EPDU was used during colonoscopies by 9 experienced endoscopists over a period of 21 months. An external locating probe connected to the main unit was used to localize polyps by position of the scope tip against the abdominal wall and visualizing the probe location compared with the localized positions of the hepatic and splenic flexures. True polyp location was verified both surgically and in cecal polyps in which the ileocecal valve or terminal ileum were clearly visualized. Results: There were 348 patients who underwent colonoscopy with the EPDU. Patients having undergone colon resections were excluded (41) for a total of 307 study patients. A total of 235 polyps were located using the EPDU in 85 patients. There was one polyp in 55 patients (64.7\%), 2 polyps in $16(18.8 \%)$, and 3 or more polyps in 14 patients (16.5\% range $3-9)$. The location of 35 were confirmed at the time of operation (12) or based on location within the right colon (23). There was $100 \%$ accuracy for the twelve polyps in 11 patients verified at the time of operation. Of those polyps confirmed via operation, 4 were hepatic flexure $(30.8 \%)$, 4 sigmoid $(30.8 \%), 1$ rectosigmoid $(7.7 \%), 1$ descending colon $(7.7 \%), 1$ cecal $(7.7 \%)$, and 1 distal transverse colon $(7.7 \%)$. Two polyps, one in the sigmoid and the other in the descending colon were located with the EPDU and verified within the same patient at operation. Discussion: The EPDU accurately located all 12 polyps in patients undergoing operation. Additionally, the shape of the EPDU colonoscope was accurate in confirming the cecal and ascending location of polyps confirmed by anatomical markers (terminal ileum and ileocecal valve). The EPDU is a safe and efficient way to locate lesions within the colon during colonoscopy. 
EFFICACY OF PERCUTANEOUS TREATMENT OF BILIARY TRACT CALCULI USING THE HOLMIUM-YAG LASER J W Hazey MD, M McCreary BA, G Guy MD, W S Melvin MD The Ohio State University Medical Center

Introduction: Few western studies have focused on percutaneous techniques utilizing percutaneous transhepatic choledochoscopy (PTHC) and the Holmium-YAG laser (HYl) to ablate complex biliary calculi in patients unable or unwilling to undergo surgical or endoscopic removal We report the efficacy of the HYl in clearing complex biliary calculi using percutaneous access techniques.

Methods and Procedures: We retrospectively reviewed thirteen non-asian patients with complex secondary biliary calculi treated percutaneously with the HYl. Percutaneous access was accomplished via the left, right or bilateral hepatic ducts and upsized to allow for passage of a 7 Fr video choledochoscope. Lithotripsy was performed via choledochoscopic vision using a HYl with 200 and 365 micron fibers generating 0.6 to 1.0 joules of energy at frequencies of 8 to $15 \mathrm{~Hz}$. Patients underwent treatment until stone clearance was confirmed by PTHC. Downsizing and subsequent removal of percutaneous catheters completed the treatment course.

Results: Seven male and six female patients underwent treatment with an average age of 69 . All thirteen patients had their biliary tract stones cleared successfully. Eight of the thirteen patients were treated as outpatients. Average length of percutaneous access was 108 days. One patient continues to have a catheter in place. The average number of HYl treatments required for clearance was 1.6 with no patients requiring more than three treatments. Eight of thirteen patients underwent a single HYl treatment to clear their calculi. Five patients underwent percutaneous access and subsequent removal as their sole therapy for biliary stones. Seven of thirteen patients underwent prior unsuccessful attempts at endoscopic removal. Five patients were cleared of their calculi after percutaneous laser ablation of large stones and percutaneous basket retrieval of remaining stone fragments. There was one complication of pain requiring admission and no deaths.

Conclusions: PTHC with subsequent HYl ablation is safe and efficacious but requires prolonged access to the biliary tree and often multiple procedures to ensure clearance of all calculi.

\section{ENDOSCOPIC ULTRASOUND (EUS) IN THE EVALUATION OF NISSEN FUNDOPLICATION INTEGRITY: A BLINDED COM- PARISON WITH CONVENTIONAL TESTING}

Charles Y Kim MD, Eugene Y Chang MD, Ann K Seltman MD, Brian Diggs PhD, John G Hunter MD, Raquel Davila MD, Blair A Jobe MD, Portland VA Medical Center; Oregon Health \& Science University Introduction: In patients who develop symptoms after Nissen fundoplication (NF), the precise mechanism of anatomic failure can be difficult to determine. In swine, we have previously reported the endosonographic hallmarks defining an intact NF and the known causes for failure. This clinical trial tests the hypothesis that a defined set of endosonographic criteria can be applied to determine fundoplication integrity in humans.

Methods: 16 subjects were enrolled at a mean of 6 yrs post-NF (range 1$30 \mathrm{yrs}$ ). A GERD-specific questionnaire and medication history were completed. Prior to EUS, all patients underwent complete conventional testing (EGD, esophagram, manometry, 24-hour $\mathrm{pH}$ ). A diagnosis was rendered based on combined test results and for EGD alone. EUS was then performed by an observer blinded to symptoms, medication use, and conventional test diagnoses. EUS diagnosis was rendered based on the previously established swine criteria. Because EUS is uniformly performed in combination with EGD, the diagnoses were compared so as to examine the added contribution of EUS in this context.

Results: The technique and criteria defined in the swine model were easily applied to all subjects. All symptomatic patients had heartburn and were taking proton pump inhibitors (PPI). No asymptomatic patients were taking PPI. In symptomatic patients, EUS discovered 5 additional diagnoses compared to EGD alone, and 6 additional diagnoses when compared to combined conventional test diagnoses (Table). In asymptomatic subjects, EUS identified 2 diagnoses which were determined to be normal using conventional testing modalities

\begin{tabular}{|c|c|c|c|c|c|c|}
\hline & \multicolumn{3}{|c|}{ Symptomatic $(n=7)$} & \multicolumn{3}{|c|}{ Asymptomatic $(\mathbf{n}=9)$} \\
\hline Finding & EGD & $\begin{array}{l}\text { EGD } \\
+ \text { EUS }\end{array}$ & $\begin{array}{l}\text { Conventional } \\
\text { testing }\end{array}$ & EGD & $\begin{array}{l}\text { EGD } \\
+ \text { +EUS }\end{array}$ & $\begin{array}{c}\text { Conventional } \\
\text { testing }\end{array}$ \\
\hline Slipped & 0 & 2 & 0 & 0 & 1 & 0 \\
\hline Herniation & 5 & 6 & 5 & 1 & 1 & 1 \\
\hline Dehiscence & 2 & 4 & 2 & 0 & 1 & 0 \\
\hline Loose & 0 & 0 & 1 & 0 & 0 & 0 \\
\hline Normal & 0 & 0 & 0 & 8 & 6 & 8 \\
\hline
\end{tabular}

Conclusions: EUS examination of hiatal anatomic relationships is feasible. Combined EUS and EGD is a more sensitive alternative to the conventional set of tests in patients who present with symptoms after NF.

\section{SURVEILLANCE COLONOSCOPY IN POST-POLYPECTOMY} PATIENTS - WHY WE DO IT

Ruth O'Mahony MD, Mark A Liberman MD

Cleveland Clinic Florida - Naples

OBJECTIVE: To determine polyp recurrence rates among different pathologic subtypes in patients who have previously undergone colonoscopic polypectomy.

METHODS: Retrospective review of an existing database with additional data obtained from patients? medical records and pathology reports.

RESULTS: A total of 4779 patients underwent screening colonoscopy at Cleveland Clinic Florida-Naples from 1999-2001. 785 patients had polyps. Of these, 342 presented for follow-up within 48 months (mean time to follow-up 42 months). 227 patients had further pathology found on follow-up. Eight had malignancies detected on their first colonoscopy. Of these, three were confined to a polyp and completely resected endoscopically without recurrence during the follow-up period. The remaining five patients required surgical resection. Six new cancers were detected in the follow-up group. One of these patients previously had a hyperplastic polyp, the other five previously had adenomatous polyps. Three of these cancers were managed endoscopically while three required surgical resection. Overall rates of polyp recurrence were similar regardless of initial pathologic type. $67 \%$ of patients with hyperplastic or adenomatous polyps had recurrence. Patients with initially hyperplastic polyps were most likely to have further hyperplastic polyps (75\% of recurrences). Patients with adenomatous or dysplastic polyps were most likely to recur with adenomas $(52 \%$ and $67 \%$ of recurrences respectively).

CONCLUSIONS: The high likelihood of polyp recurrence emphasizes the importance of compliance with post-polypectomy surveillance. Our lower than expected incidence of colorectal cancer is likely due to aggressive follow-up and early intervention, further underscoring the need for surveillance. Patients with hyperplastic polyps are most likely to have recurrent hyperplasia and hence do not require surveillance as frequently. Patients with adenomatous or dysplastic polyps are more likely to have recurrent adenomas or dysplasia and therefore require more careful surveillance.

\section{NATURAL ORIFICE TRANSVISCERAL ENDOSCOPIC SURGERY(NOTES) AS A DIAGNOSTIC TOOL IN THE INTEN. SIVE CARE UNIT (ICU)}

Raymond Onders MD, Jeffrey Marks MD, Michael Rosen MD, Michael McGee MD, Amitabh Chak MD, Ashley Faulx MD, Anthony Ignagni MS, Steve Schomisch BS, Jeffrrey Ponsky MD

University Hospitals of Cleveland and CASE School of Medicine

Background: Autopsy studies confirm that many ICU patients die from unrecognized sources of abdominal sepsis or ischemia. CT scans can be of limited utility for these diagnoses and difficult to obtain in critically ill patients who require significant support for transport. Bedside laparoscopy has been described but still is cumbersome to perform. Bedside flexible endoscopy as a diagnostic tool or for placement of gastrostomy tubes is a standard ICU procedure. Natural orifice transvisceral endoscopic surgery (NOTES) can provide access to the peritoneal cavity as a bedside procedure and decrease the number of patients with unrecognized intra-abdominal catastrophic events.

Methods: Pigs were anesthetized and standard endoscopy was performed. Using a Seldinger technique a guidewire was placed into the gastric lumen at a standard site for a PEG and brought out through the mouth. The guidewire was maintained as an access point through the mouth, stomach, peritoneal cavity and skin throughout the procedure. Different methods of accessing the peritoneal cavity through the gastric wall were then attempted. The trans-gastric endoscope was used to explore all quadrants of the abdominal cavity. The small bowel was run to complete the exploration. The trans-gastric access location was then managed with the use of a gastrostomy tube. The animals were euthanized and analyzed.

Results: Eight pigs were studied and complete abdominal exploration including diaphragm visualization was possible in all cases. Endoscopic guided biopsies were performed, adhesions lysed, and the gallbladder was successfully drained percutaneously. The small bowel was run successfully with percutaneous needlescopic suture graspers. A needle knife cautery along the guidewire and subsequent balloon dilation was determined to be the most consistent way to access the peritoneal cavity.

Conclusions: These animal studies support the concept that NOTES with management of the gastric opening with a gastrostomy tube may be another approach for finding unrecognized sources of abdominal sepsis or mesenteric ischemia in difficult ICU patients. These encouraging results warrant a prospective human trial to assess safety and efficacy. 


\section{THE USE OF URINARY TRYPSINOGEN-2 DIP STICK TEST IN} EARLY DIAGNOSIS OF POST-ERCP PANCREATITIS

Senthil Sankaralingam MD, Cheryl Wesen MD, Mohammad Barawi MD, Rigel Galera MD, Larry Lloyd MD

St. John Hospital and Medical center, Detroit, MI

Introduction: The reported incidence of post Endoscopic Retrograde Cholangio Pancreaticography (ERCP) pancreatitis varies between 1.3' $24.4 \%$. Trypsinogen-1 and trypsinogen-2 (tryp'2) have been studied in Europe as markers for acute pancreatitis. The kidneys appear to excrete tryp'2 as evidenced by steep rise in urinary tryp' 2 in acute pancreatitis. We hypothesized that tryp' 2 should be able to detect acute pancreatitis in post ERCP patients.

Methods \& Materials: This is a prospective, blinded study of patients who had ERCP performed at our institution. IRB approval was obtained prior to this study. Urine samples were collected pre ERCP, 1 hour post ERCP and $4 \mathrm{hr}$ post ERCP, and evaluated using the urine dipstick (Actim Pancreatitis Medix Biomedica OY AB, Finland TM) to detect tryp'2. After the patient had been evaluated and treated in the standard fashion, the dipstick results were compared with the results of serum pancreatic enzymes, and clinical findings by reviewing the chart. We used Fisher's exact test to evaluate success of urine dipstick results in predicting pancreatitis. The sensitivity, specificity, positive and negative predictive values were calculated. All values are reported as mean \pm SEM.

Results: Urinary tryp' 2 was evaluated in 30 patients. Fifteen men and 15 women participated in our study with age ranging from 18 - 86 yrs (mean $=55)$. Five out of $29(17 \%)$ patients were diagnosed with post-ERCP pancreatitis. The amylase and lipase level for post ERCP patients with and without pancreatitis were $650 \pm 145$ vs $134 \pm 26(\mathrm{P}=0.023)$ and $1658 \pm$ 594 vs $84 \pm 17(\mathrm{P}=0.057)$ respectively. Six out of 28 patients tested positive in 1 hour and 5/29 patients tested positive in 4 hours. The one hour test post ERCP in one patient, who later developed pancreatitis, could not be done because he had difficulty urinating. The sensitivity of 1 hour test was $91 \%$ and specificity was $100 \%$. The positive predictive value was $100 \%$ and negative predictive value was $66.6 \%$. The sensitivity of 4 hour test was $95 \%$ and specificity was $100 \%$. The positive predictive value was $100 \%$ and negative predictive value was $83.3 \%$.

Conclusion: The urinary tryp'2 Dip Stick Test is useful in early diagnosis of post ERCP pancreatitis. It allows physicians to begin management early in the course and has several potential benefits including avoidance of blood draws, reduced cost and early discharge of patients with negative test.

HYBRID MINIMALLY INVASIVE SURGERY - A BRIDGE BETWEEN LAPAROSCOPIC AND TRANSLUMENAL SURGERY

Samuel P Shih MD, Ozanan R Meireles MD, Sergey V Kantsevoy MD, Eric J Hanly MD, Anthony N Kalloo MD, Sanjay B Jagannath MD, Donna M Beitler RN, Michael R Marohn DO

The Johns Hopkins University School of Medicine

Introduction: Peroral translumenal approach to the peritoneal cavity appears safe, feasible, and may further reduce the invasiveness of surgery. However, flexible endoscopes and current endoscopic devices have multiple limitations which include the lack of a stable platform, restrictions on retraction and spatial incongruity. These limtations inside the peritoneal cavity can potentially be overcome by blending the use of both a laparoscope and a flexible upper endoscope - a hybrid approach

Aim: To develop a hybrid minimally invasive technique for cholecystectomy in a porcine model.

Methods: Hybrid cholecystectomies were performed on 50kg pigs in acute experiments under general anesthesia. A modified PEG technique was used to access the peritoneal cavity through the anterior gastric wall. Upper endoscope was advanced into the peritoneal cavity to provide visualization for placement of a $10 \mathrm{~mm}$ port. Further insufflation was maintained through this port. Visualization was augmented with a laparoscope. The cystic duct was identified, dissected, clipped and transected by the endoscope using a laparoscopic grasper for traction. The gallbladder was retracted into the stomach and the stomach closed with clips.

Results: Five hybrid cholecystectomies were performed without complications. The laparoscopic port enabled a stable pneumoperitoneum, improved spatial orientation and visualization, and provided good traction and counter-traction. Postmortem examination revealed secure clip placement.

Conclusion: The hybrid approach facilitates peroral cholecystectomy and should be an initial step to the development of transgastric endoscopic procedures.
ENDOSCOPIC ABLATION OF INTESTINAL METAPLASIA WITH HIGH GRADE DYSPLASIA (IM-HGD) IN ESOPHAGECTOMY PATIENTS USING A BALLOON-BASED ABLATION SYSTEM

C. Daniel Smith MD, Pablo Bejarano MD, Raman Muthusamy MD, Marco Patti MD, W. Scott Melvin MD, Brian J Dunkin MD

Emory University, Atlanta, GA, University of Miami, Miami, FL, Univ. of California, San Francisco, CA, Ohio State University, Columbus, Ohio Objective: To determine the optimal treatment parameters for the ablation of IM-HGD using a balloon-based ablation system (HALO360, BRRX Medical, Inc.).

Methods: Immediately prior to esophagectomy, subjects underwent endoluminal ablation of 1 or 2 circumferential $3 \mathrm{~cm}$ segments of the esophagus containing IM-HGD using the HALO360 System. Treatment settings were randomized to 10,12 , or $14 \mathrm{~J} / \mathrm{cm} 2$ and 2 to 6 applications. Following esophagectomy multiple sections from each ablation zone were evaluated using H\&E staining and microscopy.

Results: Eight male patients were treated and 11 treatment zones analyzed. There were no device-related adverse events. At resection, there was no evidence of periesophageal or transmural thermal injury. Gross examination of the ablation zones showed clearly demarcated sections of coagulated, sloughing epithelium. Maximum ablation depth was to the lamina propria or muscularis mucosae (MM) in 10/11 specimens. One section treated at the highest energy $(14 \mathrm{~J} / \mathrm{cm} 2,4 \mathrm{x})$ had edema in the submucosa. In the well overlapped areas of treatment $91 \%$ (10/11) of specimens had no evidence of IM-HGD remaining. In one specimen the majority of IM-HGD was ablated, but small focal areas remained. In 3 specimens there was IM-HGD at the edge of the treatment zones where overlap of the multiple energy applications was incomplete. Nine specimens had "ghost cells" of IM-HGD that did not appear viable.

Conclusions: Complete ablation of IM-HGD, without deep injury is possible using this device. A dose related increase in treatment depth is seen as energy density and application number increases, but this is limited primarily to the MM. Small residual foci of IM-HGD at the edges of some ablation zones appears to be from failure to thoroughly overlap the multiple treatment applications. Clinically this is avoided by treating all visible IM-HGD rather than a selected zone. This study, along with non-esophagectomy clinical trials currently underway, will identify the optimal energy density setting and applications number for treating HGD in patients who otherwise would be subjected to PDT or surgical esophagectomy.

\section{COMPARISON OF COLONIC STENTING VERSUS OPEN} SURGERY FOR MALIGNANT LARGE BOWEL OBSTRUCTION Henry S Tilney MRCS, Richard E Lovegrove MRCS, Sanjay Purkayastha MRCS, Parvinder S Sains MRCS, Ara W Darzi MD, Paris P Tekkis MD, Alexander G Heriot MD, Department of Surgical Oncology and Technology, Imperial College London, UK

Objective: Colonic stents potentially offer effective palliation to those with bowel obstruction due to incurable malignancy, and a "bridge to surgery" for those in whom emergency surgery would necessitate a stoma. The present study compared the outcomes of stents and open surgery in the management of malignant large bowel obstruction.

Methods: A literature search of the Medline, Ovid, Embase and Cochrane databases was performed to identify comparative studies reporting outcomes on colonic stenting and surgery for large bowel obstruction. Random effects meta-analytical techniques were applied to identify differences in outcomes between the two groups. Sensitivity analysis of high quality studies, those reporting on more than 35 patients, those solely concerning colorectal cancer and studies performing intention to treat analysis was undertaken to evaluate the study heterogeneity.

Results: Ten studies satisfied the criteria for inclusion, reporting outcomes on 451 patients. Stent insertion was attempted in 244 (54.1\%), and successful in $226(92.6 \%)$. Length of stay was shorter by 7.72 days in the stent group $(\mathrm{p}<0.001)$, who also had lower mortality $(\mathrm{p}=0.03)$ and medical complications $(\mathrm{p}<0.001)$. Stoma formation at any point during management was significantly lower than in the stent group (OR 0.02, $\mathrm{p}<0.001$ ), and ?bridging to surgery? did not adversely influence survival.

Conclusions: Colonic stenting offers effective palliation for malignant bowel obstruction with short lengths of stay and low stoma rates, but data on quality of life and economic evaluation is limited. There is no evidence of differences in long term survival between those who have stents followed by subsequent resection and those undergoing emergency bowel resections. 


\section{LONG-TERM FOLLOW-UP OF ENDOSCOPIC STENTING IN PATIENTS WITH CHRONIC PANCREATITIS SECONDARY TO PANCREAS DIVISUM}

Michael Vitale MD, Gary C Vitale MD, David S Vitale, John C Binford, Ben Hill

Center of Advanced Surgical Technologies, Department of Surgery, Universtiy of Louisville

Introduction: This study evaluated the efficacy of endoscopic stenting in patients with chronic pancreatitis due to pancreas divisum. Pancreas divisum is the most common congenital anatomic variant of pancreatic development and may lead to pancreatitis. Endoscopic stenting of the pancreatic duct through the minor papilla represents a nonsurgical treatment approach. Methods and Procedures: Between 1995 and 2005, 32 patients with chronic pancreatitis due to pancreas divisum were treated with endoscopic stenting of the pancreatic duct through the minor papilla or combined major and minor papilla. Each patient underwent an endoscopic retrograde cholangiopancreatography to confirm the diagnosis of pancreas divisum prior to the endoscopic stenting. Results: Twenty-four patients were followed up for an average period of 54 months. Eight patients were lost to long-term follow-up after successful endoscopic therapy and stent removal. 13 patients $(55 \%)$ were treated with endostents without requiring surgery and $11(45 \%)$ patients needed surgery after stenting. In the patients who improved after stenting, $10(77 \%)$ decreased their pain level average 8.8 pre-stenting to 4.2 post-stenting on a scale of 1 to $10.3(23 \%)$ patients remained the same. Pain medication intake reported by patients and statewide narcotic electronic data found $8(62 \%)$ patients with a decrease in pain medication intake, $3(23 \%)$ unchanged and $2(15 \%)$ with an increase in their pain medication intake. Nausea and vomiting improved in $10(77 \%)$ patients after stenting with $3(23 \%)$ patients reporting no improvement. Of the 13 patients, $11(85 \%)$ are symptom free after a 5 year follow-up and $2(15 \%)$ patients had recurrence after 24 months. 11 patients had surgery (pancreatectomy/Puestow/splanchnicectomy) an average of 25 months post-stenting. $10(91 \%)$ of these patients had good results with no recurrence after a mean follow-up of 37 months. No mortality was reported in this study. Conclusions: Endoscopic stenting of the pancreatic duct is a safe and effective first treatment for patients with pancreatitis secondary to pancreas divisum. Surgery, when performed for endoscopic stenting failure, is effective as an adjunctive treatment.

\section{HEPATOBILIARY/PANCREATIC SURGERY}

PERIOPERATIVE OUTCOME AFTER LAPAROSCOPIC RADIOFREQUENCY ABLATION OF LIVER TUMORS: AN ANALYSIS OF 521 ABLATIONS

Eren Berber MD, Adrian Dan MD, Allan E Siperstein MD, The Cleveland Clinic Foundation, Cleveland, Ohio

Objectives: Radiofrequency thermal ablation (RFA) is gaining increased acceptance for the treatment of unresectable primary and metastatic liver tumors. Undertstanding the morbidity and laboratory changes after RFA is important for operative indications and the perioperative management.

Methods and Procedures: We prospectively analyzed the 30-day morbidity and mortality of patients undergoing laparoscopic RFA for liver tumors in a 10 -year period. Laboratory studies included a complete blood count, electrolytes, liver function tests, prothrombin time/INR and tumor markers obtained preoperatively, on postoperative day (POD) 1, day 7 and at 3 months.

Results: A total of 521 ablations were performed in 428 patients. Three hundred and forty-six patients underwent a single ablation and 82 repeat ablations. The pathology was metastatic adenocarcinoma in $269(52 \%)$, hepatocellular cancer in $106(20 \%)$, metastatic neuroendocrine cancer in $77(15 \%)$, and other tumors in $69(13 \%)$. A total of 1636 lesions (mean 3.1 per patient, range 1-16) were ablated. The mean $+/-$ SD tumor size was $2.7+/-1.6 \mathrm{~cm}$ (range 0.3-11.5 cm). All cases were completed laparoscopically. The 30-day mortality was $0.4 \%(n=2)$ and morbidity $2.6 \%(n=14)$ including liver abscess in 3 patients, intra-abdominal hemorrhage in 2 patients, trocar injury in 2 patients and flank abscess, arrhythmia, pulmonary embolism, post-procedure pain requiring admission, angioedema urticaria, wound infection, and recurrent ascites in 1 patient each. The average length of stay was 1.0 day. Serum AST, ALT and bilirubin levels increased 14,10 and 2 folds, respectively, on POD 1 with return to baseline in 3 months. Serum alkaline phosphatase and GGT levels showed a $25 \%$ increase on POD 7 with return to baseline in 3 months. There were no significant changes in platelet counts or prothrombin times postoperatively Conclusions: To our knowledge, this is the largest series of patients with liver tumors treated with laparoscopic RFA. This study allows us to understand the expected morbidity of the procedure. Despite significant patient comorbidities, this procedure was tolerated with a low morbidity and mortality. Postoperative coagulopathy was not observed. Postoperative rise of liver function tests is expected and reflects the liver injury response to RFA. This information can be used to expand the patient population that may benefit from laparoscopic RFA.

\section{RESULTS OF LAPAROSCOPIC LIVER RESECTION. RETRO- SPECTIVE STUDY ABOUT 56 PATIENTS}

Ibrahim dagher PhD, H. Richa MD, A. Champault MD, J. Proske MD, A. Carloni MD, C. Smadja, D. Franco MD

Department of Surgery, Antoine Beclere Hospital, Paris, France

INTRODUCTION: Laparoscopic access is becoming an established technique for liver resection, but this advanced procedure is still limited to centers with considerable experience in both hepatic and laparoscopic surgery. Preliminary retrospective reports include essentially minor resections and show some advantage on postoperative recovery.

AIMS \& METHODS: We report our experience in laparoscopic liver resection. From 1998 to 2005, 56 laparoscopic liver resections were performed. The liver parenchyma was normal in 26 patients and pathological in 30.16 patients had cirrhosis. Tumors of $4.9 \mathrm{~cm}$ (ranging from 2 to 13) were located in all liver segments except segment I.

RESULTS: Liver resection was anatomical in 37 patients ( $>3$ segments: 15 patients, 2 segments: 15, one segment: 7) and atypical in 19 patients. Operative time was $251+/-113$ minutes. Laparotomy was required in 4 patients (7\%), 3 times for continuous diffuse bleeding and for anatomical difficulties in one patient. Significant gas embolism was observed and efficiently treated in one patient. Six patients $(11 \%)$ were transfused. Operative complications (conversion to laparotomy, bleeding and transfusion) were significantly more frequent during atypical resections. Post operative complications occurred in five patients (9\%): trocar site bleeding, cardiac failure, respiratory failure, one blood and one biliary collection. One patient died of a liver failure. The mean hospital stay was 5 days. No ascites and no transient liver failure occurred.

CONCLUSION: Laparoscopy is a feasible and safe access for liver resection. In our experience, operative difficulties are less common during anatomical resections including major hepatectomies. The postoperative morbidity rate is low and our results seem to be similar to laparotomy. 
LAPAROSCOPIC PANCREATIC RESECTION: A SINGLE INSTITUTION EXPERIENCE OF 31 CASES

David Hazzan MD, Edward H Chin MD, Daniel Labow MD, Michel Gagner MD, W-Barry Inabnet MD, L-Brian Katz MD, Demetrius Pertsemlidis MD, Mark Reiner MD, Barry Salky MD

Mount Sinai Medical Center, Division of Minimally Invasive Surgery

Background: The reported experience with laparoscopic pancreatic resections remains limited to case reports and series. As a result, substantive data on current indications and outcomes after laparoscopic pancreatectomies is lacking. Our study reviews the recent indications, complications, and outcomes after laparoscopic pancreatic resection.

Methods: A retrospective review was performed for all patients who underwent laparoscopic distal pancreatectomy or enucleation between November 1993 until September 2005 at the Mount Sinai Medical Center.

Results: 31 patients (11 men, 20 women) were identified. The mean age was 51 years (range 22 to 83 years). 2 cases (6.4\%) required open conversion and 2 cases $(6.4 \%)$ required conversion to a hand-assisted technique. The median operative time was 242 minutes (range 90-396 minutes), and median blood loss was $220 \mathrm{cc}$. Overall morbidity was $22 \%$, with no mortalities. Postoperative complications included three pancreatic leaks (9.6\%), one peri-pancreatic abscess $(3.2 \%)$, one prolonged ileus, one early small bowel obstruction and one case of superficial phlebitis. No patients required reoperation. The median length of stay was 5 days (range 1-26 days).

Conclusions: This study represents the largest reported single institution experience with laparoscopic pancreatic resection. The morbidity rate compares favorably with recently published open and laparoscopic series. Laparoscopic pancreatic surgery can be performed safely with all the potential benefits of minimally invasive surgery.

\section{LAPAROSCOPIC PYLORUS PRESERVING PANCREATICODU- DENAL RESECTION FOR PERIAMPULLARY MALIGNANCIES - AN OUTCOME OF 35 PATIENTS}

Chinnuswamy Palanivelu MD, Senthilnathan P, Senthilkumar R, Parthsarathy

R, Rajapandian S, Dept of Minimal Access Surgery and Surgical Gastroenterology, Gem Hospital, India

In this fast growing laparoscopic era more and more complex and challenging surgeries have been performed by laparoscopic method. The aim of this article is to emphasis the technical feasibility and safety of laparoscopic pylorus preserving pancreaticodudenal (LPPD) resections. Patient is positioned in the semilithotomy reverse Trendelenburg position. The initial assessment, staging and resectability of the lesion are performed with laparoscopic ultrasound and Doppler. After kocherisation, right gastroepiploic vein and artery are clipped, divided and the first part of duodenum is divided using endo GIA stapler, $1-2 \mathrm{~cm}$ distal to the pyloric. The CBD is divided $2 \mathrm{~cm}$ above the pancreatic border. Jejunum distal to the duodenojejunal flexure is divided using endo linear cutter. Neck of pancreas is divided using harmonic scalpel. All the lymphofatty tissue including the lymph nodes are dissected out skeletonising the vessels around the celiac plexus and IVC and are placed into an endobag which is removed through the extended umbilical port site. The camera port is extended and the specimen is removed. The edges of the duodenum is trimmed freshly and end to side anastomosis is performed, $30-40 \mathrm{~cm}$ distal to the divided end of the jejunum. After replacing the bowel inside the peritoneal cavity the wound is closed and camera trocar is reintroduced. Gastrointestinal continuity may be performed intracorporeally or by hand sewn technique. End of the CBD is trimmed and end to side choledochojejunostomy is performed with single layer interrupted 4-0 vicryl sutures. The pancreaticojejunal anastamosis is fashioned in an end to end fashion with polypropylene in single layer. We now prefer pancreatico gastric anastomosis in most of our patients. The total number of cases that we have performed is 35 (19 were male and 16 female). The age varied from 28 to 63 years. Mean age is 48.7 years. The indications were ampullary growth (23), carcinoma head of pancreas (7) lower CBD growth (3) and duodenal carcinoma (2). Mean duration of surgery was 6.4 hours $(400 \mathrm{mts})$. The average blood loss was $395 \mathrm{ml}$. The mean postoperative high dependency unit (HDU) stay was 3.2 days and the average hospital stay was 10.2 days. All the patients had excellent recovery except for one who had prolonged gastric stasis. Then were 2 pancreatic leaks and one biliary leak in one. LPPD is technically feasible in a centre where advanced laparoscopic procedures are routinely performed.

\section{OUTCOMES ANALYSIS OF LAPAROSCOPIC RESECTION OF} PANCREATIC NEOPLASMS

Richard A Pierce MD, William G Hawkins MD, Steven L Strasberg MD, David C Linehan MD, Valerie J Halpin MD, Christopher Eagon MD, Michael Brunt MD, Margaret M Frisella RN, Brent D Matthews MD, Department of Surgery, Washington University, St. Louis, Missouri Introduction: Experience with laparoscopic resection of pancreatic neoplasms remains limited. The purpose of this study is to critically analyze the indications for and outcomes after laparoscopic resection of pancreatic neoplasms.

Methods: The medical records of all patients undergoing laparoscopic resection of pancreatic neoplasms from July 2000 to July 2005 were reviewed. Data are expressed as means $\pm \mathrm{SD}$ and ranges.

Results: Laparoscopic pancreatic resection was performed in 19 patients (M:F; 7:12) with a mean age of 55.7 years (range, 26-78) and mean BMI of $26 \mathrm{~kg} / \mathrm{m} 2 \pm 3.6$. Nine $(47.4 \%)$ patients had previous intra-abdominal surgery. Indications for pancreatic resection were cyst (1), glucagonoma (1), gastrinoma (1), insulinoma (2), metastatic tumor (2), intraductal papillary mucinous tumor (3), nonfunctioning neuroendocrine tumor (4) and mucinous/serous cystadenoma (5). Mean tumor size was $2.5 \mathrm{~cm} \pm 1.7$. Laparoscopic distal pancreatectomy was attempted in 16 patients and completed in 15 patients (spleen preserving, $\mathrm{n}=8$ ). Laparoscopic enucleation was performed in 3 patients. Laparoscopic ultrasound $(n=6)$ and a handassisted technique $(\mathrm{n}=1)$ were utilized selectively. Mean operative time was $225 \mathrm{~min} \pm 63.9$ and mean blood loss was $310 \mathrm{ml}$ (range, 20-2500). The mean postoperative LOS was 4.3 days \pm 2.2 . There was one intraoperative complication (bleeding from splenic vein) requiring conversion to an open procedure. Five patients experienced postoperative complications including a UTI (1), bilateral lower extremity DVT and pulmonary embolus (1), peripancreatic fluid collection (1) and pancreatic duct leak (3). Two pancreatic duct leaks were managed by percutaneous drainage. The reoperation rate was $5.3 \%$ and the overall pancreatic-related complication rate was $26.3 \%$. There was no 30-day mortality. One patient developed pancreatitis and a pseudocyst 5 months postoperative. An ERCP demonstrated pancreatic divisum with dorsal duct dilatation. This was managed successfully with a pancreatic duct stent.

Conclusions: Laparoscopic pancreatic resection is safe and feasible in selected patients with neuroendocrine tumors and cystic neoplasms of the pancreas. The rate of pancreatic duct leak was $16 \%$ and remains an area of development for the minimally invasive technique.

\section{INDICATION FOR AN IMMEDIATE REOPERATION AFTER A CHOLECYSTECTOMIE FOR AN INCIDENTAL GALLBLAD- DER CARCINOMA}

Paolucci Vittorio PhD, Goetze Thorsten MD

Ketteler-Krankenhaus Department of Surgery

Introduction: The immediate reoperation after a cholecystectomie for an incidental gallbladder carcinoma is disscussed controversly. For a T1 tumor a cholecystectomie is enough. For T2 and more advanced stages a reoperation is permitted.The reoperation includes a resection of the liver and lymphnode exstirpation. In which T- stage such a reoperation should be undertaken is discussed controversly. Some authors recommend a reoperation in case of T1b- stage and improve the 5 year survival from 60 to $100 \%$. Others recommend it only when the margins are positive or when the subserosal invasion is $>2 \mathrm{~mm}$. The question is, if T1 tumors profit from a reoperation or if this is only an additional lethality. Material and method: To obtain data we use the CAES/CAMIC-register. Results: 417 cases of incidental gallbladder carcinomas a registered.In 64 patients with T1- tumor there was no reoperation. In 21 patients with T1- tumor there was a reoperation. Graph 1 shows survival according to Kaplan-Meier for T1- tumors. There is a prognostic advantage for T1- tumors with a reoperation. In 105 patients with T2- tumor there was no reoperation. In 75 patients with T2- tumor there was a reoperation.Graph 2 shows survival according to Kaplan-Meier graph for T2- tumors with a prognostic advantage for T2- tumors with reoperation.Graph $3 / 4$ shows no better survival for T3/4- tumors after reoperation.
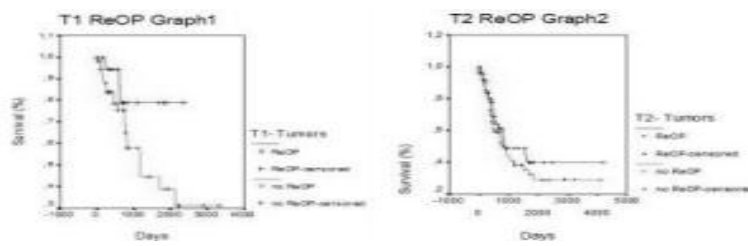

Discussion: There is a higher survival for T1 and T2- tumors after an immediate reoperation $(\log$ - rank $<0,05)$ in our patients. For T3/4- tumors there seems to be no prognostic benefit according to the survival. 


\section{HERNIA SURGERY}

\section{BILATERAL LAPAROSCOPIC INGUINAL HERNIA REPAIR IN PATIENTS WITH OCCULT CONTRALATERAL INGUINAL DEFECTS}

Victor Bochkarev MD, Chad Ringley MD, Dmitry Oleynikov MD

University of Nebraska Medical Center, Omaha, NE

INTRODUCTION: A prospective clinical study was undertaken to reveal the occurrence rate of an occult contralateral inguinal deffects in patients diagnosed with unilateral groin hernia prior to undergoing a laparoscopic totally extraperitoneal (TEP) repair and to compare clinical outcomes of bilateral versus unilateral TEP in this group of patients.

METHODS: One hundred consecutive patients with uncomplicated primary or recurrent unilateral hernias were enrolled in the study. Exclusion criteria included: bilateral inguinal hernias found on the preoperative physical exam, femoral hernias and prior lower abdominal celiotomy. TEP repair was performed by the same laparoscopic surgeon in all 100 subjects over a 48 month period. All patients underwent laparoscopic exploration of the contralateral groin and unilateral or bilateral TEP repair based on intraoperative findings.

RESULTS: Median follow-up was 24 (2 - 46) months. Median age was 48 (18 - 73). There were 89 men and 11 women. All the subjects were sratified into 2 groups, first of which consisted of 78 patients $(78 \%)$ with intraoperative confirmation of unilateral hernias. Forty five $(58 \%)$ of the unilateral hernias occurred on the right, while $33(42 \%)$ were on the left. The second group of patients consisted of $22(22 \%)$ subjects who had bilateral inguinal defects discovered only intraoperatively. Of those 22 patients $19(86 \%)$ patients were diagnosed with left and $3(14 \%)$ patients with right inguinal hernias preoperatively. Average operative time was $38.7 \mathrm{~min}$ in the first group and 53.9 in the second group. Minor complication occurred in $3(3.8 \%)$ patients in the first group and in $2(9 \%)$ in the second group. There were no major complications. Median period of hospitalization was 1.1 days in both groups. Median period of returning to normal activity was 6.2 days after unilateral repair and 8.4 days after bilateral TEP. There were no recurrences for the follow up period in either group.

CONCLUSION: This study revealed an occurrence rate of $22 \%$ for occult contralateral inguinal defects. Routine contralateral groin exploration with proper evaluation during TEP is valuable. Clinical outcomes of bilateral TEP repairs for these patients are as good as those of unilateral TEP for patients with single inguinal hernias.

\section{OVER FIVE HUNDRED CONSECUTIVE LAPAROSCOPIC TOTALLY EXTRAPERITONEAL HERNIA REPAIRS USING MESH WITHOUT FIXATION}

Scott J Ellner DO, Ibrahim M Daoud MD, Yusuf Gulleth MD

Saint Francis Hospital, Hartford Connecticut, Fellowship in Minimally Invasive Surgery

Background: Five hundred and eleven consecutive laparoscopic totally extraperitoneal (TEP) inguinal hernia repairs without mesh fixation were performed by a single surgeon between October 2001 and August 2005. This paper will review the patient outcomes of this ambulatory surgical procedure over a 5 year period.

Methods: Three hundred and sixty-two patients with primary or recurrent inguinal hernias underwent laparoscopic TEP repair without staple or suture fixation of mesh. Patients with contraindications to general anesthesia, scotal or strangulated hernias, and prior prostatectomy were excluded. Once preperitoneal laparoscopic dissection and reduction of the hernia sac from the myopectineal orifice was sufficiently completed, a preformed polypropylene mesh (3D Max ${ }^{\circledR}$ Bard) was placed without fixation. All patients were, subsequently, discharged within 3 hours after surgery.

Results: Three hundred and twenty-one patients (89\%) had primary hernias (217 were unilateral and 106 were bilateral). Forty-one $(11 \%)$ patients had recurrent hernias ( 26 were unilateral and 15 were bilateral). The mean age was 46 years with a male to female ratio of 3:1. Average operative time was 31 minutes (range of 12 to 55 minutes). Intraoperative complications were minimal. Pneumoperitoneum occurred in $14 \%$ of the patients resulting in a 3.5\% transabdominal preperitoneal repair (TAPP). There was one case of prolonged bleeding. Post-operative complications included urinary retention $(0.6 \%)$, superficial wound infection $(0.6 \%)$, significant bruising $(1.2 \%)$, and port site abscess $(0.6 \%)$. No re-operations or hospitalizations were needed. Of $93 \%$ of patients seen for post-operative follow-up $96.5 \%$ reported return to full activity with marked improvement. Eighty percent of patients did not require narcotic analgesia after post-operative day 3 . One recurrence $(0.2 \%)$ was reported.

Conclusion: Laparoscopic TEP hernia repair without mesh fixation is a safe procedure with low recurrence and the potential for eliminating nerve injury. Return to full activity occurred in the early post-operative period with minimal use of narcotic pain medication.
OPEN VS LAPAROSCOPIC VENTRAL HERNIA REPAIR: A PROSPECTIVE COMPARATIVE STUDY

Davide Lomanto MD, Avinash Katara MS,Shridhar Iyer MS, Jeffrey Domino MPH, Asim Shabbir,Wei-Keat Cheah, Jimmy So, Minimally Invasive Surgical Centre - MISC, Dept of Surgery, National University of Singapore, Singapore

Since its introduction in 1992, laparoscopic incisional hernia repair has revolutionized the management of ventral hernia. To date, preliminary studies show that laparoscopic approach seems to have a better outcome than the historical conventional approach. In fact, open ventral hernia repair either after primary suture or after mesh repair is known to be associated with significant morbidity and high recurrence rates. Laparoscopic approach is increasingly becoming an attractive option and may possibly replace open repairs. Our objective was to compare open versus laparoscopic repair for ventral hernia. 100 patients underwent 50 laparoscopic and 50 open ventral hernia mesh repairs from 2001 to October 2004. There were 86 female and 14 male patients (mean age $55.66 \mathrm{yrs}$; range $30-83 \mathrm{yrs}$ ) in the study. No significant difference between the two groups was noted regarding patient demographics except that the mean hernia size for laparoscopic group was larger significantly larger $(94 \mathrm{~cm} 2)$ as compared to open $(55 \mathrm{~cm} 2)$ $(\mathrm{p}<0.002)$ In the laparoscopic group $23.5 \%$ of the patients had a previous open repair while only $16.2 \%$ in the open group. In both groups the hernia was reducible in $65 \%$ of cases. Open repair was done using standard RivesStoppa technique with mesh while laparoscopic repair was performed using three trocars placed laterally in the abdominal wall. IPOM was utilized with both transfascial suture and spiral staplers for fixation of double-layer polyester mesh coated with collagen membrane. The mean follow-up time was 18 months. We found no significant difference in the operative time between the two groups (laparoscopic $110 \mathrm{~min}$ vs open $95 \mathrm{~min}$ ). Pain score and analgesic requirement was not significantly different between the two groups for the first 48 hours but a significantly less pain was noticed at 72 hours $(\mathrm{p}<0.02)$. Hospital stay was significantly less in the laparoscopic group ( 2.2 vs 3.6days, $\mathrm{P}<0.02)$. There was no difference in overall complication rates $(\mathrm{p}=0.072)$. Two patients in the open group vs one in the laparoscopic required the removal of the mesh for infection. There was two recurrence (4\%) in laparoscopic group and $6(12 \%)$ in open group. In conclusion, laparoscopic ventral hernia repair offers significant advantages and should be considered for repair of primary and incisional ventral hernias larger than $3 \mathrm{~cm}$. In our series significantly larger ventral hernias were repaired with better short and medium term outcomes.

\section{LAPAROSCOPIC PARASTOMAL HERNIA REPAIR USING A NON-SLIT MESH TECHNIQUE}

G J Mancini MD, B J Ramshaw MD, B T Heniford MD, Y M Novitsky MD, K A LeBlanc MD, M J Elieson MD, A E Park MD, S M Kavic MD, G R Voeller MD, E A Goldenberg BA

Departments of Surgery at University of Missouri, Emory University, Carolinas Medical Center, University of Maryland, Louisiana State University, and University of Tennessee

INTRODUCTION: The management of parastomal hernia $(\mathrm{PH})$ is associated with high morbidity and recurrence rates between 20 to $70 \%$. This study describes a novel laparoscopic approach and evaluates outcomes.

METHODS: A consecutive multi-institutional series of patients undergoing PH repair between 2001 and 2005 were analyzed retrospectively. Laparoscopy was utilized by modifying the open Sugarbaker technique. A non-slit ePTFE mesh was placed to provide $5 \mathrm{~cm}$ overlay coverage of stoma and defect. Transfascial sutures secured the mesh, allowing stoma exit from the lateral edge. Five advanced laparoscopic surgeons performed all the procedures. Primary outcome measure was recurrence.

RESULTS: Twenty-five patients with a mean age of 60y and a BMI of 29 underwent surgery. Six had previous stoma revisions. Mean size of the hernia defect was $64 \mathrm{~cm}^{2}$, mean ePTFE size $365 \mathrm{~cm}^{2}$, respectively. There was no conversion with overall postoperative morbidity of $23 \%$ and mean LOS of 3.3days. One patient died from pulmonary complications, one patient had a trocar site infection, and one patient had a mesh infection requiring mesh removal. At a median follow-up of $19 \operatorname{mos}(2-38) 4 \%$ (total $=1$ ) of the patients recurred.

CONCLUSION: Laparoscopic non-slit mesh technique for the repair of parastomal hernias appears to be a promising management approach. In the experienced hands in may provide for a safe repair with low rates of hernia recurrence. 
VENTRAL HERNIA REPAIR WITH SURGISIS GOLD. THREE YEARS EXPERIENCE

Valentine N Nfonsam MD, Stacy Brethauer MD, Adrian Dan MD, Adheesh Sabnis MD, Alan Siperstein MD, Bipan Chand MD, Steven Rosenblatt MD

Cleveland Clinic Foundation, Cleveland, Ohio

INTRODUCTION: An ideal prosthetic material for difficult ventral hernia repair has not yet been developed. However, Surgisis Gold may be beneficial in hostile or non-ideal situations such as contaminated cases. Surgisis Gold is a four- or eight- ply acellular, bioactive prosthetic mesh that is derived from porcine small intestine submucosa. We review our experience with the use of Surgisis in ventral hernia repair and compare its effectiveness in clean and contaminated cases.

MATERIALS AND METHOD: Retrospective analysis of patients who underwent laparoscopic or open repair of ventral hernias with Surgisis mesh was performed. In the laparoscopic group, the mesh was secured with tacks and four transfixation sutures. In the open group, the mesh was sewn to the edges of the fascial defect. Patients were classified by wound: clean (Group A), clean contaminated (Group B) and contaminated (Group C). Patients presented with primary, incisional or recurrent hernias.

RESULTS: From October 2001 to March 2005, 34 patients underwent ventral hernia repair with Surgisis mesh. There were 16 females $(52.9 \%)$ with an average age of 54 years (34-79). Fifteen patients (44.1\%) were operated on for recurrent ventral hernia. Classification according to groups is as follows: Group A, 13 patients (38.2\%), Group B, 13 patients (38.2\%) and group C, 8 patients $(23.5 \%)$. Sixteen patients $(47.1 \%)$ underwent an open procedure and $18(52.9 \%)$ had a laparoscopic repair. Post operative findings include seroma in 30 patients $(88 \%)$ and recurrence in 4 patients $(11.8 \%)$. All recurrences were in group $\mathrm{C}$ and all had an open hernia repair. One of the four patients had ongoing sepsis and had the mesh removed. The median follow up period was 16 months (3-36 months).

CONCLUSION: Surgisis mesh can be safely utilized in clean contaminated and contaminated cases. In contaminated cases, the recurrence rate was found to be $50 \%$, yet this still offered a permanent repair in difficult, high risk cases.

\section{INTRA-ABDOMINAL PRESSURE IN OBESE AND NON-OBESE} INDIVIDUALS

B L Paton MD, W S Cobb, K Head RN, H J Norton PhD, T S Kuwada MD, K W Kercher MD, B T Heniford

Carolinas Medical Center, Charlotte NC

Objective: It is assumed that obese patients have higher intra-abdominal pressures (IAP) which may be a proposed mechanism to explain the increased risk of hernia formation following surgery. The purpose of this study is to compare the normal range of IAP in obese and normal weight individuals during routine activities.

Methods: After IRB-approval, 12 morbidly obese and 20 normal weight healthy individuals were enrolled in an IAP study. Pressure readings were obtained through a transurethral bladder catheter. Each subject performed 12 different tasks including bench pressing 25 pounds and arm curling 10 pounds. Statistics were performed by the Wilcoxon rank sum test and Spearman's correlation with a $\mathrm{p}<0.05$ considered statistically significant. Results: The mean BMI in the obese group averaged $45.8 \mathrm{~kg} / \mathrm{m}^{2}$ (range, 39 to $55.3 \mathrm{~kg} / \mathrm{m}^{2}$ ) and the mean BMI in the normal weight group averaged $24.6 \mathrm{~kg} / \mathrm{m}^{2}$ (range; $18.4-31.9 \mathrm{~kg} / \mathrm{m}^{2}$ ). The obese group generated statistically higher IAP readings for all activities performed. Coughing and jumping generated the highest IAP for both groups. Using Spearmans correlation, increased BMI correlated with increased IAP for all activities including sitting, standing, bending at the waist and knees, coughing and performing a valsalva.

\begin{tabular}{|l|c|c|}
\hline \multicolumn{3}{|c|}{ IAP in Normal weight and Obese Individuals } \\
\hline Maneuver & Normal $(\mathrm{mmHg})$ & Obese $(\mathrm{mmHg})$ \\
\hline Standing & $20(15-27)$ & $46(22-90)$ \\
\hline Jumping & $171(43-252)$ & $212(150-250)$ \\
\hline Coughing & $107.6(64-141)$ & $185(80-255)$ \\
\hline Bench press & $7(2-34)$ & $22(5-35)$ \\
\hline Bend knees & $20.6(14-30)$ & $56.7(27-85)$ \\
\hline
\end{tabular}

Conclusion: Obese individuals have statistically higher IAP than those of normal weight regardless of activity, and in many activities increasing BMI directly correlates with increasing IAP. Coughing also generates considerable IAP. Based on our observations, weight reduction, by surgery or other means, and control of chronic cough prior to initial laparotomy or ventral hernia repair may decrease the incidence of hernia or recurrent hernia.
POOLED DATA ANALYSIS OF LAPAROSCOPIC VS OPEN VENTRAL HERNIA REPAIR: 13 YEARS OF PATIENT DATA ACCRUAL

Richard A Pierce MD, Margaret M Frisella RN, Brent D Matthews MD, L. Michael Brunt MD

Department of Surgery and Institute for Minimally Invasive Surgery, Washington University School of Medicine, St. Louis, Missouri

Introduction: The purpose of this study is to analyze the published perioperative results and outcomes of Laparoscopic (LVHR) and Open (OVHR) ventral hernia repair with a focus on complications and hernia recurrences.

Methods: Perioperative outcomes, complications and follow-up data were compiled from all English-language reports of LVHR published from 1996 through August 2005 that accrued patients over a 13 year period (from 1991 through October 2003). Series with fewer than 20 cases of LVHR, those that did not report details of complications, and those in which the patients were included in a later or larger series were excluded. Data were extracted from 28 reports that dealt with LVHR alone (Unpaired Studies) and 12 that directly compared LVHR to OVHR (Paired Studies). Statistical methods used were Chi square analysis and Fisher's exact test.

Results: A total of 5196 patients who underwent repair of 5223 hernias reported in 40 published series were included (LVHR, 4342 patients; OVHR, 854 patients). In the overall analysis (combined Paired and Unpaired Studies), LVHR was associated with significantly fewer wound complications $(3.7 \%$ vs. $15.8 \%, \mathrm{p}<.0001)$, total complications $(22.1 \%$ vs. $33.0 \%, \mathrm{p}<.0001)$, and hernia recurrences $(5.0 \%$ vs. $13.4 \%, \mathrm{p}<.0001)$. Each of these outcomes maintained statistical significance when only the Paired Studies were analyzed. LVHR was also associated with fewer neurologic complications ( $0 \%$ vs. $0.2 \%, \mathrm{p}=0.027)$ but a higher incidence of prolonged suture site pain ( $1.8 \%$ vs. $0.4 \%, \mathrm{p}=.0015)$; neither of these outcomes reached statistical significance in the Paired Study analysis. No differences in GI, cardiac, pulmonary, urinary, or thromboembolic complications were found. The overall mortality rate was $0.09 \%$ with LVHR and $0.12 \%$ with OVHR ( $\mathrm{p}=\mathrm{NS})$. An overall trend toward shorter hospital length of stay was also observed for LVHR.

Conclusions: The early published literature on LVHR indicates fewer wound-related and overall complications, and a lower rate of hernia recurrence compared to OVHR. Further controlled trials are necessary to substantiate these findings and to assess the health care economic impact of this approach. 
ENDOSCOPIC TRANSAXILLARY APPROACH TO THE THYROID GLAND: OUR EARLY EXPERIENCE

Titus D Duncan MD, Ijeoma Ejeh MD, Qammar Rashid MD

Atlanta Medical Center; Morehouse School of Medicine

Introduction

The surgical treatment of thyroid disease typically involves a transverse incision made through the skin of the neck. Although this technique has proven to be safe and efficient in the hands of most surgeons, the end result of this approach is a noticeable scar within a highly visible area of the neck.

Endoscopic transaxillary approach to the thyroid, eliminates scarring on the neck and anterior chest wall completely hiding all incisions when the arm is in a normal postural position. This endoscopic approach allows for improved illumination and magnification of the operative field improving visualization thereby enhancing safe dissection. We describe our initial technique and results of transaxillary endoscopic approach to the thyroid. Materials and Methods

After performing a feasibility study espousing the efficacy and safety of this approach, we set out to perform endoscopic transaxillary thyroid lobectomy for unilateral thyroid disease. There were 35 patients involved in this study. There were 23 females and 2 male patients. Average age of all patients was 33 (range 19 to 71 ).

Results

All patients had successful completion of lobectomy and isthmusectomy using the transaxillary approach. Temporary hoarseness occurred in two patients with subsequent complete resolution within three weeks of the surgery. One patient had to be returned to the operating room for postoperative bleeding from a superficial vessel on top of the pectoralis muscle, that was controlled endoscopically. There were no long term complications and overall patient satisfaction was excellent. All patients were satisfied with the cosmetic result.

Discussion

Most minimal access techniques to the thyroid involve an anterior approach with multiple small incisions in the neck or chest region. Although these techniques are less invasive than the open cervical approach with improved cosmetic results, scars are still highly visible. We report our series of thyroidectomy using a transaxillary approach to the thyroid region. We show that endoscopic transaxillary thyroidectomy is a safe and viable alternative to the open technique in select patients.

COMPARISON OF PROCEDURE SPECIFIC VIRTUAL REALITY SIMULATORS: CONSTRUCT AND FACE VALIDITY

James R Korndorffer Jr. MD 1 , Thomas P. McIntyre MD², John T. Paige MD $^{3}$, Kent R. Van Sickle MD ${ }^{4}$, Shishir K. Maithel MD², Dimitris Stefanidis MD ${ }^{1}$, Daniel J Scott MD, Danie B. Jones ${ }^{2}$

'Tulane Center for Minimally Invasive Surgery, Department of Surgery, Tulane University Health Sciences Center;

2Department of Surgery, Beth Israel Deaconess Medical Center;

3Department of Surgery, Louisiana State University Health Sciences Center

${ }^{4}$ Department of Surgery, University of Texas Health Sciences Center at San Antonio;

5 Department of Surgery, University of Texas Health Sciences Center at Dallas

contact author email: jkorndo@tulane.edu

Background: Basic-task virtual reality (VR) simulators have been extensively studied however little is known regarding procedure-specific VR simulators. The purpose of this study was to compare the construct and face validity of the three commercially available VR laparoscopic cholecystectomy (LC) simulators: Lap Mentor, Lap Sim, SEP.

Methods: Participants visiting the 2005 SAGES Learning Center were voluntarily enrolled. Subjects completed a demographic survey and were randomly assigned to one of the three simulators. Each completed one repetition of the LC task on the assigned simulator and proceeded to other simulators as their time allowed. Simulator specific preset performance metrics were automatically generated and recorded. To determine construct validity, metric results for each simulator were divided according to subjects' training status, number of LCs performed and number of advanced laparoscopic case performed, then compared using ANOVA on ranks and rank sum. To determine face validity, subjects that completed all 3 simulators used a visual analog scale to rate each simulator regarding six parameters.

Results: Eighty participants completed one trial on the assigned simulator and 32 completed one trial on all 3 simulators. Construct validity was demonstrated for: 1) Lap Mentor in 2 of 19 metrics using training status (cautery time, safe cautery); and 1 of 19 metrics using number of LCs or number of advanced cases (cautery time); 2) Lap Sim in 1 of 16 metrics using number of LCs (ripped ducts or vessels) and 2 of 16 using number of advanced cases (ducts or vessels ripped, blood loss); and 3) SEP showed no construct validity for any of the 5 metrics. Face validity results (mean \pm s.d.) are shown below. $(20=$ best rating)

\begin{tabular}{|c|c|c|c|}
\hline & Lap Mentor & Lap Sim & SEP \\
\hline Relevance to LC* & $13.8 \pm 3.5$ & $9.3 \pm 4.9$ & $10.3 \pm 4.3$ \\
\hline Simulates Movements of LC* & $12.3 \pm 4.2$ & $8.9 \pm 4.6$ & $9.3 \pm 4.0$ \\
\hline Useful Performance Measures* & $13.2 \pm 4.2$ & $8.5 \pm 4.7$ & $9.9 \pm 4.7$ \\
\hline Precision* & $12.6 \pm 4.2$ & $8.6 \pm 4.7$ & $9.5 \pm 5.2$ \\
\hline Image Quality $\dagger$ & $14.4 \pm 3.3$ & $10.6 \pm 4.9$ & $11.8 \pm 4.9$ \\
\hline Appropriate Force Feedback & $9.8 \pm 5.9$ & $7.7 \pm 4.6$ & $5.6 \pm 4.6$ \\
\hline
\end{tabular}

* Lap mentor rated significantly better than Lap Sim and SEP

$\dagger$ Lap Mentor rated significantly better than Lap Sim only

$\doteqdot$ Lap Mentor rated significantly better than SEP only

Conclusions: Few simulator metrics demonstrated significant construct validity and while the Lap Mentor was rated to have better face validity, no simulator achieved excellent face validity. Improvements in metrics and interfaces are needed before procedure-specific VR simulators can be used for assessment of surgical skill. Further study is needed to evaluate the educational value of these simulators.
A RELIABLE METHOD FOR INTRA-ABDOMINAL PRESSURE MONITORING DURING NATRUAL ORIFICE TRANSVISCERAL ENDOSCOPIC SURGERY (NOTES)

Michael F McGee MD, Michael J Rosen MD, Jeffrey Marks MD, Amitabh Chak MD, Raymond P Onders MD, Ashley Faulx MD, Anthony Ignagni, Steve Schomisch, Jeffrey Ponsky MD

Case Advanced Surgical Endoscopy Team, Case Western Reserve University, University Hospitals of Cleveland, Department of Surgery, Department of Gastroenterology, Cleveland, Ohio, USA

Background: Natural Orifice Transvisceral Endoscopic Surgery (NOTES) provides access to the peritoneal cavity to perform abdominal surgical procedures without skin incisions. NOTES requires pneumoperitoneum to visualize and manipulate abdominal organs, akin to laparoscopy. A reliable method to monitor pneumoperitoneum pressures during NOTES has not yet been identified. Accurate measurement of pneumoperitoneum is essential to avoid potentially deleterious effects of intra-abdominal compartment syndrome. This study evaluated several methods of monitoring intra-abdominal pressures with a standard gastroscope during NOTES.

Methods: Four female pigs $(25 \mathrm{~kg})$ were sedated and a single channel gastroscope was passed trans-gastrically into the peritoneal cavity. Pneumoperitoneum was achieved via a pressure insufflator through a percutaneous, intraperitoneal 14-gauge catheter. Three other pressures were recorded via separate catheters. First, a 14-gauge percutaneous catheter passed intraperitoneally measured true intra-abdominal pressure. The second transducer was a 14-gauge tube attached to the endoscope used to measure endoscope tip pressure. The third pressure transducer was connected to the biopsy channel port of the endoscope. The abdomen was insufflated to a range (10$30 \mathrm{mmHg}$ ) of pressures, and simultaneous pressures were recorded from all pressure sensors.

Results: Pressure correlation curves were developed for all animals across all intraperitoneal pressures (mean error -4.25 to $-1 \mathrm{mmHg}$ ). Endoscope tip pressures correlated with biopsy channel pressures $\left(\mathrm{R}^{2}=0.99\right)$. Biopsy channel and endoscope tip pressures fit a least-squares linear model to predict actual intraabdominal pressure $(\mathrm{R}=0.99$ for both). Both scope tip and biopsy channel port pressures were strongly correlative with true intra-abdominal pressures $\left(\mathrm{R}^{2}=0.98, \mathrm{R}^{2}=0.99\right.$ respectively $)$

Conclusion: This study demonstrates that monitoring pressure through an endoscope is reliable and predictive of true intra-abdominal pressure. Gastroscope pressure monitoring is a useful adjunct to NOTES. Future NOTES procedures should incorporate continuous intra-abdominal pressure monitoring to avoid the potentially deleterious effects of pneumoperitoneum during NOTES. Future gastroscopes should integrate pressure monitoring abilities.

\section{COMPARISON OF INTRA-ABDOMINAL PRESSURES USING THE GASTROSCOPE AND LAPAROSCOPE IN TRANSGASTRIC SURGERY}

Ozanan R Meireles MD, Samuel P Shih MD, Sergey V Kantsevoy MD, Anthony N Kalloo MD, Sanjay B Jagannath MD, Eric J Hanly MD, Donna M Beitler RN, Michael R Marohn DO, Johns Hopkins University

Introduction: Peroral transgastric endoscopic (PTE) approach for intraabdominal procedures appears feasible, although multiple aspects of this approach need further development.

Aim: To measure and compare intra-peritoneal pressure in a porcine model using the gastroscope and the laparoscope as insufflation sources.

Methods: All experiments were performed on $50-\mathrm{kg}$ female pigs under general anesthesia. Standard upper endoscope was advanced perorally through the gastric wall incision and peritoneal cavity was insufflated with operating room air. The intra-peritoneal pressure was measured by a standard laparoscopic insufflator manometer through the endoscope biopsy channel and through a $5 \mathrm{~mm}$ trans-abdominal laparoscopic port. The source of insufflation was then switched to the standard laparoscopic insufflator, using $\mathrm{CO}_{2}$ and intra-peritoneal pressures were measured again.

Results: Six acute experiments were performed. The pressure measurement showed good correlation regardless of measurement sites, independent of the type of gas used for insufflation; room air or $\mathrm{CO}_{2}$. The handactivated insufflation using the gastroscope revealed a wide variation of pressures (ranging from 4 to $32 \mathrm{mmHg}$ ) while the standard laparoscopic insufflator demonstrated minimal fluctuation ( 8 to $15 \mathrm{mmHg}$ ) around the predetermined value.

Conclusion: Use of a gastroscope as the single insufflation source revealed large amplitude of pressure variation that could potentially cause hemodynamic instability, compared with the well calibrated and controlled pressures generated by a standard laparoscopic insufflator. The PTE approach for intra-abdominal surgeries may promises a less invasive option, and although its underlying physiology needs further investigation, the already established insuffaltion from standard laparoscopy may minimized the risks of intra-abdominal hypertension in PTE. 
APPENDICITIS IN ELDERLY - A CHANGE IN THE LAPAROROSCOPIC ERA

Charudutt Paranjape MD, Samir Dalia BA, James Pan BS, Ann Salvator MS, Mark Horattas MD

Akron General Med. Ctr., NE Ohio Universities College of Medicine (NEOUCOM)

Introduction: Appendicitis in elderly patients is associated with significant morbidity and mortality. Early and correct diagnosis along with minimal invasive surgery can lead to more favorable outcomes as compared with pre-laparoscopic era. Methods: Retrospective review of 116 elderly patients (age > 60) from 1999-2004 is compared with our previously published studies from 1978- 1988 ( $\mathrm{N}=96)$ and 1988-1998 ( $\mathrm{N}=113)$ respectively. Results: In our present series (1999-2004), more cases were done laparoscopically $(n=68)$ than open $(n=48)$. Perforated appendicitis had significantly more Length of Stay (LOS), more complications and longer Operating time as compared with non-perforated cases. The laparoscopic cases had significantly less LOS, fewer complications and comparable Operating time compared with open cases.

Compared with our previous studies from (1978- 1988) and (1988-1998), the present series (1999-2004) has patients presenting with fewer classical symptoms. CT scanning was more accurate in the present study and was more routinely used. Patients in the present series had more correct preoperative diagnosis. Perforated appendicitis was encountered less frequently and was associated with fewer complications. The $4 \%$ mortality

\begin{tabular}{|c|c|c|c|}
\hline & Lap $(n=68)$ & Open $(n=48)$ & p-value \\
\hline LOS ( days) & $5.3+\% .4 .3$ & $9.8+\$ .97$ & 0001 \\
\hline CT scan done & $75 \%$ & $B 5 \%$ & 0.17 \\
\hline Accuracy of CT & $92 \%$ & $97 \%$ & 025 \\
\hline COMPLICATIONS & $18 \%$ & $37 \%$ & 02 \\
\hline OR Time (min) & $82.5+1.39 .4$ & $80.4+4.48 .1$ & 0.40 \\
\hline
\end{tabular}

rate in the previous two series decreased to less than $1 \%$ in this series.

Conclusion: Minimally invasive surgery combined with increased use and accuracy of pre-operative CT scans have changed the clinical management of acute appendicitis in elderly patients leading to decreased length of stay ,decreased mortality and more favorable outcomes.

\section{RETURN OF BOWEL FUNCTION FOLLOWING LAPAROSCOP- IC COLON RESECTION IS FASTER WITH THORACIC EPIDURAL ANALGESIA}

Ali Taqi MD, Franco Carli MD, Xi Hong MD, Shahram Zandi MD, Giovanni Mistraletti MD, Barry Stein MD, Patrick Charlebois MD Department of Anesthesia and Surgery. McGill University Health Centre. Montreal, Quebec, Canada

Background: The use of epidural analgesia for laparoscopic colectomy has been questioned. However, no attempts have been made to standardize the epidural analgesia regimen and the perioperative surgical and nursing care program. The aim of this study was to determine whether thoracic epidural analgesia for laparoscopic colectomy favors the restoration of bowel function and provides superior analgesia when used within a traditional, non- accelerated, perioperative care program.

Methods: Fifty patients scheduled for elective laparoscopic colon resection for benign and malignant lesions were randomized to patient controlled analgesia (PCA) with morphine $(\mathrm{n}=25)$ and thoracic epidural analgesia $(n=25)$. All groups received general anesthesia and multimodal pain relief which included naproxen and acetaminophen for up to 4 postoperative days. A traditional, non-accelerated, perioperative surgical and nursing care program was implemented. Return of bowel function (time to passage of gas and bowel movements), dietary intake, postoperative quality of analgesia, and readiness for discharge and length of hospital stay were recorded by a blind researcher.

Results: Restoration of bowel function occurred sooner in the epidural group $(\mathrm{p}<0.005)$ by an average $1-2$ days, and resumption of full fluid diet was achieved earlier $(\mathrm{p}<0.05)$. Intensity of pain during the first two postoperative days was significantly lower at rest, on coughing and on walking in the epidural group $(\mathrm{p}<0.005)$ Readiness for discharge and hospital length of stay was otherwise similar in both groups.

Conclusions: Thoracic epidural analgesia after laparoscopic colectomy, with a traditional, non-accelerated, perioperative care program, favors the return of bowel function and earlier dietary intake, and provides superior pain relief.
LAPAROSCOPIC INTRALUMINAL SURGERY A SAFE APPROACH FOR GASTROINTESTINAL DISEASE

Jorge M Trevino MD, Morris E Franklin MD, John J Gonzalez MD, Gregory Kim MD, Texas Endosurgery Institute

\section{Overview:}

Advances in laparoscopic surgery have allowed its application in endoluminal surgery. Laparoscopic-assisted endoluminal surgery has been used for a variety of indications. We review our experience with this technique to determine its safety, feasibility and efficacy in the hands of an experienced laparoscopic surgeon.

Methods:

Between 1996 and 2005, data was collected retrospectively of all patients having undergone laparoscopic endoluminal surgery at the Texas Endosurgery Institute. All patients underwent endoluminal port placement using a $5 \mathrm{~mm}$ ballon trocar for the camera and $2 \mathrm{~mm}$ for working ports, under direct visualization after a pneumoperitoneum was established. All the operations were performed in conjunction with upper endoscopy for assistance in port placement under intraluminal visualization, insufflation, and specimen retrieval. The endoluminal port sites were then closed with laparoscopic intracorporeal suturing after the intraluminal portion of the operation was completed.

Results:

Thirty five patients from 1996 to 2005 underwent laparoscopic endoluminal surgery. Indications for the procedure were varied and included: diagnostic procedure, carcinoid tumors, pancreatic pseudocysts, gastric and esophageal polyps, duodenal webs, gastric adenocarcinoma, and benign obstructing ulcer disease. All cases were completed successfully with no recurrence of the original pathology and minimal complications.

Conclusions:

We were able to successfully complete procedures and establish diagnoses in all 35 patients using this technique and found it to be a safe, feasible, and effective alternative to more conventional therapies. It is a technique that will likely have more applications in the future as our experience and instrumentation improves and should be performed by anyone with previous experience in advanced laparoscopic surgery

\section{LAPAROSCOPIC MANAGEMENT OF NON OBSTRETIC EMER- GENCY IN THE THIRD TRIMESTER OF PREGNANCY}

Ajay Upadhyay MD, Steven Stanten MD, George Kazantsev MD Rupert Horoupian MD, Arthur Stanten MD, Alta Bates Summit Medical Center

[Aims] Laparoscopic management of non obstetric acute abdominal pain during pregnancy remains controversial and represents a unique challenge. A gestational age of 28 weeks has been considered an upper limit for laparoscopy by some authors. Most reported cases are in the first and second trimester. We report a case series of Laparoscopic surgery in the third trimester of pregnancy.

[Methods] Medical records of third trimester patients who underwent open or Laparoscopic surgery between 1997 and 2005 were reviewed.

[Results] There were total twelve patients in this study. Eight patients underwent laparoscopic surgery while four had open surgery. In the Laparoscopic group, there were three appendectomies, three cholecystectomies and two adenexal surgeries. In the LS group the procedures were successfully completed using laparoscopic approach in seven patients, these had no complications and subsequently had normal full term deliveries. One patient in the LS group had to be converted to an open approach; she subsequently developed post operative hemorrhage and pre-term labor, requiring a cesarean section on the 3rd post operative day. The OS group included two appendectomies and two patients at 37 and 38 weeks who underwent a planned cesarean section followed by a total colectomy and Right hemicolectomy. In summary, we show that the even in the third trimester of pregnancy, access is easily obtained, space is generally not a problem, trocar placement can be optimized and there is minimal uterine manipulation.

[Conclusions] Our study shows that laparoscopic surgery is feasible and can be safely performed in the third trimester with an acceptable risk to both the fetus and the mother. 
POST-HERNIORRAPHY INGUINODYNIA: A TREATMENT ALGORITHM FEATURING DIAGNOSTIC LAPAROSCOPY

Sharon L Bachman MD, Mercedeh Baghai MD, Gregory J Mancini MD, Bruce J Ramshaw MD

Missouri Center for Advanced Techniques in Surgery, Department of Surgery, University of Missouri-Columbia

Objective: Inguinodynia remains a significant complication of all types of inguinal herniorraphy, and can be frustrating for both patient and surgeon. We present a treatment algorithm utilizing initial diagnostic laparoscopy (DL) for patients with inguinodynia.

Description: One surgeon's database of hernia repairs was reviewed Patients identified with inguinodynia were selected and treatment and follow-up data were evaluated.

Falure of conservative treatment
Diagnostic Laparoscopy
Adhesions? Adhesiolysis
hernia recurrence? $\rightarrow$ mesh herniorraphy
TAPP dissection (pertioneal take-down): 3 steps
1. Evaluate laterally for cutaneous nerve entrapment
2. Evaluate me dialily for canalicord nerve entrapmert
3. Remove offending tacks or mesh lateral to epigastric vessels
No pathology noted, consider repeat/different herniorrapy
Continuation of symptoms post-operatively? $\rightarrow$ Open mesh exeision/neurectomy

The following algorithm was utilized:

Preliminary Results: 10 patients with inguinodynia had DL performed between $1 / 1 / 2003$ and 7/31/2005. 4 had complete resolution of all pain, 5 had significant improvement of pain and required no narcotics and 1 had persistent pain without change. DL led to the identification of recurrent hernia in $1(10 \%)$, mesh contraction or migration with possible nerve entrapment in $8(80 \%), 2$ patients (20\%) had tacks causing neuralgia and one patient $(10 \%)$ had developed a suture granuloma. Conclusion: Mesh contraction and displacement is the most frequent finding during DL performed for persistent groin pain. DL improved or resolved pain in $90 \%$ patients with chronic inguinodynia, and is an effective first step in a treatment algorithm for this difficult problem.

\section{ENDOSCOPIC MUCOSECTOMY USING A MULTIPURPOSE THERAPEUTIC HOOD (TXHOOD)}

Tatsuyuki Kawano MD,

Department of Surgery, Tokyo Medical and Dental University Hospital

Endoscopic resection including endoscopic mucosectomy (endoscopic mucosal resection (EMR) and endoscopic submucoal dissection (ESD)) is a minimally invasive treatment for patients with early esophageal carcinoma (EEC) because almost all EECs are curable with endoscopic mucosectomy, esophagi are preserved and precise diagnoses of esophageal tumors are confirmed with histological examination for resected specimens. Nowadays although techniques of EMR in one piece resection (OPR) are established for relatively small lesions $2 \mathrm{~cm}$ in diameter or less with some equipments and techniques, wider lesions should be resected with piecemeal resection (PMR) techniques. The ESD is an appropriate technique for mucosal lesions of any size, however, the techniques of ESD are relatively difficult and serious complications, e.g. perforation, massive bleeding, are reported more frequently than EMR.

We devised a noble technique of ESD and performed basic experiments for ensuring safety under the permission of IRB. The new techniques of ESD were undergone easily using newly designed equipments named multipurpose therapeutic hood (TxHood). A TxHood had some lines of therapeutic tools, e.g. electric needle knife, snare wire, injection needle, and the lines were selected freely before insertion of an enodoscope covered with a TxHood. The main techniques of resection of the target mucosal and submucosal tissue were endoscopic submucosal saline injections on demand through a working channel of endoscope or TxHood, cut or swing cut with a needle knife attached on TxHood and grasping of target area with a grasping forceps through a working channel of endoscope. In the experiments, an electric needle knife was set parallel with a shaft of endoscope and offered the safety and the ease of handling for dissecting procedures. We performed 15 resections of mucosae and submucosae in average size of $3.5 \times 2.5 \mathrm{~cm}$ (from $2 \times 2 \mathrm{~cm}$ to $7 \times 4 \mathrm{~cm}$ ). The average time of endoscopic resection for each target areas was about 15 minutes with no perforation or uncontrollable bleeding.

We conclude from the basic study on the ESD using a newly devised TxHood and former experiences of endoscopic mucosectomy for EECs that the new techniques of ESD with a Txhood are useful in the treatment for EEC and may be applicable for all mucosal or submucosal tumors in the gastro-intestinal tract.
A PILOT STUDY OF BOTULINUM TOXIN INJECTION FOR THE TREATMENT OF DELAYED GASTRIC EMPTYING FOLLOWING ESOPHAGECTOMY AND VAGOTOMY

Michael S Kent MD, Arjun Pennathur MD, Matthew J Schuchert MD, Thomas Fabian MD, James D Luketich MD, Rodney J Landreneau MD University of Pittsburgh Medical Center

Objective: Esophagectomy and vagotomy lead to significant impairment in gastric emptying, unless a pyloroplasty or pyloromyotomy is performed. These procedures may be technically challenging during minimally invasive esophagectomy, and are associated with a small but definable morbidity, such as leak and dumping syndrome. We sought to determine our early experience with a technique of minimally invasive ablation of pyloric function, in which the pylorus is injected with botulinum toxin.

Methods: Seven patients who had undergone esophagectomy and injection of the pylorus with botulinum toxin were identified. Four patients underwent botulinum toxin injection at the time of minimally invasive IvorLewis esophagectomy, and the remaining three were treated endoscopically following surgery. The three latter patients had undergone esophagectomy with either no ablative pyloric procedure $(n=2)$, or inadequate pyloromyotomy $(n=1)$, and had presented in the post-operative period with delayed gastric emptying. In all patients, 200 Units of botulinum toxin was injected in a systematic fashion, equally divided in all four quadrants into the pyloric musculature. A laparoscopic needle aspirating device or an endoscopic needle catheter was utilized for performing this injection. We evaluated the complications, postoperative clinical symptoms and assessed gastric emptying with a barium contrast study.

Results: There were no complications associated with botulinum toxin injection. All four patients who underwent primary laparoscopic botulinum toxin injection at the time of esophagectomy were discharged home tolerating a soft diet and demonstrated normal gastric emptying on the contrast study performed in the post-operative period. The three patients who underwent post-operative endoscopic injection experienced immediate improvement in symptoms of gastric outlet obstruction, tolerated a soft diet and demonstrated a moderate improvement in gastric emptying assessed by barium contrast study.

Conclusions: Injection of the pylorus with botulinum toxin shows promise to simplify the preservation of gastric emptying in patients undergoing esophagectomy. Longer-term studies are needed to clarify the durability of this technique and to compare its efficacy with the accepted procedures of pyloromyotomy or pyloroplasty.

\section{EASY LAPAROSCOPIC VIEWING WITH A NEWLY DEVEL- OPED ROTATING LAPAROSCOPIC VIDEO MONITOR}

Jae-Hwang Kim MD, Seok-Won Jang MD, Je-Hyung Lee MD, Min-Chul Shim MD

College of Medicine, Yeungnam University

(Background) Surgeons generally use more than 2 video monitors during major laparoscopic surgery, and this is different from the minor laparoscopic surgery such as cholecystectomy. The image of the monitor must be adjusted for the operator's eye and this is good to the operator; however, for the assistant who stands on the other side, it is a problem because of the image is rotated up to 180 degrees. This is one of major reasons why surgeons need more training and experience to overcome this difficult view. (Purpose) We wanted to evaluate the improvement of the laparoscopic performance with using the normalized video image as compared with the previous upside down image. (Methods) Ten surgery residents who had no experience with major laparoscopic surgery were recruited. They performed a simple laparoscopic procedure using the laparoscopic training kit with a newly developed rotating laparoscopic video monitor (patent pending) that could be controlled by pushing button on the floor. The monitor rotates 180 degrees both right and left side on a central axis of the image. We named the $i{ }^{\circledR}$ Normalized $_{i}^{-}$view as the best image for performing the procedure and it can be made by rotating the image with the performer ${ }^{-} \mathrm{s}$ foot control. The study procedure was placing red and blue rubber rings onto 2 red and blue standing bars in 5 minutes. The performers were divided in 2 groups $(\mathrm{n}=5$ each) and each group performed one practice test and one final test with the $i{ }^{\circledR} 180$ degree rotat$\mathrm{ed}^{-}{ }^{-}$and $i{ }^{\circledR}$ normalized $i^{-}$view in a cross-over designed order. We compared the number of successfully placed rubber rings in both situations. (Results) The number of inserted rings in practice with the ${ }^{\circledR} 180$ degree rotated $i^{-}$and ${ }_{i}{ }^{\circledR N}$ Normalized $i_{i}^{-}$images were $1.6 i_{-} 1.83$ and $8.9 i_{-} 2.64$, respectively $(\mathrm{p}<0.01)$ and in final test, they were $3.3_{i}-2.40$ and $11.9 i_{-} 4.01$ respectively $(\mathrm{p}<0.01)$.

(Conclusions) We confirmed that changing the $i{ }^{\circledR}$ rotated $_{i}^{-}$laparoscopic video image to the easy $i{ }^{\circledR}$ normalized ${ }_{i}{ }^{-}$image (the normal eye view) allows a dramatic improvement for laparoscopic performance. Using a rotating laparoscopic video monitor could maximize the capability of the assistants for performing major laparoscopic surgery at any location of the body. 
DIAPHRAGM PACING WITH NATURAL ORIFICE TRANSVISCERAL ENDOSCOPIC SURGERY (NOTES): POTENTIAL FOR DIFFICULT TO WEAN INTENSIVE CARE UNIT(ICU) PATIENTS Raymond Onders MD, Jeffrey Marks MD, Anthony Ignagni MS, Michael McGee MD, Michael Rosen MD, Amitabh Chak MD, Ashley Faulx MD, Robert Schilz DO, Steve Schomisch BS, Jeffrey Ponsky MD

University Hospitals of Cleveland and CASE School of Medicine

Background: Up to $50 \%$ of ICU patients require mechanical ventilation with $20 \%$ on a ventilator for over 7 days. Over $40 \%$ of time is spent weaning a patient from mechanical ventilation. Failure to wean from mechanical ventilation can in part be due to rapid onset of diaphragm atrophy, barotrauma, posterior lobe atelectasis, and impaired hemodynamics which are normally improved by maintaining a more natural negative chest pressure. We have shown that laparoscopic implantation of a diaphragm pacing system successfully provides adequate ventilation in spinal cord injured patients. Our preliminary data also suggests that DPS may benefit amyotrophic lateral sclerosis (ALS) patients with partial diaphragmatic atrophy. With the knowledge we have gained from these patients, we propose that acute ventilator assist with interventional neurostimulation of the diaphragm in the ICU is feasible and could facilitate weaning from mechanical ventilation. Current DPS implantation is carried out electively in the operating room but transfer of critically ill patients for procedures is not always possible or safe. NOTES has the potential to expand the benefits of DPS to this acute patient population by allowing it to be done at the bedside like the common gastrostomy tube. This study evaluates the feasibility of this approach in a porcine model.

Methods: Pigs were anesthetized and peritoneal access with the flexible endoscope was obtained using a guidewire, needle knife cautery and balloon dilatation. The diaphragm was mapped to locate the motor point (where stimulation provides complete contraction of the diaphragm) with a novel endoscopic electrostimulation catheter. An intramuscular electrode was then placed at the motor point with a percutaneous needle. This was then attached trostomy tube. Results: Four pigs were studied and the diaphragm could be mapped with the endoscopic mapping instrument to identify the motor point. In one animal, under trans-gastric endoscopic visualization a percutaneous electrode was placed into the motor point and the diaphragm could be paced in conjunction with mechanical ventilation.

Conclusions: These animal studies support the concept that trans-gastric mapping of the diaphragm and implantation of a percutaneous electrode for therapeutic diaphragmatic stimulation is feasible. These encouraging results warrant a prospective human trial to assess safety and efficacy. to the diaphragm pacing system. The gastrotomy was managed with a gas-

EVALUATING AN OPTIMAL GASTRIC CLOSURE METHOD FOR TRANSGASTRIC SURGERY

Marvin Ryou MD, David W Rattner MD, William R Brugge MD, Reina Pai MD, Christopher C Thompson MD

Brigham \& Women's Hospital, Boston, MA; Massachusetts General Hospital, Boston, MA

Introduction: We compared the effectiveness of various techniques for gastrotomy closure by assessing leak pressures in an ex vivo porcine stomach model.

Methods: Whole stomachs from adult white pigs were suspended in a plexiglass box to facilitate endoscopic technique. Standard gastrotomies were made by needle knife incision and dilation with an $18 \mathrm{~mm}$ CRE balloon. 5 stomachs were tested per arm (4 total). The first arm used standard QuickClips (Olympus); the second, a prototype device developed by LSI Solutions, which simultaneously makes an incision and places surrounding sutures; the third, hand-sewn (5 interrupted full-thickness sutures with 3-0 Prolene) by a senior surgeon; the final, a control with open gastrotomy. After closure, each stomach was inflated by an automated pressure gauge. The pressures to achieve air leakage (bubbles under water submersion) and liquid leakage (dye) were recorded.

Results: The unclosed controls demonstrated air leakage at a mean pressure of $15 \mathrm{~mm} \mathrm{Hg}$ (95\%CI: 14-16), representing baseline system resistance. The QuickClip closures leaked air at a mean pressure of $34.2 \mathrm{~mm}$ $\mathrm{Hg}$ (95\% CI: 20.7-47.6). The prototype gastrotomy device yielded a mean air leak pressure of $98 \mathrm{~mm} \mathrm{Hg}$ (95\%CI: 23.9-172.0), while dramatically diminishing time for incision and hole closure to approximately $5 \mathrm{~min}$ utes. The hand-sewn closures leaked air at a mean pressure of $52.2 \mathrm{~mm}$ $\mathrm{Hg}$ (95\% CI: 21.2-83.2). When comparing arms, all were statistically significant when compared to unclosed gastrotomies (p-values 0.009 [clips]; 0.02 [sewn]; 0.018 [prototype]). The prototype compared to clips was also statistically significant ( $\mathrm{p}$-value 0.018 ). Liquid-leak pressures produced similar results to air.

Conclusions: The prototype gastrotomy device decreases procedure time and yields leak-resistant gastrotomy closures that are superior to clips and rival hand-sewn interrupted stitches.

\section{ROBOTICS}

TELE-SURGERY IN AN EXTREME ENVIRONMENT IN THE ABSENCE OF A LOCAL PHYSICIAN - THE NEEMO 7\&9 MISSIONS Mehran Anvari PhD, David Williams MD, Robert Thirsk MD, Lee Morin MD, Craig McKinley MD, Timothy Broderick MD, Anil Kapoor MD, Herawaty Sebajang MD, Geoffrey Hall PhD, Anthony Adili MD, Julian Dobranowski MD Centre for Minimal Access Surgery, McMaster University, Hamilton, ON, Canadian Space Agency, National Aeronautics and Space Administration (NASA), Telemedicine and Advanced Technology Research Centre (TATRC), Ft. Detrick, MD

Introduction: Telementoring, both with and without robotic assistance, can effectively facilitate transfer of knowledge from one surgeon to another during live surgery. Recent experience with robotic-assisted remote telepresence surgery (RARTS) has demonstrated that a surgeon can safely perform advanced procedures from a distance. The scientific goal of the NEEMO missions is to evaluate the potential for these technologies to enable provision of emergency surgical care in an extreme environment in the absence of a physician.

Methods: Coordinated by NASA, the NEEMO missions utilize the Aquarius undersea habitat as a training analogue for space missions. During NEEMO 7 (Oct. 11-21, 2004), experts at the Centre for Minimal Access Surgery (CMAS) in Hamilton, $\mathrm{ON}$, used telementoring with robotic assistance to guide Aquarius crewmembers through several simulated surgical procedures including lap cholecystectomy, arterial anastomosis, cystoscopy and removal of a renal stone. NEEMO 9 (Oct. 3-20, 2005) will investigate the use of tele-presence surgery using a portable two-arm robot to allow a remote surgeon to carry out emergency surgery with latencies ranging from $150 \mathrm{~ms}$ to 2 seconds. For both missions, the Aquarius crew includes 3 astronauts, 2 habitat technicians and one surgeon as a control.

Results: NEEMO 7 demonstrated that with proper telementoring technique, non-physicians could successfully be guided through all of the simulated surgical procedures, although not as quickly or as efficiently as the surgeon control. The mentoring skills of the remote surgeon and the image quality provided by the telecommunications network were found to be critical to successful telementoring. Telerobotic assistance could not be properly evaluated during NEEMO 7 because the robotic platform was too bulky for the confines of Aquarius. A newly developed and more compact system will be evaluated during NEEMO 9 in October 2005

Conclusions: The technologies evaluated during the NEEMO missions may play a significant role in providing emergency medical and surgical care in extreme environments in the absence of a local physician, such as field of battle or human space exploration, and also in remote regions around the globe.

\section{ROBOT ASSISTED LAPAROSCOPIC SURGERY OF THE INFRARENAL AORTA; THE EARLY LEARNING CURVE}

Jeroen Diks MSc, Denise Nio MD, H.J. Bonjer MD, Jan A. Rauwerda PhD,

VU University Medical Center, Amsterdam, The Netherlands

\section{Introduction:}

Laparoscopic aortic surgery to date has not been widely embraced among vascular surgeons. This lack of faith is probably due to the technical difficulties, especially concerning the aortic anastomosis.

Recently, robot assisted laparoscopic surgery (RALS) has been introduced to facilitate endoscopic surgical manipulation. Increasing the degrees of freedom, introducing 3-D visualization and facilitating hand-eye coordination, it potentially reduces the learning curve, thereby stimulating recognition of laparoscopic aortic surgery among vascular surgeons.

Materials / Methods:

Between February 2002 and May 2005, 17 men, median age 55 (range: 3672 ), were treated in our institution with robot-assisted laparoscopic aortobifemoral bypasses (ePTFE) for aortoiliac occlusive disease.

Five patients were operated with the Zeus ${ }^{\circledR}$ system between February 2002 and February 2003. In January 2004 our institution acquired a da Vinci® surgical system and between February 2004 and May 2005 an additional 12 patients were operated. Dissection was performed laparoscopically and the robot was used to make the aortic anastomosis.

Results:

Median operative time was 365 minutes (range: 225 - 589), with a median clamp-time of 86 minutes (range: 25 - 205). Median blood loss was $1000 \mathrm{ml}$ (range: $100-5800$ ). A robot-assisted anastomosis was successfully performed in fifteen patients. Three patients were converted to a laparotomy, one due to bleeding of an earlier clipped lumbal artery after completion of the robotic anastomosis, the others due to difficulties with laparoscopic exposure of the aorta and technical failure of the robotic system. One patient died unexpectedly on post-operative day 3 as a result of a massive myocardial infarction. Median hospital stay was 4 days (range: 3 - 57). Conclusions:

Our experience with RALS shows it is a feasible technique for aortoiliac bypass surgery. After an initial learning curve, operation time, aortic clamptime and hospital stay have been decreased to a fairly acceptable range. Reduction of the learning curve for laparoscopic aortic surgery with the use of a robotic surgical system might stimulate wide implementation of laparoscopic treatment for aortoiliac disease. Willem Wisselink PhD 
EFFECT OF THE "LEARNING CURVE" ON OUTCOMES AFTER ROBOTIC ASSISTED DONOR NEPHRECTOMY (RALN) Maria V Gorodner MD, Santiago A Horgan MD, Carlos Galvani MD, Giuliano Testa MD, Howard Sankary MD, Enrico Benedetti MD University of Illinois at Chicago

Background: Robotic technology has emerged as a promising adjunct to advanced minimally invasive surgery (MIS). Herein we present our experience and the evolution of the technique with RALN over a 5 year period. We hypothesize that changes in surgical technique improve outcomes following RALN.

Patients and Methods: 213 patients underwent RALN between 10/2000 and $8 / 2005$. Patients were divided into 2 groups based upon surgical technique: Group A (initial technique, $\mathrm{n}=74$ ), and Group B (current technique, $\mathrm{n}=139$ ). Retrospective review from prospective collected data was performed.

Results: Overall, $68 \%$ of patients were overweight or obese (BMI $>=25$ ) Mean age was 35 years. Surgery time, complication rate and conversion rate were decreased in Group B.

\begin{tabular}{|l|c|c|c|}
\hline & Group A & Group B & p value \\
\hline Multiple renal arteries & $19(26 \%)$ & $42(30 \%)$ & NS \\
\hline Surgery time (min) & $201 \pm 42$ & $117 \pm 36$ & $<0.001$ \\
\hline WIT (sec) & $97 \pm 19$ & $95 \pm 27$ & NS \\
\hline Hospital stay (days) & $2 \pm 1$ & $2 \pm 1$ & NS \\
\hline Complications & $18(24 \%)$ & $10(7 \%)$ & $<0.001$ \\
\hline Graft loss & $2(3 \%)$ & $1(0.7 \%)$ & NS \\
\hline Conversion & $4(5 \%)$ & 0 & $<0.05$ \\
\hline
\end{tabular}

WIT: warm ischemia time. In the recipients, 1 year patient survival was $100 \%$ and graft survival was $98 \%$.

Conclusion: Specific changes in our operative technique over time improved patient safety and diminished complications with RALN RALN can be performed expeditiously with minimal complications and risk for conversion to open nephrectomy with appropriate training and experience.

\section{REMOTE STEREOSCOPIC ROBOTIC TELESURGERY USING THE} PUBLIC INTERNET

Eric J Hanly MD, Brian E Miller PhD, Barry C Herman MSc, Michael R Marohn DO, Timothy J Broderick MD, Samuel P Shih MD, Joseph Sterbis MD, Charles Doarn BA, Brett R Harnett BS, Christopher J Hasser PhD, Mark A Talamini MD, Ozanan Meireles MD,Gerry R Moses PhD, Ron Marchessault BA, Noah S Schenkman MD

Walter Reed Army Medical Center, Johns Hopkins University, University of Cincinnati, Intuitive SurgicaI, Telemedicine and Advanced Technology Research Center

INTRODUCTION: Providing surgeons the ability to mentor and perform procedures from remote locations will have a profound impact on the quality and type of care that rural patients receive in their towns and that soldiers receive on the battlefield. Remote telesurgery using monoscopic vision has been performed clinically with the Zeus surgical robot, but at a great financial cost $(>\$ 1 \mathrm{M})$. Because of its complexity, the daVinci Surgical System 'an advanced surgical robot with stereoscopic vision' has never been used for remote surgical applications.

METHODS: The daVinci Surgical System was modified to enable network communication between multiple Surgeon's consoles and a single patient-side cart (the robot). Two low latency video CODECs were used at each site to enable stereoscopic video streaming. Unlike previous telesurgery models, Internetbased connectivity was used to establish a cost-effective solution applicable to a wide variety of clinical settings (cost to lease for 6 months the telecommunications equipment and bandwidth used in this study is $<\$ 100 \mathrm{~K}$ ). The utility of the system to facilitate remote collaborative stereoscopic telesurgery was evaluated through a combination of dry lab exercises and animal lab surgery.

RESULTS: Surgeons located in Cincinnati, Ohio, and in Denver, Colorado, successfully operated with residents in Sunnyvale, California (approximate distances of 2,400 and 1,300 miles, respectively) to perform nephrectomies in six Californian swine. The modified daVinci system was capable of shared control between the remote surgeon and the local resident. Remote surgical task performance data is presented in detail. Round-trip latency was high ( $\sim 550-980 \mathrm{~ms})$, but remote surgeons quickly adapted and performed telesurgical nephrectomies in the pigs without complication.

CONCLUSIONS: This low-cost, proof-of-concept study represents a number of surgical and telemedicine milestones including the first U.S.-based telesurgery, the first telesurgery using the daVinci Surgical System, the first use of stereoscopic (3D) surgical video streaming, the first robotic collaborative telesurgery (two consoles), and the first telesurgery over the Internet using non-dedicated lines. In this configuration, the daVinci Surgical System offers a unique opportunity to develop a network of machines at various remote locations which may all be used to extend the reach of expert specialty surgeons.
A COMPUTERIZED ANALYSIS OF ROBOTIC VERSUS LAPAROSCOPIC TASK PERFORMANCE

V K Narula MD, W C Watson MD, S S Davis MD, K Hinshaw BS, B J Needleman MD, D J Mikami MD, J W Hazey MD, J H Winston MD, P Muscarella MD, M Rubin, V Patel MD, W S Melvin MD The Ohio State University. CMIS. Columbus, $\mathrm{OH}$

Introduction: Robotic technology has been postulated to improve performance in advanced surgical skills. We utilized a novel computerized assessment system to objectively describe the technical enhancement in task performance comparing robotic and laparoscopic instrumentation.

Methods and Procedures: Advanced laparoscopic surgeons (2-10 yrs experience) performed 3 unique task modules using laparoscopic and Telerobotic Surgical Instrumentation (Intuitive Surgical, Sunnyvale, CA). Performance was evaluated using a computerized assessment system (ProMIS, Dublin, Ireland) and results were recorded as time (sec), total path $(\mathrm{mm})$ and precision. Each surgeon had an initial training session followed by two testing sessions for each module. A Paired Student's T-Test was used to analyze the data

Results: 10 surgeons completed the study. Objective assessment of the data is presented in the table below. 8/10 surgeons had significant technical enhancement utilizing robotic technology

\begin{tabular}{|l|l|l|l|}
\hline & \multicolumn{2}{|c|}{ Laparoscopic vs Robotic } \\
\hline & Time (sec) & Total Path $(\mathrm{mm})$ & Precision \\
\hline Module 1 & 210 vs $161 \#$ & 11649 vs $5571 *$ & 1434 vs $933 *$ \\
\hline Module 2 & 119 vs $68 *$ & 5573 vs $1949 *$ & 853 vs $406 *$ \\
\hline Module 3 & 77 vs $55^{*}$ & 4488 vs $2390 *$ & 552 vs $358 *$ \\
\hline \multicolumn{4}{|c|}{$\#=\mathrm{p}<0.009 *=\mathrm{p}<0.001$} \\
\hline
\end{tabular}

Conclusions: The ProMIS computerized assessment system can be modified to objectively obtain task performance data with robotic instrumentation. All the tasks were performed faster and with more precision using the robotic technology than standard laparoscopy.

\section{NATURAL ORIFICE SURGERY WITH A WIRELESS ENDOLU- MINAL MOBILE ROBOT}

Mark E Rentschler MS, Jason Dumpert MS, Stephen R Platt PhD, Shane M Farritor PhD

Dmitry Oleynikov MD, Nebraska Medical Center

In vivo robotics has evolved to provide wireless endoluminal mobile robotic capability. Such an approach provides a distinct benefit compared to conventional laparoscopy where multiple entry incisions are required for tools and cameras. A miniature robot that is inserted thought the mouth would then be able to enter the abdominal cavity through a gastrotomy thereby obviating the need for any skin incisions. In this study we developed an endoluminal robot capable transgastric exploration under esophagogastroduodenoscopic (EGD) control.

A miniature, wireless robot was developed and inserted into an 2 anesthetized pigs. The robot has a built in camera, wheels and biopsy capability. The robot measures $15 \mathrm{~mm}$ by $75 \mathrm{~mm}$ and is cylindrical. Under EGD control a gastrotomy was created and the miniature robot was deployed into the abdominal cavity under remote control. The robot was able to explore the porcine organs, perform a biopsy and was then retrieved.

The ability to explore the abdominal cavity though a natural orifice, allows the surgeon to perform procedures without an abdominal incision. The Miniature robot was able to provide an enhanced field of view of the abdominal cavity from multiple angles. The built in grasper was capable of obtaining a biopsy from a variety of abdominal organs. Ultimately, future procedures will include a family of robots working together inside the luminal and abdominal cavities after insertion through the esophagus. Such technology will help reduce patient trauma while providing surgical flexibility. 
FIRST INTRAOPERATIVE TELEMENTORING SESSIONS USING THE RP-6 TM REMOTE PRESENCE ROBOTIC SYSTEM Joseph B Petelin MD, James T Methvin DO

Department of Surgery, University of Kansas School of Medicine, Kansas City Kansas, Surgix Minimally Invasive Surgery Institute, Kansas City.

Introduction: The RP-6? (InTouch Health, Santa Barbara) remote presence ?robot? has been used as a teleconsultation/telerounding device worldwide. The authors describe the first use of the system for intraoperative telementoring, and provide a live demonstration of the system.

Methods: The RP6? is a 5?4? tall, 215 pound robot that can be remotely controlled from an appropriately configured computer located anywhere on the Internet (i.e. this planet). The system is composed of a control station (a computer), a mechanical robot, a wireless network (at the home facility--the hospital), and a high-speed Internet connection at both the home (hospital) and remote locations. The RP6? system allows the remote party (physician, etc.) to control the movements of the robot itself, see and hear at the home location (hospital), and be seen and heard at the home location (hospital) while not physically being there.

Results: Deployment of the system at the hospital was accomplished in January 2005. Multispecialty use of the system included intensivists, orthopedists, ER physicians, cardiologists, and general surgeons. Initial use was limited to tele-rounding and nurse-physician consultation. Recently on September 4, 2005 we used it for intraoperative telementoring/consultation in 2 cases while the MIS fellow operated and the mentor was not on site. The robot was tele-driven by the mentor into the OR, and around the OR table. Real-time video capture by the RP-6TM allowed remote telestration by the mentor to the fellow. In both cases, operative time was reduced by an estimated $30 \%$. Both the fellow and the mentor felt that the interaction was very beneficial to the conduct of the case. The nurses present also expressed significant satisfaction that the mentor could be ?telepresent? for the case.

Conclusions: Our early experience suggests a significant benefit to patients, hospitals, nurses, and physicians. The implications for future development are enormous.

\section{ROBOTIC ASSISTED BILIARY PANCREATIC DIVERSION WITH DUODENAL SWITCH: PRELIMINARY EXPERIENCE}

\section{R. Sudan MD, V. Puri MD, D Sudan MD}

Department of Surgery, Creighton University Medical Center, Omaha, NE.

Introduction: Minimally invasive (MI) surgical techniques decrease length of hospitalization and morbidity for general surgery procedures. Application of MI techniques to obesity surgery had previously been limited to stapled techniques and primarily for the roux-en-y gastric bypass. We present the initial series of totally intracorporeal robotic assisted biliary pancreatic diversion with duodenal switch (BPD/DS) using 5 ports.

Methods: Forty-seven patients underwent robotic assisted BPD/DS between October 2000 and July 2004. Their demographic, anthropometric, operative and follow-up data were maintained in a prospective fashion and reviewed retrospectively. The mean age of patients was $38 \pm 10$ years. The mean preoperative body weight was $126.1 \pm 14.7 \mathrm{~kg}$ with a mean BMI of $45 \pm 3.6 \mathrm{~kg} / \mathrm{m}^{2}$. Surgical patients had a minimum of 4 comorbid conditions.

Results: Forty-four of the 47 procedures were completed intracorporeally with a mean operative time of $542 \& \# 61617 ; 135$ minutes (range 378-800 $\min$ ). Mean loss of excess body weight at 1 year is $74 \%$ with a mean follow-up of 19 months. Seventy-five percent of co-morbidities have resolved. The incidence of gastrointestinal leaks was $12 \%$ and postoperative small bowel obstruction $8 \%$. The metabolic and liver function tests at one year were satisfactory.

Conclusions: Minimally invasive robotic surgery can be applied to complex abdominal operations like BPD/DS. The da VinciTM (Intuitive Surgical, Inc., Sunnyville, CA) surgical robot allows for hand-sewn bowel anastomosis similar to the open technique. The short-term weight loss and metabolic results are comparable to the open operation.

\section{ROBOTIC VS LAPAROSCOPIC COLECTOMY}

Arthur L Rawlings MD, Jay H Woodland MD, Prakash Gatta MD, Ravindra Vegunta MD, David L Crawford MD

University of Illinois College of Medicine at Peoria

This study compares thirty robotic colectomies with twenty-seven laparoscopic colectomies done by one MIS fellowship trained surgeon at a tertiary institution. Since the introduction of the DaVinci Robotic System, minimally invasive surgeons have explored its use for a variety of procedures. This study is based on information that was prospectively collected from 9/2002 to the present. Data analyzed (SPSS 12.0 for Windows) included indications for surgery, gender, age, BMI, EBL, length of operation, length of stay (LOS), complications, and average OR cost of operation. Male to female ratios, patient age, BMI and EBL were similar between the groups $(\mathrm{p}>0.05)$. Operations included 13 robotic and 12 lap sigmoid colectomies and 17 robotic and 15 lap right colectomies. Preop diagnosis for robot: Cancer (5); Diverticulitis (8); Polyp (16); Carcinoid (1). Preop diagnosis for lap: Cancer (9); Diverticulitis (12); Polyp (5); Crohns (1). Total right colectomy case time (minutes): Robot 218.9 vs Lap $169.2(\mathrm{p}=0.002)$. Total sigmoid colectomy case time (minutes): Robot 225.2 vs Lap 199.4 ( $\mathrm{p}=0.128$ ). LOS right colectomy (days): Robot 5.2 vs Lap 5.5 ( $\mathrm{p}=0.8$ ). LOS sigmoid colectomy (days): Robot 6.0 vs Lap 6.6 ( $\mathrm{p}=0.9$ ). Robotic complications: 1) Patient slid off OR table to floor after the robotic portion of the procedure; 2) Persistent left hip paresthesia; 3) Transverse colon injury from ultrasound shears; 4) Cecal injury from cautery; 5) Anastomotic leak; 6) Urinary retention beginning POD 5. Laparoscopic complications: 1) Anastomotic leak; 2) Partial small bowel obstruction. Two robotic and two lap cases were converted to open. Average OR cost for lap was $\$ 6,464$ (OR time $\$ 1,131$, personnel $\$ 249$, supplies $\$ 5,084$ ). The average OR cost for robotic was $\$ 8,117$ (OR time $\$ 1,378$, personnel $\$ 485$, supplies $\$ 6,254$ ), a difference of $\$ 1,653$ per case. Conclusions: Indications for surgery, gender, age, BMI, EBL, length of hospital stay, and number of conversions to open were statistically similar between the groups. The difference in the length of operation was statistically significant only in the right colectomy group. The reason for this is the completely intracorporeal anastomosis performed in a robotic right colectomy. Complications in the robot group were more numerous but not attributable to equipment. The average OR cost of robotic colectomy at our institution is $\$ 1,653$ (25.5\%) higher than when done laparoscopically. 


\section{SOLID ORGAN REMOVAL}

\section{A REVIEW OF LAPAROSCOPIC DONOR NEPHRECTOMY: 498 CASES}

Edward H Chin MD, Michael Edye MD, Daniel M Herron MD, David Hazzan MD, Scott A Ames MD, Jonathan S Bromberg MD Mount Sinai Medical Center, NY

Introduction: Several large series have been published on the feasibility of laparoscopic donor nephrectomy, focusing on short-term success and immediate complications. Objective: to examine the results of laparoscopic donor nephrectomy, with medium-term and long-term donor followup. Methods: We examined the results of two surgeons performing almost 500 lap donor nephrectomies (LDN) from 1996-present. Prospectively collected databases were reviewed for 498 patients that underwent LDN Demographics, medical history, intraoperative events, and complications were noted. Patients were followed between 6 months and 9 years after surgery to assess for delayed complications, especially hypertension, renal insufficiency, incisional hernia, small bowel obstruction, and chronic pain. Results: $55 \%$ were female, and $45 \%$ male. Mean age was 40 . Left kidneys were procured in $85 \%$ of cases, and right kidneys in $15 \%$. Intraoperative complication rate was $2.8 \%$, most commonly bleeding. Mean blood loss was $198 \mathrm{~mL}$. Graft survival was $98.2 \%$, and acute tubular necrosis was seen in $2 \%$. Warm ischemia time averaged 3.4 minutes, and operative time 3 hours. Conversion rate was $1.6 \%$. Immediate postoperative complications were seen in $3.8 \%$. Average length of stay was 2.5 days. Mean donor creatinine at two weeks was 1.56. Long-term complications were rare, and included three cases of small bowel obstruction, two cases of incisional or leg pain, one case of hypertension requiring medication, and one case of renal insufficiency. Conclusions: LDN can be performed safely with acceptable immediate morbidity. Better data is necessary to assess long-term risks faced by LDN.

\section{LAPAROSCOPIC PARTIAL SPLENECTOMY}

David Grossman MD,Laura Ludwig DO,Roberto Bergamaschi MD,Selman Uranues MD, Lehigh Valley Hospital, Allentown, Pennsylvania

Introduction: The aim of this study was to evaluate whether laparoscopic partial splenectomy is feasible and safe. The immunologic function of the spleen and its important role in immune defense has led to splenic-preserving surgery.

Methods: Data on consecutive patients presenting with localized benign or malignant disease of the spleen were included in a prospective database. Surgical technique consisted of six steps: patient positioning and trocar placement, mobilization of spleen, vascular dissection, parenchymal resection, and sealing / tamponading the transected edge, and removal of specimen.

Results: From 1999 to 2005, 38 patients underwent laparoscopic partial splenectomy. The indications included splenomegaly of unknown origin, splenic cysts, benign tumors (hamartoma, fibroma, schwannoma), metastasis from ovarian carcinoma, infarcts, and intrasplenic pancreatic cysts. The median operative time was 110 minutes. There was no postoperative mortality. Postoperative complications occurred in 1.7 percent of the patients. There were no reoperations. Three patients required blood transfusions.

Conclusion: Laparoscopic partial splenectomy is feasible and safe in patients with localized benign or malignant disease of the spleen.
LAPAROSCOPIC ADRENALECTOMY: OUR EXPERIENCE

Emanuele Lezoche MD, Mario Guerrieri MD, Francesca Crosta MD, Pamela Zenobi MD, Maddalena Baldarelli MD, Giovanni Lezoche MD 1 Dpt of Surgery 'Paride Stefanini' II Clinica Chirurgica University 'La Sapienza' Roma, Italy

2 Dpt of General Surgery University of Ancona, Italy

Aim: to report our results in laparoscopic adrenalectomy by a retrospective evaluation .

Methods: 251 patients underwent laparoscopic adrenalectomy from January 1994 to September 2005 in our institution. 153 were female and 98 male with a mean age 52,8 years (range 19-75). In 119 cases the lesion was localized in the right gland, while in 142 in the left. In 10 patients the lesion was bilateral. The imaging study was performed with CT scan or MRI. 6,2 cm was the mean size of lesions (range 1,5-12). Endocrinology samples and scintigraphy completed preoperative patient workup. Surgical approach was in 213 cases anterior transperitoneal with supine patient, flank approach in 24 cases, anterior submesocolic in 23 cases and retroperitoneal approach in one. Associated surgical procedures were: cholecystectomy 13 , ovariectomy 4 , appendectomy 1 , uterine myomectomy 1 and left kidney cyst fenestration 1 .

Results: Mean operative time was $83 \mathrm{~min}$. for right adrenalectomy (70150), $114 \mathrm{~min}$. for left (90-300) and $204 \mathrm{~min}$. for bilateral adrenalectomy. Intraoperative major complications were observed in 6 patients : bleeding in 4 pts, splenic colonic flexure tear in one and rhythm instability in one. Oral intake started in the first 24 hour and the mean hospital stay was 2,5 days (1-8). Definitive histology resulted as follows: Cushing adenoma 67, Conn adenoma 64, Pheochromocytoma 35, Incidentaloma 78, Metastases 9, Adrenogenital syndrome 2, Myelolipoma 4, Carcinoma 2. Mean follow-up was 62 months (3-132).The patients treated for metastates underwent postoperative Chemotherapy. Out of 9 pts, three died at 6 and 18 months after the procedure respectively. The patients treated for carcinoma underwent MR imaging controls every six months and are disease free at 18 months.

Conclusion: our experience as well as reported in the recent literature suggests that laparoscopic adrenalectomy is safe and effective. Clinical outcome benefits from minimally invasive technique in terms of short hospital stay, rapid return to work and best cosmetic results.

THE LEARNING CURVE IN LAPAROSCOPIC ADRENAL SURGERY: COMPARISON OF RIGHT AND LEFT ADRENALECTOMY

S Perretta MD, A. M Paganini MD, M. Guerrieri MD, R. Campagnacci MD, A. Desanctis MD, F. Crosta MD, G. Lezoche MD, E. Lezoche MD Dept. of General Surgery, University of Ancona, Ancona, Italy *II Clinica Chirurgica, Università La Sapienza, Roma, Italy.

Background: Laparoscopic Adrenalectomy (LA) has become the procedure of choice for the surgical management of most adrenal tumors. Its learning curve varies among surgeons, it may be influenced by patients selection, operative complexity and technique, lesions side and size. Aim: multidimensional analysis of the learning curve in LA: right-sided versus left-sided adrenalectomies. Methods: This is a single-center study using prospective collected data from 241 patients who underwent LA between August 1992 and August 2005. The preoperative variables considered were patient-specific (age, gender, BMI,comorbid conditions) and disease-specific (histology, side and size of the lesion). The level of experience of the surgical and anaesthesia team and surgical approach (anterior, flank, submesocolic) was also considered. Outcome measures studied were: operative time (OpT), conversion rate (CR), intraoperative and postoperative complications. Multifactorial logistic Regression analysis was used to identify patient-, surgeon/anaesthesiologist-, and procedure-related factors associated with conversion. A risk-adjusted Cumulative Sum model was used for evaluating the learning curve for right and left-sided resections. Results: There were 9 (3\%) CR to open surgery: The CR for right-sided adrenal resections was $1.25 \%(\mathrm{n}=3)$ compared with $2.5 \%$ for left-sided LA $(\mathrm{n}=6)$. Independent predictors of $\mathrm{CR}$ were $\mathrm{BMI}$ (odds ratio $[\mathrm{OR}]=3.46$ per unit increase), and side (left versus right procedures, $\mathrm{OR}=2.85$ ). The level of experience of the surgical and anaesthesia team was also a significant predictor. Tumor histology and size, and surgical approach did not affect the CR nor OpT with any of the techniques used. Mean OpT for right (141 pts) and left adrenalectomy (100 pts) was: $91 \mathrm{~min}$ and $121 \mathrm{~min}$. As the experience of the operative team increased, the OpT decreased significantly. OpT correlated significantly with BMI increase for both right and left LA. The learning curve, was of 28 and 41 cases for right and left LA respectively. Postoperative complications did not change throughout the series and were not dependent on operative experience and side. Conclusions: Several preoperative factors, such as BMI, side of the adrenal tumor as well as surgeons experience and technique can significantly affect outcomes in LA. Consideration of these factors may help in case and approach selection, estimation of OpT, risk of CR and complications. 
THORACOSCOPIC SYMPATHETIC CHAIN CLIPPING IS EQUIVALENT TO TRANSECTION IN SYMPTOMATIC HYPERHIDROSIS

Bryan A Whitson MD, Rafael S Andrade MD, Peter S Dahlberg MD, Michael A Maddaus MD

University of Minnesota Department of Surgery

INTRODUCTION: Symptomatic hyperhidrosis is treated by thoracic sympathetic chain interruption via traditional transection or a newer clipping approach. In the setting of severe compensatory hyperhidrosis, clipping has the advantage of potential reversibility. Our aim was to evaluate the efficacy and equivalence of the two methods. METHODS: Retrospectively, all patients undergoing thoracoscopic sympathectomy for primary hyperhidrosis from January 1, 1999 through June 30, 2005 were reviewed. Demographic, operative, and postoperative data were collected and analyzed. RESULTS: 55 operations were performed for refractory sweating in the following locations: palmar $(71 \%)$, axillary $(65 \%)$, plantar (52\%), head/neck (19\%), and Raynaud's (2\%). 69\% (38/55) of patients were clipped and $31 \%(17 / 55)$ were transected. There was no difference in age, sex, or blood loss. Three ganglial levels were interrupted in 58\%; two levels were interrupted 33\%; and a single level in $21 \%$. The incidence of bothersome compensatory hyperhidrosis was $10.4 \%$ (3 clipped, 2 ablated; all truncal), of which 1 patient (clipped) underwent clip removal for debilitating symptoms. There were three small pneumothoracies; all were in the transected group and treated expectantly.

\begin{tabular}{|c|c|c|c|}
\hline$[$ Mean \pm SD $]$ & Overall $(\mathrm{n}=55)$ & Clip $(\mathrm{n}=38)$ & Transect $(\mathrm{n}=19)$ \\
\hline EBL $(\mathrm{cc})$ & $7.9 \pm 9.9$ & $6.3 \pm 5.4$ & $11.9 \pm 15.9$ \\
\hline OR Length (Min) & $42.8 \pm 22.7$ & $35.9 \pm 14$ & $58.9 \pm 30.6$ \\
\hline LOS (Days) & $0.22 \pm 0.5$ & $0.08 \pm 0.27$ & $0.53 \pm 0.72$ \\
\hline
\end{tabular}

CONCLUSION: Thoracoscopic sympathectomy for primary hyperhidrosis, either via clipping or transection, can be performed safely and routinely as an outpatient. Both clipping and transection yield excellent results. Compensatory hyperhidrosis is minimal. In the event of debilitating compensatory hyperhidrosis, thoracoscopic clipping has the added benefit of potential reversibility. Both approaches have minimal operative length, blood loss and length of stay. Thoracoscopic sympathetic chain clipping is equivalent to chain transection. 